\title{
ESTUDO TAXONÔMICO DE NEMATÓIDES FITOPARASITOS COLETADOS NO "CAMPUS" LUIZ DE QUEIROZ, PIRACICABA, SÃO PAULO, BRASIL
}

\section{MÁRIO MASSAYUKI INOMOTO}

Engenheiro Agrônomo

Orientador: Prof.Dr. AILTON ROCHA MONTEIRO

Tese apresentada à Escola Superior de Agricultura "Luiz de Queiroz", da Universidade de São Paulo, para obtenção do título de Doutor em Ciências, Área de Concentração: Entomologia.

\section{PIRACICABA}

Estado de São Paulo

Fevereiro - 1995 
Ficha catalografica preparada pela Seça de Livros da Divisăo de Hiblioteca e Documentaçăo - FCLQ/USF

\section{Inomoto, Mário Massayuki}

Isae Estudo taxonäico de nematoides fitoparasitos colei. tados no "Campus" Luiz de Queiroz, Piracicatia, Săo Fau 10. Erasil. Piracicaba, 1995. 95p. ilus.

Tese - ESALB

Gibliografia.

1. Nematóde parasito de planta - Classificacáo Firacicaba, SF 2. Flanta - Farasitologia I. Escola Su perior de Agricultura Luiz de Queiroz, Firacicaba 


\title{
ESTUDO TAXONÔMICO DE NEMATÓIDES FITOPARASITOS COLETADOS NO "CAMPUS" LUIZ DE QUEIROZ, PIRACICABA, SÃO PAULO, BRASIL
}

\author{
MÁRIO MASSAYUKI INOMOTO
}

Aprovada em: 04.04.1995

Comissão julgadora:

Prof. Dr. Ailton Rocha Monteiro ESALQ/USP

Prof. Dr. Roberto Antonio Zucchi ESALQ/USP

Prof. Dr. Luiz Carlos Camargo Barbosa Ferraz ESALQ/USP

Prof $^{\mathrm{a}}$. Dr ${ }^{\mathrm{a}}$. Marineide Mendonça Aguillera CCA/UFSCAR

Prof. Dr. Anário Jaehn FCA/UNESP

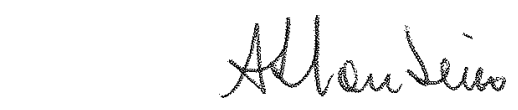

Prof. Dr. AILTON ROCHA MONTEIRO Orientador 
A meus pais, Michio e Mieko, e a meu irmão, Wilson,

DEDICO. 


\section{AGRADECIMENTOS}

Sou muito grato a todos que, ao cederem-me um pouco, às vezes muito, na verdade, do seu tempo, tornaram a realização deste trabalho mais fácil. Gostaria, ainda, de manifestar de modo especial meu reconhecimento:

Ao Prof. Dr. Ailton Rocha Monteiro, meu orientador;

Ao Prof. Dr. Luiz Carlos Camargo Barbosa Ferraz;

A meus amigos Rosana Bessi, Sônia Regina Antedomênico Cardoso de Morais, Vera Lúcia Durrer e Cláudio Marcelo Gonçalves de Oliveira;

Ao Prof. Dr. Ricardo Ribeiro Rodrigues. 


\section{INDICE}

Página

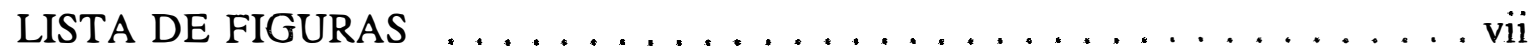

LISTA DE TABELAS ....................... viii

LISTA DE ABREVIATURAS E SÍMBOLOS $\ldots \ldots \ldots \ldots \ldots \ldots$. . . . . ix

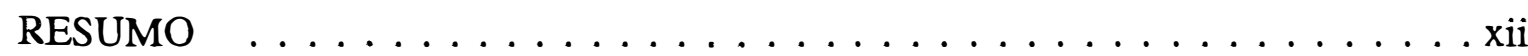

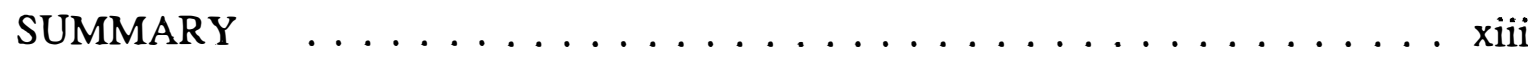

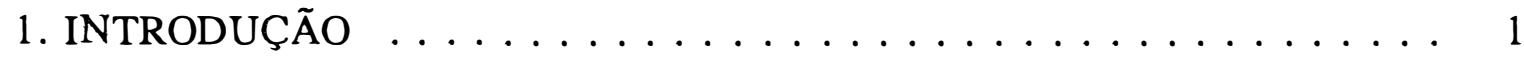

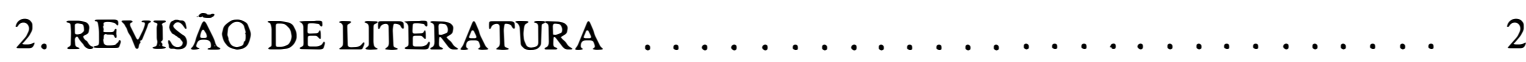

2.1. Sistemática do Filo Nemata ................ 2

2.2. Nematóides fitoparasitos no Brasil . . . . . . . . . . . . 4

2.3. Nematóides fitoparasitos no "campus" Luiz de Queiroz . . . . . . . . 4

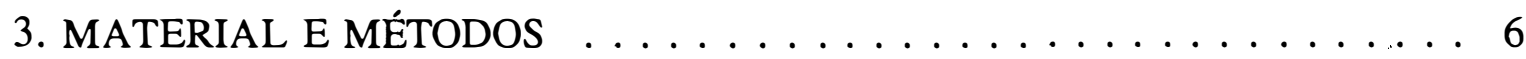

3.1. Coleta das amostras ................... 6

3.2. Extração dos nematóides . . . . . . . . . . . . . . . 8

3.3. Identificação e medição dos nematóides . . . . . . . . . . . . . 10

3.4. Freqüência de ocorrência $(\%)$ dos nematóides . . . . . . . . . . 10

3.5. Densidade populacional dos nematóides (agrupados por família) . . . 10

3.6. Índice de similaridade . . . . . . . . . . . . . . . . . 11

3.7. Estudo morfológico de algumas espécies . . . . . . . . . . . 12

3.8. Depósito do material estudado . . . . . . . . . . . . . . 12

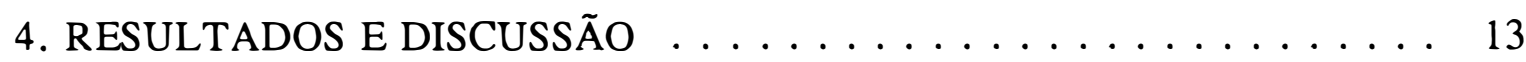

4.1. Levantamento populacional . . . . . . . . . . . . . . . 13

4.2. Identificação das espécies autóctones $\ldots \ldots \ldots$. . . . . . . . . 14

4.3. Influência da cobertura vegetal na fauna nematológica . . . . . . . 18

4.4. Estudo morfológico de algumas espécies . . . . . . . . . . . 20

4.5. Descrição de novas espécies . . . . . . . . . . . . . . 41

4.5.1. Descrição de Trophurus n. sp. . . . . . . . . . . . . 41

4.5.2. Chaves para identificação de espécies de Trophurus Loof, 1956 . 49 
4.5.3. Descrição de Criconema n. sp. . . . . . . . . . . . . . 52

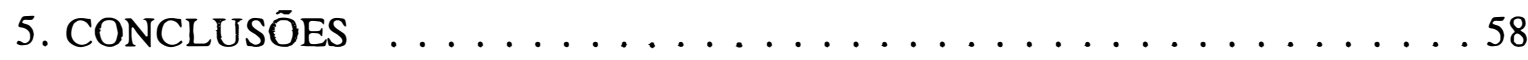

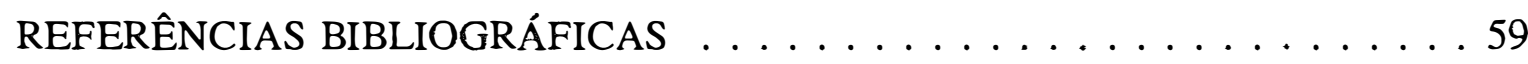

APÊNDICE 1: primeiro registro de ocorrência de nematóide fitoparasitos no Brasil

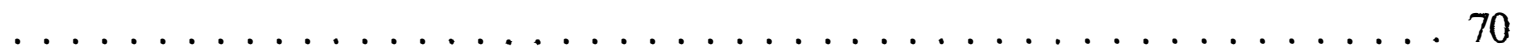

APÊNDICE 2: lista de abreviaturas do mapa do "campus" Luiz de Queiroz . . 87

APÊNDICE 3: resultados do levantamento populacional . . . . . . . . . . . 89 


\section{LISTA DE FIGURAS}

Página

Figura 1. Localização dos pontos de amostragem no "campus" Luiz de Queiroz ..................... 7

Figura 2. Ramo genital anterior de Xiphinema krugi . . . . . . . . 31

Figura 3. Esclerotização vulvares de Paratrichodorus anthurii . . . . . . 31

Figura 4. Região labial de Rotylenchus caudaphasmidius . . . . . . . . 31

Figura 5. Apêndices dos anéis de Criconema braziliense . . . . . . . . 31

Figura 6. Corpo de Ogma cataracticum . . . . . . . . . . . . 31

Figura 7. Disco labial de Discocriconemella mineira . . . . . . . . . 43

Figura 8. Disco labial de Discocriconemella repleta . . . . . . . . . 43

Figura 9. Região pós-vulvar de Discocriconemella repleta . . . . . . . . 43

Figura 10. Cauda de fêmea de Trophurus n. sp. (holótipo) . . . . . . . . 43

Figura 11. Cauda de macho de Trophurus n. sp. (parátipos) . . . . . . 43

Figura 12. Trophurus n. sp. (holótipo e parátipos) ............ 44

Figura 13. Criconema n. sp. (holótipo e parátipo) ........... 53

Figura 14. Região anterior de Criconema n. sp. (parátipo) . . . . . . . 54

Figura 15. Região posterior de Criconema n. sp. (holótipo) . . . . . . . 54 
LISTA DE TABELAS

Página

Tabela 1. Freqüência de ocorrência (\%) das espécies de nematóides fitoparasitos e freqüência e densidade populacional $\left(\mathrm{n} / 250 \mathrm{~cm}^{3}\right)$ das famílias de nematóides em amostras de solo da rizosfera no "campus" Luiz de Queiroz . . . . . . . . . . . . . . . 15

Tabela 2. Medidas de fêmeas do material tipo de Trophurus n. sp. . . . 45

Tabela 3. Medidas de machos do material tipo de Trophurus n. sp. . . . 46

Tabela 4. Medidas de fêmeas do material tipo de Criconema n. sp. . . 55

Tabela 5. Nematóides fitoparasitos já registrados no Brasil e referências sobre o primeiro registro . . . . . . . . . . . 70 


\section{LISTA DE ABREVIATURAS E SÍMBOLOS}

$\mathbf{n}=$ número de exemplares medidos

comp. $=$ comprimento

larg. = largura

ø = diâmetro

$\mathbf{v I}=$ vista lateral

\section{Medidas em $\mu \mathrm{m}$ :}

$\mathbf{L}=$ comprimento do corpo

Oes = comprimento do esôfago: distância da extremidade anterior do corpo ao final das glândulas esofagianas

$\mathbf{E P}=$ distância da extremidade anterior do corpo ao poro excretor

Odt $=$ comprimento do odontostílio

Odf $=$ comprimento do odontóforo

St $=$ comprimento do estilete

dadg = distância da abertura da glândula dorsal à base do estilete

r.g.a. = comprimento do ramo genital feminino anterior

esp. = comprimento do espículo

gub. = comprimento do gubernáculo

$\mathbf{t}=$ comprimento da cauda

$\mathbf{h}=$ comprimento da porção hialina da cauda

VB $=$ diâmetro do corpo ao nível da vulva

Número de anéis:

$\mathbf{R}=$ número total de anéis do corpo

$\mathbf{R}_{\mathbf{S t}}=$ número de anéis do corpo entre a extremidade anterior do corpo e a base do estilete (incluindo na contagem o anel à altura da base do estilete)

$\mathbf{R}_{\text {Oes }}=$ número de anéis do corpo da região esofagiana 
$\mathbf{R}_{\mathrm{ex}}=$ número de anéis do corpo entre a extremidade anterior e o poro excretor (incluindo na contagem o anel à altura do poro excretor)

$\mathbf{R}_{\text {Hem }}=$ número de anéis do corpo entre a extremidade anterior do corpo e o hemizonídio (incluindo na contagem o anel à altura do hemizonídio)

$\mathbf{R}_{\mathbf{v}}=$ número de anéis do corpo entre a vulva e a extremidade da cauda (incluindo na contagem o anel à altura da vulva)

$\mathbf{R}_{\mathbf{v a n}}=$ número de anéis do corpo entre a vulva e o ânus (excluindo-se da contagem os anéis à altura da vulva e do ânus)

$\mathbf{R}_{\mathrm{an}}=$ número de anéis da cauda

\section{Porcentagens:}

$\mathbf{M}=$ comprimento do cone do estilete $\mathrm{x} 100 /$ comprimento do estilete

$\mathbf{G a}=$ comprimento do ramo genital feminino anterior $\times 100 /$ comprimento do corpo

$\mathbf{G p}=$ comprimento do ramo genital feminino posterior $\mathrm{x} 100 /$ comprimento do corpo

$\mathrm{V}=$ distância da extremidade anterior do corpo à vulva $\mathrm{x} 100 /$ comprimento do corpo

St $\% \mathbf{L}=$ comprimento do estilete $\times 100 /$ comprimento do corpo

St\% Oes = comprimento do estilete $\times 100 /$ comprimento do esôfago

EP\% $\mathbf{L}=$ distância da extremidade anterior do corpo ao poro excretor $\mathrm{x} 100 /$ comprimento do corpo

EP\% Oes = distância da extremidade anterior do corpo ao poro excretor $\times 100 /$ comprimento do esôfago

VA\% $\mathbf{t}=$ distância entre a vulva e o ânus $\mathrm{x} 100 /$ comprimento da cauda

\section{Relacões:}

$\mathbf{a}=$ comprimento do corpo / maior diâmetro do corpo

$\mathbf{b}=$ comprimento do corpo / distância da extremidade anterior do corpo à junção esôfago-intestino

$\mathbf{b}^{\prime}$ = comprimento do corpo / comprimento do esôfago

$\mathbf{c}=$ comprimento do corpo / comprimento da cauda 
$\mathbf{c}^{\prime}$ = comprimento da cauda / diâmetro do corpo ao nível do ânus

d = comprimento da cauda / distância da vulva à extremidade da cauda

$\mathrm{e}=$ comprimento do corpo / distância da extremidade anterior do corpo ao poro excretor

$\mathbf{z}=$ comprimento do corpo / comprimento do estilete

VL/VB = distância da vulva à extremidade da cauda / diâmetro do corpo ao nível da vulva

VL/St = distância da vulva à extremidade da cauda / comprimento do estilete 


\title{
ESTUDO TAXONÔMICO DE NEMATÓIDES FITOPARASITOS COLETADOS NO "CAMPUS" LUIZ DE QUEIROZ, PIRACICABA, SÃO PAULO, BRASIL
}

\author{
Autor: MÁRIO MASSAYUKI INOMOTO \\ Orientador: PROF. DR. AILTON ROCHA MONTEIRO
}

RESUMO

Trinta e nove espécies de nematóides fitoparasitos foram identificadas no "campus" Luiz de Queiroz ( $22^{\circ} 42^{\prime} 30^{\prime \prime}$ S, $4^{\circ} 38^{\prime} 00^{\prime \prime}$ WG, Piracicaba, São Paulo, Brasil), das quais 17 na vegetação nativa. A maior parte destas, provavelmente autóctones, desapareceu ou tornou-se rara quando a vegetação nativa foi substituída pelas plantas do parque da ESALQ ou por plantas cultivadas. As famílias mais bem representadas foram Hoplolaimidae e Criconematidae. Dezoito espécies raras ou pouco freqüentes no Brasil, inclusive 2 novas espécies (Trophurus n. sp. e Criconema n. sp.), foram identificadas. O presente trabalho estudou pormenorizadamente algumas delas (Xiphidorus minor, Paratrichodorus anthurii, Rotylenchus caudaphasmidius, Criconema braziliense, Ogma cataracticum, Criconema palustris, Criconemella sp., Discocriconemella mineira, $D$. repleta e as 2 novas espécies). 


\title{
TAXONOMIC STUDY OF PLANT PARASITIC NEMATODES \\ COLLECTED FROM LUIZ DE QUEIROZ "CAMPUS", PIRACICABA, SÃo PAULO STATE, BRAZIL
}

\author{
Author: MÁRIO MASSAYUKI INOMOTO \\ Adviser: PROF. DR. AILTON ROCHA MONTEIRO
}

\section{SUMMARY}

Trirty nine species of plant parasitic nematodes were identified at Luiz

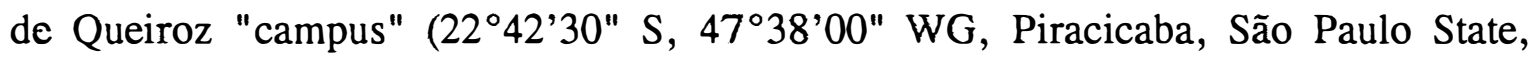
Brazil). Seventeen species were collected from native vegetation and were probably native from this area. Most of these species disappeared or became rare when the native vegetation was replaced by plants of ESALQ park or cultivated plants. The most frequently nematodes collected belonged to Hoplolaimidae and Criconematidae. Eighteen rare species, including 2 new species (Trophurus n. sp. and Criconema n. sp.), were identified. The present work studied some of them (Xiphidorus minor, Paratrichodorus anthurii, Rotylenchus caudaphasmidius, Criconema braziliense, Ogma cataracticum, Criconema palustris, Criconemella sp., Discocriconemella mineira, D. repleta and the 2 new species) in detail. 


\section{INTRODUÇÃO}

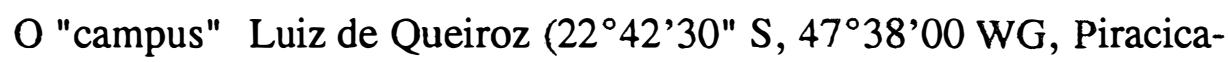
ba, São Paulo, Brasil) está situado numa área que era coberta por um tipo de vegetação denominado floresta mesófila semi-decídua. Com a construção da faculdade e a formação do parque da ESALQ e dos campos experimentais, a maior parte dessa vegetação desapareceu, restando apenas pequenas áreas de remanescentes degradados. Houve, provavelmente, grandes mudanças na fauna nematológica durante esse processo, pois ela é estreitamente relacionada à vegetação.

O objetivo deste trabalho foi identificar as espécies de nematóides fitoparasitos que ocorrem dentro do "campus" Luiz de Queiroz, compararando as populações dos remanescentes da vegetação nativa com as do parque e as das áreas cultivadas. Dessa maneira, além de possibilitar o conhecimento da fauna nematológica autóctone do "campus" Luiz de Queiroz, verificou-se o quão intensamente a retirada da vegetação nativa influiu na composição dessa fauna. Além disso, é apresentado um estudo morfológico das espécies coletadas pouco comuns na fauna brasileira e a descrição de 2 novas espécies. 


\section{REVISÃO DE LITERATURA}

\subsection{Sistemática do Filo Nemata}

Neste trabalho foi adotada a sistemática do Filo Nemata segundo MAGGENTI (1990) e MAGGENTI et alii (1987). Segundo essas proposições, há um total de 12 famílias de nematóides fitoparasitos, conforme pode ser observado abaixo:

Filo Nemata

Classe Adenophorea

Subclasse Enoplia

Superordem Marenoplica ( 3 ordens, 14 famílias)

Superordem Terrenoplica

Ordem Isolaimida (1 família)

Ordem Mononchida (7 famílias)

Ordem Dorylaimida

Subordem Dorylaimina

Superfamília Dorylaimoidea

Família Dorylaimidae

Família Encholaimidae

Família Tylencholaimidae

Família Tylencholaimellidae

Família Leptonchidae

Família Belonenchidae 
Família Longidoridae ${ }^{1}$

Superfamília Actinolaimoidea (4 famílias)

Superfamília Belondiroidea (5 famílias)

Subordem Diphtherophorina

Família Diphtherophoridae

Família Trichodoridae ${ }^{1}$

Subordem Nygolaimina (4 famílias)

Ordem Stichosomida (8 famílias)

Subclasse Chromadoria (5 ordens, 35 famílias)

Classe Secernentea

Subclasse Rhabditidae (2 ordens, 43 famílias)

Subclasse Spiruria (2 ordens, 43 famílias)

Subclasse Diplogasteria

Ordem Diplogasterida (4 famílias)

Ordem Tylenchida

Subordem Tylenchina

Superfamília Tylenchoidea

Família Tylenchidae ${ }^{1}$

Família Anguinidae ${ }^{1}$

Família Dolichodoridae ${ }^{1}$

Família Belonolaimidae ${ }^{1}$

Família Pratylenchidae ${ }^{1}$

Família Hoplolaimidae ${ }^{1}$

Família Heteroderidae $^{1}$

Superfamília Criconematoidea

Família Criconematidae ${ }^{1}$

\footnotetext{
${ }^{1}$ Famílias nas quais há espécies fitoparasitas.
} 
Família Tylenchulidae ${ }^{1}$

Subordem Aphelenchina

Família Aphelenchidae

Família Paraphelenchidae

Família Aphelenchoididae ${ }^{1}$

Família Seinuridae

Família Entaphelenchidae

Subordem Sphaeruliina (3 famílias)

\subsection{Nematóides fitoparasitos no Brasil}

Foi registrada a ocorrência de pelo menos 238 espécies de nematóides fitoparasitos no Brasil (Apêndice 1). Muitas espécies ainda estão por ser identificadas, principalmente quando forem realizados levantamentos em áreas cobertas pela vegetação nativa, pois os poucos levantamentos realizados em áreas com essa vegetação (ou em áreas recentemente desmatadas) forneceram material suficiente para a descrição de várias espécies. Alguns gêneros de nematóides coletados no país são tão raros no restante do mundo, que é lícito afirmar que são gêneros tipicamente brasileiros ou sul-americanos. É o caso de Xiphidorus Monteiro, 1976 (MONTEIRO, 1976; MONTEIRO et alii, 1981; RASHID et alii, 1986, ; UESUGI et alii, 1985) e Allotrichodorus RodriguezM., Sher \& Siddiqi, 1978 (RASHID et alii, 1985; RODRIGUEZ-M. et alii, 1978).

\subsection{Nematóides fitoparasitos no "campus" Luiz de Queiroz}

A vegetação natural da área era constituída principalmente por floresta classificada como mesófila semi-decídua, caracterizada pela ocorrência em regiões com temperatura e umidade médios e pela deciduidade, na estação seca, observada em algumas espécies típicas dessa formação. O dossel, de $15 \mathrm{~m}$ de altura, é irregular, havendo a presença de árvores emergentes até $30 \mathrm{~m}$ de altura. Nos estratos superiores, 
predominam Anacardiaceae, Bombacaceae, Caesalpiniaceae, Mimosaceae, Apocynaceae, Fabaceae, Lecythidaceae e Lauraceae. A floresta mesófila semi-decídua, na região de Piracicaba, sofreu uma intensa intervenção humana. Os poucos remanescentes localizam-se em áreas de difícil acesso e apresentam um grande número de espécies pioneiras. São os chamados remanescentes degradados (RODRIGUES, no prelo).

Dentro do "campus" Luiz de Queiroz estão alguns dos poucos remanescentes dessa formação em Piracicaba. São escassos os conhecimentos sobre a fauna nematológica que desenvolvia-se sobre esse tipo de vegetação, e os efeitos que sua substituição por bosques implantados (caso do parque da ESALQ), campos de cultivo e pastagens tiveram sobre essa fauna.

LORDELLO (1955) descreveu Xiphinema krugi Lordello, 1955 a partir de material coletado da rizosfera de vegetação nativa do "campus" Luiz de Queiroz. ZAMITH \& LORDELLO (1975) e LORDELLO \& ZAMITH (1958) estudaram a fauna nematológica de 3 áreas de vegetação nativa no "campus" Luiz de Queiroz. Em solo de um remanescente às margens do ribeirão Piracicamirim, coletaram Paratrichodorus porosus (Allen, 1957) Siddiqi, 1974, Rotylenchus sp. e Hemicycliophora sp. Identificaram Xiphinema sp., Helicotylenchus sp. e Aphelenchoides sp., em solo de um remanescente próximo à pedreira do "campus" Luiz de Queiroz, e Tylenchorhynchus sp., Rotylenchus sp., Helicotylenchus sp. e Aphelenchoides sp., em solo de um remanescente próximo ao pavilhão de Engenharia do "campus" Luiz de Queiroz.

MONTEIRO \& MENDONÇA (1972) descreveram Helicotylenchus caipora Monteiro \& Mendonça, 1972 a partir de exemplares coletados em um remanescente de floresta no "campus" Luiz de Queiroz. Outra espécie de Hoplolaimidae identificada nessa área foi Rotylenchus caudaphasmidius Sher, 1965 (MENDONÇA, 1976). 


\section{MATERIAL E MÉTODOS}

\subsection{Coleta das amostras}

Foram coletadas 41 amostras de solo ou de solo + raízes de diferentes áreas do "campus" Luiz de Queiroz, entre os meses de junho de 1992 e janeiro de 1995, (Figura 1 e Apêndice 3). Retiraram-se 14 amostras de áreas cobertas por remanescentes degradados de floresta. Dessas, 8 foram coletadas de um remanescente circundado pelo pomar do Departamento de Horticultura da ESALQ. Coletaram-se 3 amostras de um remanescente conhecido como "mata da pedreira", devido à sua proximidade com a pedreira do "campus" Luiz de Queiroz. De outro remanescente, às margens do ribeirão Piracicamirim, coletaram-se 2 amostras. Uma única amostra foi retirada de um remanescente muito alterado pelo homem, onde a vegetação baixa era ausente devido ao tráfego de animais de criação, localizado às margens do rio Piracicaba e próximo a uma área de pastagem. O objetivo da realização das coletas nessas áreas foi a identificação da fauna nematológica autóctone.

Coletaram 10 amostras do parque da ESALQ. Nesse caso, considerouse como parque toda a área verde do "campus" Luiz de Queiroz que era mantida com a dupla finalidade de servir de área de lazer à população que freqüenta o "campus" e de abrigar plantas de interesse científico. Coletaram-se materiais, portanto, não somente do parque da ESALQ propriamente dito, implantado pelo paisagista Arsenio Puttemans, mas tambem áreas verdes criadas posteriormente. $O$ objetivo da realização dessas coletas foi verificar o efeito da substituição da vegetação nativa por bosques implantados e jardins na composição da fauna nematológica da área em estudo. 


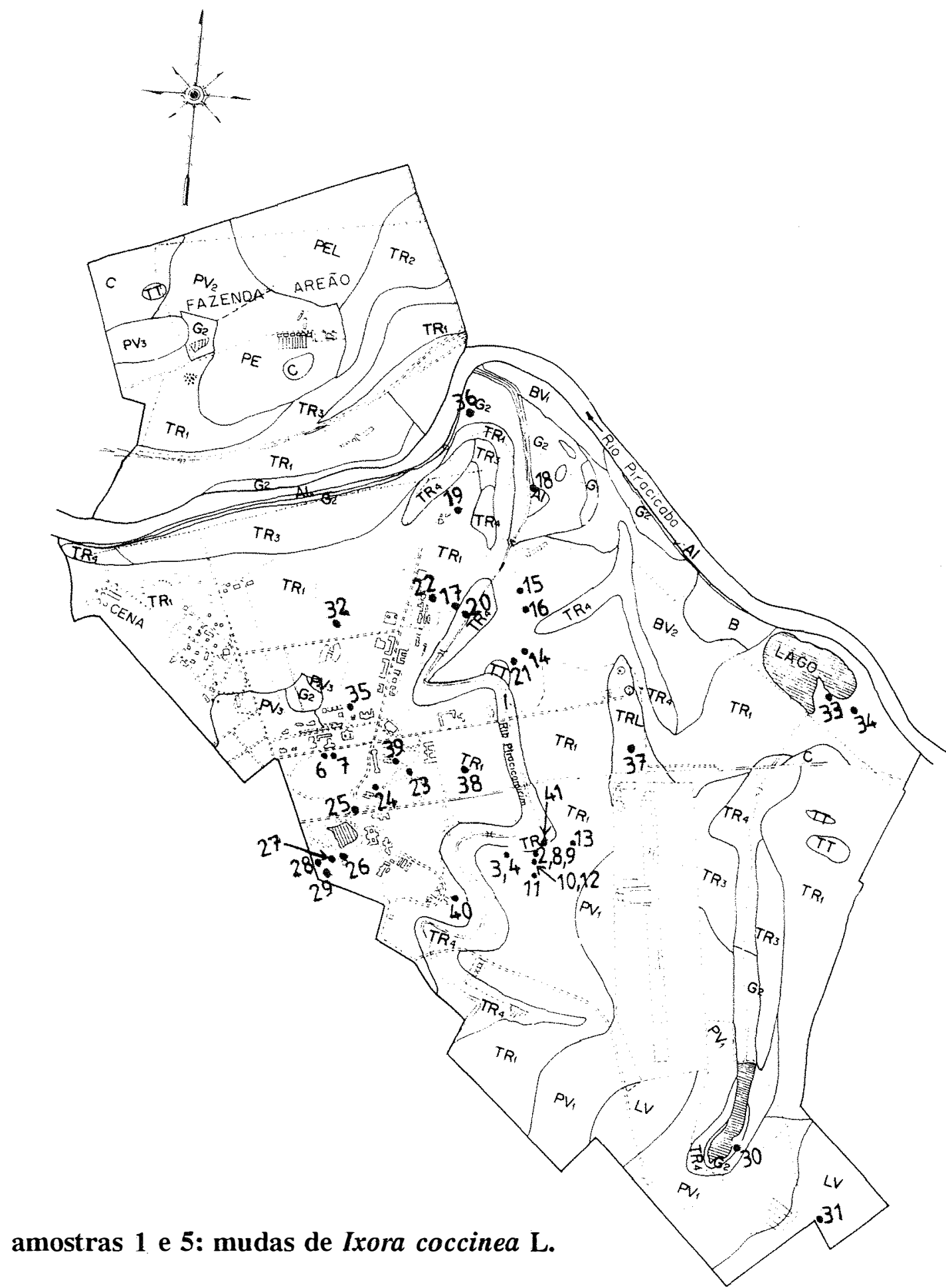

Figura 1. Localização dos pontos de amostragem no "campus" Luiz de Queiroz (sobre mapa do "campus" Luiz de Queiroz de VIDAL-TORRADO et alii, 1993). 
Também fizeram-se coletas de amostras, num total de 13, de áreas cultivadas com plantas anuais ou perenes, dentro do "campus" Luiz de Queiroz, com o objetivo de obter dados sobre a capacidade da fauna nematológica autóctone de adaptar-se a esse tipo de vegetação. Além disso, coletaram-se amostras de: a) 2 mudas de uma planta ornamental (Lxora coccinea L.), fornecidas pelo Departamento de Horticultura da ESALQ; b) rizosfera de Chorisia speciosa St. Hill. (paineira); c) rizosfera da vegetação às margens de um lago. Essas amostras não receberam classificação especial e foram listadas neste trabalho como "outros".

A profundidade de amostragem variou de 5 a $60 \mathrm{~cm}$ e a coleta foi feita com auxílio de enxadão. As amostras retiradas de áreas de remanescentes degradados de floresta e do parque da ESALQ normalmente foram compostas exclusivamente de solo, pois a identificação das raízes nesse tipo de vegetação é muito difícil. Nas áreas cultivadas ou quando a identificação das raízes foi possível, tanto solo como raízes foram coletados. Nas áreas de vegetação menos densa, as amostras foram compostas de 3 subamostras. Nas áreas de vegetação mais fechada, pela dificuldade de coleta, cada amostra foi retirada de um único ponto. As amostras, contendo cerca de $1.500 \mathrm{~cm}^{3} \mathrm{de}$ solo e, quando possível, $20 \mathrm{~g}$ de raízes, foram acondicionadas em sacos plásticos e conservadas sob refrigeração a $3-6^{\circ} \mathrm{C}$.

\subsection{Extração dos nematóides}

A extração dos nematóides foi feita logo em seguida à coleta. No caso do solo, utilizou-se peneiramento seguido de centrifugação em solução de sacarose (JENKINS, 1964): $250 \mathrm{~cm}^{3}$ de solo foram suspensos em 5 litros de água de torneira e, após aproximadamente 30 segundos de repouso, essa suspensão passou sucessivamente por uma peneira de 20 "mesh" (abertura de malha de 0,84 mm) e uma de 400 "mesh" (abertura de malha de $0,037 \mathrm{~mm}$ ). O material retido nesta foi centrifugado a 1.800 r.p.m. por 5 minutos, para separação da água do solo contendo nematóides. Esse precipitado foi ressuspendido em solução de sacarose com densidade $1,15 \mathrm{~g} / \mathrm{ml}$ e novamen- 
te centrifugado a 1.800 r.p.m., desta vez por um minuto. O sobrenadante passou então por uma peneira de 500 "mesh" (abertura de malha de 0,025 mm), que reteve os nematóides. Estes foram enxagüados com água corrente e transferidos para recipientes de vidro cilíndricos do tipo "snap-cap" de $60 \mathrm{ml}$ de capacidade.

Em algumas amostras, a extração foi feita por peneiramento combinado com o método de Baermann modificado para recipiente raso (FLEGG \& HOOPER, 1970 p. 6): o material retido na peneira de 400 "mesh" foi transferido para um conjunto composto de um prato de louça contendo água de torneira, uma peneira de plástico e uma camada filtrante ("nematode-filter" fabricada por Brocades-Stheeman \& Pharmacia) sobre essa peneira. Os nematóides ativos, depositados na camada filtrante, atravessaramna, depositando-se no fundo do prato e, depois de $48 \mathrm{~h}$, foram transferidos para os recipientes de vidro.

Os nematóides das raízes foram extraídos por metodologia semelhante à proposta por COOLEN \& D'HERDE (1972): $5 \mathrm{~g}$ de raízes foram desintegradas em liquidificador comum contendo $250 \mathrm{ml}$ de água por 1 minuto; esse material passou por peneiramento e centrifugação em solução de sacarose, à semelhança da metodologia para extração dos nematóides do solo, mas havendo a necessidade de se juntar caulim em pó ( $1 \mathrm{~cm}^{3} /$ amostra), que funcionou como agente floculante, antes das centrifugações.

Depois da extração, os nematóides foram mortos por aquecimento, em banho maria, a $55-60^{\circ} \mathrm{C}$. A fixação foi feita pela adição de solução de formol a $40 \%$ (v./v.) P.A. (puro para análise) neutralizado com excesso de $\mathrm{CaCO}_{3}$, em quantidades suficientes para que a suspensão de nematóides chegasse a um concentração de $2 \%$ de formol.

O volume da suspensão foi reduzido por sifonamento até 5 ou $10 \mathrm{ml}$, e uma alíquota de $1 \mathrm{ml}$ foi utilizada para a contagem dos nematóides fitoparasitos presentes. Utilizou-se para tanto de um microscópio óptico e uma lâmina de contagem de Peters. 


\subsection{Identificação e medição dos nematóides}

A identificação foi feita a partir de exemplares montados em lâminas provisórias com formol a $4 \%$. Essas lâminas foram seladas pela fusão de uma mistura de parafina + vaselina líquida ( $2: 1$ v./v.), colocada entre a lâmina e a lamínula.

Para a identificação de espécies de Meloidogyne, as fêmeas foram retiradas de raízes não fixadas e recortadas para se montar lâminas de perineais, segundo a técnica de HARTMAN \& SASSER (1985). Quando necessário, também foram montadas fêmeas obtidas de raízes fixadas com lactoglicerol (1 parte de ácido lático a $85 \%$ (v./v.) P.A., 4 partes de glicerina P.A. e 3 partes de água destilada) fervente, para estudo da região anterior e da região perineal de cada exemplar.

As medições foram feitas em microscópio óptico dotado de ocular micrométrica. A medição de exemplares muito compridos ou com o corpo curvo foi feita sobre desenhos executados com auxílio de câmara clara acoplada ao microscópio. Chaves de classificação e descrições de espécies foram utilizadas na identificação.

\subsection{Freqüência de ocorrência (\%) dos nematóides}

Foi calculada pela fórmula:

$$
\text { Freq. }=\frac{\mathrm{n} \times 100}{\mathrm{~N}},
$$

onde $\mathrm{n}=$ número de amostras em que determinado nematóide ocorreu, e $\mathrm{N}=$ número total de amostras coletadas em determinado tipo de cobertura vegetal (remanescente de floresta, parque da ESALQ, área cultivada ou outros).

\subsection{Densidade populacional dos nematóides (agrupados por família)}

Foi calculada pela fórmula: 


$$
\text { dens. }=\frac{\mathrm{nF}}{\mathrm{nA}}
$$

onde $\mathrm{nF}=$ número total de nematóides de determinada família em determinado tipo de cobertura vegetal, e $\mathrm{nA}=$ número total de amostras em que foi feita a quantificação.

\section{6. Índice de similaridade}

Para a comparação das faunas entre pares de tipos de cobertura vegetal, consideraram-se apenas os nematóides identificados até o nível de espécie. O índice foi calculado pela a fórmula de Jaccard (CARES, 1984):

$$
\text { ISj }=\frac{c}{(a+b+c)},
$$

onde $\mathrm{a}=$ número de espécies presentes apenas no tipo de cobertura vegetal "a", b = número de espécies presentes apenas no tipo de cobertura vegetal "b", $\mathrm{e} \mathrm{c}=$ número de espécies presentes tanto em "a" como em "b".

\subsection{Estudo morfológico de algumas espécies}

Algumas das espécies assinaladas no levantamento populacional eram pouco freqüentes no Brasil ou eram de difícil identificação. Por essa razão, foram objetos de um exame mais minucioso. Para tanto, foram infiltrados com glicerina P.A., para montagem de lâminas permanentes. Procedeu-se de 2 maneiras diferentes. Na primeira, logo após a extração, os nematóides foram transferidos, ainda vivos, sob microscópio estereoscópico e com auxílio de uma agulha, para um recipiente de vidro cilíndrico de $12 \mathrm{ml}$ de capacidade e contendo cerca de $4 \mathrm{ml}$ de água destilada. Logo depois, foram mortos por aquecimento. O volume no recipiente foi então reduzido ao mínimo possível, por meio de sifâo, e ao volume restante foi adicionado meio de Golden (8 partes de glicerina P.A., 30 partes de solução de formol a $40 \%$ (v./v.) P.A. neutralizado com ex- 
cesso de $\mathrm{CaCO}_{3}$, e 350 partes de água destilada) até completar a capacidade do recipiente, e ácido pícrico o suficiente para dar um tom ligeiramente amarelado à suspensão. Os nematóides foram lentamente infiltrados com glicerina, em estufa a $42^{\circ} \mathrm{C}$ (HOOPER, 1970).

No outro procedimento, foram aproveitados nematóides provenientes das suspensões utilizadas no levantamento populacional. Esses, já estando fixados, foram transferidos diretamente para recipientes contendo o meio de Golden.

Encerrado esse processo, o meio contendo os nematóides foi transferido para vidro-de-relógio do tipo "BPI" (Bureau of Plant Industry), que foi depois colocado em um recipiente de vidro do tipo "snap cap" de $30 \mathrm{ml}$ contendo sílica gel azul. Mantido aí durante alguns dias, houve um processo adicional de desidratação do meio.

O meio de montagem foi glicerina P.A. desidratada com sílica gel azul. Quatro pedaços de fibra de vidro com aproximadamente o mesmo diâmetro dos nematóides foram utilizados como calço, para impedir que o peso da lamínula deformasse o corpo dos nematóides. Também dessa vez as lâminas foram seladas pela fusão de uma mistura de parafina + vaselina.

As medições foram feitas como descrito no item 3.1.

Fotomicrografias foram tiradas de alguns exemplares, através de máquina fotográfica acoplada a microscópio óptico.

\subsection{Depósito do material estudado}

Todas as lâminas permanentes utilizadas no estudo morfológico estão depositadas na coleção nematológica da ESALQ, em Piracicaba, SP, sob a sigla Z. 


\section{RESULTADOS E DISCUSSÃO}

\subsection{Levantamento populacional}

Identificaram-se 39 táxons de nematóides fitoparasitos até o nível de espécie, no "campus" Luiz de Queiroz; além disso, 15 táxons foram identificados até o nível de gênero: a) família Longidoridae: Xiphinema brevicolle Lordello \& Costa, 1961, X. krugi Lordello, 1955, X. vulgare Tarjan, 1964, Xiphinema sp. e Xiphidorus minor Rashid, Coomans \& Sharma, 1986; b) família Trichodoridae: Paratrichodorus anthurii Baujard \& Germani, 1985, P. minor (Colbran, 1956) Siddiqi, 1974, Paratrichodorus sp.. e Paratrichodorus sp. ${ }_{\mathrm{b}}$; c) família Tylenchidae: Boleodorus sp. e Basiria sp.; d) família Anguinidae: Ditylenchus sp.; e) família Belonolaimidae: Tylenchorhynchus annulatus (Cassidy, 1930) Golden, 1971, Tylenchorhynchus sp. e Trophurus n. sp.; f) família Pratylenchidae: Pratylenchus brachyurus (Godfrey, 1929) Filipjev \& S. Stekhoven, 1941, P. zeae Graham, 1951 e Radopholus similis (Cobb, 1893) Thorne, 1949; g) família Hoplolaimidae: Hoplolaimus galeatus (Cobb, 1913) Filipjev \& S. Stekhoven, 1941, Rotylenchus caudaphasmidius Sher, 1965, Rotylenchus spp., Helicotylenchus digonicus Perry, Darling \& Thorne, 1959, H. dihystera (Cobb, 1893) Sher, 1961, H. egyptiensis Tarjan, 1964, H. erythrinae (Zimmermann, 1964) Golden, 1956, H. exallus Sher, 1966, H. multicinctus (Cobb, 1893) Golden, 1956, H. pseudorobustus (Steiner, 1914) Golden, 1956, Helicotylenchus spp., Scutellonema brachyurus (Steiner, 1938) Andrássy, 1958 e Rotylenchulus reniformis Linford \& Oliveira, 1940; h) família Heteroderidae: Meloidogyne javanica (Treub, 1885) Chitwood,1949 e Meloidogyne spp.; i) família Criconematidae: Criconema braziliense (Raski \& Pinochet, 1975) Raski \& 
Luc, 1985, Criconema sp. (nova espécie ainda inomimada em SPERANDIO, 1992), Criconema n. sp., Ogma cataracticum (Andrássy, 1979) Raski \& Luc, 1987, Ogma sp., Hemicriconemoides mangiferae Siddiqi, 1961, Criconemella denoudeni De Grisse, 1967, C. onoensis (Luc, 1959) Raski \& Luc, 1981, C. ornata (Raski, 1958) Luc \& Raski, 1981, C. palustris (Luc, 1970) Luc \& Raski, 1981, C. xenoplax (Raski, 1952) Luc \& Raski, 1981, Criconemella sp.a (nova espécie ainda inomimada em SPERANDIO,

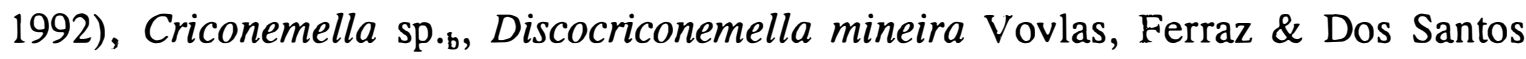
(1989), D. repleta Pinochet \& Raski, 1976, Discocriconemella sp., Hemicycliophora lutosa Loof \& Heyns, 1969 e H. poranga Monteiro \& Lordello, 1978; j) família Tylenchulidae: Tylenchulus semipenetrans Cobb, 1913 e Paratylenchus sp.; l) família Aphelenchoididae: Aphelenchoides sp. (Tabela 1).

\subsection{Identificação das espécies autóctones}

Consideraram-se como possíveis espécies autóctones aquelas que ocorreram nos remanescentes de floresta, mas não nas áreas cultivadas: Xiphinema krugi, Xiphidorus minor, Paratrichodorus sp. ${ }_{\mathrm{a}}$, Boleodorus sp., Trophurus n. sp., Rotylenchus caudaphasmidius, Rotylenchus spp., Helicotylenchus egyptiensis, H. erythrinae, $H$. exallus, Criconema braziliense, Criconema sp., Criconema n. sp., Ogma cataracticum, Ogma sp., Criconemella xenoplax, Discocriconemella mineira, D. repleta, Hemicycliophora poranga, Paratylenchus sp. e Aphelenchoides sp. São necessárias 4 ressalvas a respeito da citada lista.

A espécie de Paratrichodorus em questão provavelmente é $P$. anthurii, pois, embora tenha sido impossível identificar os exemplares coletados nos remanescentes de floresta, devido a suas más condições, encontraram-se 2 indícios importantes nesse sentido: a) $P$. anthurii foi encontrado em duas mudas de Lxora coccinea L. produzidas sobre substrato constituído de terriço retirado dos remanescentes de floresta; b) $P$. 
Tabela 1. Freqüência de ocorrência (\%) das espécies de nematóides fitoparasitos e freqüência e densidade populacional $\left(\mathrm{n}^{\circ} / 250 \mathrm{~cm}^{3}\right)$ das famílias de nematóides em amostras de solo da rizosfera no "campus" Luiz de Queiroz.

\begin{tabular}{|c|c|c|c|c|}
\hline Nematóides & $\begin{array}{l}\text { remanescentes } \\
\text { de floresta } \\
(n=14)\end{array}$ & $\begin{array}{c}\text { Parque da } \\
\text { ESALQ } \\
(n=10)\end{array}$ & $\begin{array}{c}\text { áreas culti- } \\
\text { vadas }(n=13)\end{array}$ & $\begin{array}{l}\text { outros } \\
(n=4)\end{array}$ \\
\hline
\end{tabular}

\begin{tabular}{|c|c|c|c|c|c|c|c|c|}
\hline & freq. & dens. & freq. & dens. & freq. & dens. & freq. & dens. \\
\hline Xiphinema brevicolle & 0 & & 10,0 & & 0 & & 0 & \\
\hline$X$. krugi & 7,1 & & 20,0 & & 0 & & 0 & \\
\hline X. vulgare & 0 & & 0 & & 15,4 & & 0 & \\
\hline Xiphinema sp. & 21,4 & & 10,0 & & 0 & & 0 & \\
\hline Xiphidorus minor & 21,4 & & 0 & & 0 & & 50,0 & \\
\hline Longidoridae & 50,0 & 2 & $\mathbf{4 0 , 0}$ & 4 & 15,4 & 3 & 50,0 & 3 \\
\hline Paratrichodorus anthurii & 0 & & 0 & & 0 & & 50,0 & \\
\hline P. minor & 0 & & 0 & & 7,7 & & 0 & \\
\hline Paratrichodorus $\mathrm{sp}_{\mathbf{a}_{\mathrm{a}}}$ & 14,3 & & 0 & & 0 & & 0 & \\
\hline Paratrichodorus $\mathrm{sp}_{._{\mathrm{b}}}$ & 0 & & 10,0 & & 7,7 & & 0 & \\
\hline Trichodoridae & 14,3 & 1 & 10,0 & 1 & 15,4 & 4 & 50,0 & 12 \\
\hline Boleodorus sp. & 7,1 & & 10,0 & & 0 & & 0 & \\
\hline Basiria sp. & 0 & & 10,0 & & 0 & & 25,0 & \\
\hline Tylenchidae & 7,1 & 3 & 20,0 & 7 & $\mathbf{0}$ & $\mathbf{0}$ & 25,0 & 13 \\
\hline Ditylenchus sp. & 0 & & 0 & & 7,7 & & 0 & \\
\hline Anguinidae & $\mathbf{0}$ & $\mathbf{0}$ & $\mathbf{0}$ & $\mathbf{0}$ & 7,7 & 1 & $\mathbf{0}$ & 0 \\
\hline Tylenchorhynchus annulatus & 0 & & 0 & & 7,7 & & 0 & \\
\hline Tylenchorhynchus sp. & 0 & & 0 & & 0 & & 25,0 & \\
\hline Trophurus n. sp. & 21,4 & & 0 & & 0 & & 0 & \\
\hline Belonolaimidae & 21,4 & 13 & $\mathbf{0}$ & $\mathbf{0}$ & 7,7 & 2 & 25,0 & 3 \\
\hline Pratylenchus brachyurus & 0 & & 10,0 & & 7,7 & & 0 & \\
\hline P. zeae & 0 & & 0 & & 38,5 & & 0 & \\
\hline$R$. similis & 0 & & 0 & & 7,7 & & 0 & \\
\hline Pratylenchidae & $\mathbf{0}$ & $\mathbf{0}$ & 10,0 & 1 & 46,2 & 123 & $\mathbf{0}$ & 0 \\
\hline Hoplolaimus galeatus & 0 & & 0 & & 7,7 & & 0 & \\
\hline Rotylenchus caudaphasmidius & 57,1 & & 30,0 & & 0 & & 0 & \\
\hline Rotylenchus spp. & 14,3 & & 0 & & 0 & & 25,0 & \\
\hline Helicotylenchus digonicus & 0 & & 0 & & 15,4 & & 0 & \\
\hline H. dihystera & 14,3 & & 80,0 & & 53,8 & & 0 & \\
\hline H. egyptiensis & 7,1 & & 0 & & 0 & & 0 & \\
\hline H. erythrinae & 7,1 & & 10,0 & & 0 & & 0 & \\
\hline H. exallus & 14,3 & & 0 & & 0 & & 0 & \\
\hline
\end{tabular}




\begin{tabular}{|c|c|c|c|c|c|c|c|c|}
\hline \multirow[t]{2}{*}{ Nematóides } & \multicolumn{2}{|c|}{$\begin{array}{l}\text { remanescentes } \\
\text { de floresta } \\
(n=14)\end{array}$} & \multicolumn{2}{|c|}{$\begin{array}{l}\text { Parque da } \\
\text { ESALQ } \\
(n=10)\end{array}$} & \multicolumn{2}{|c|}{$\begin{array}{c}\text { áreas culti- } \\
\text { vadas }(n=13)\end{array}$} & \multicolumn{2}{|c|}{$\begin{array}{l}\text { outros } \\
(n=4)\end{array}$} \\
\hline & freq. & dens. & freq. & dens. & freq. & dens. & freq. & dens \\
\hline H. multicinctus & 0 & & 0 & & 7,7 & & 0 & \\
\hline H. pseudorobustus & 0 & & 20,0 & & 23,1 & & 50,0 & \\
\hline Helicotylenchus spp. & 7,1 & & 0 & & 7,7 & & 25,0 & \\
\hline Scutellonema brachyurus & 0 & & 10,0 & & 15,4 & & 0 & \\
\hline Rotylenchulus reniformis & 0 & & 20,0 & & 53,8 & & 0 & \\
\hline Hoplolaimidae & 100,0 & 519 & 90,0 & 249 & 92,3 & 1.087 & 75,0 & 35 \\
\hline Meloidogyne javanica & 7,1 & & 0 & & 7,7 & & 0 & \\
\hline Meloidogyne spp. & 28,6 & & 40,0 & & 23,1 & & 25,0 & \\
\hline Heteroderidae & 35,7 & 90 & 40,0 & 22 & 30,8 & 10 & 25,0 & r \\
\hline Criconema braziliense & 28,6 & & 0 & & 0 & & 0 & \\
\hline Criconema sp. ${ }^{1}$ & 7,1 & & 0 & & 0 & & 0 & \\
\hline Criconema n.sp. & 28,6 & & 0 & & 0 & & 0 & \\
\hline Ogma cataracticum & 14,3 & & 10,0 & & 0 & & 0 & \\
\hline Ogma sp. & 7,1 & & 0 & & 0 & & 0 & \\
\hline $\begin{array}{l}\text { Hemicriconemoides } \\
\quad \text { mangiferae }\end{array}$ & 0 & & 10,0 & & 7,7 & & 0 & \\
\hline Criconemella denoudeni & 0 & & 0 & & 7,7 & & 25,0 & \\
\hline C. onoensis & 0 & & 0 & & 7,7 & & 0 & \\
\hline C. ornata & 0 & & 10,0 & & 0 & & 0 & \\
\hline C. palustris & 0 & & 0 & & 7,7 & & 0 & \\
\hline C. xenoplax & 7,1 & & 0 & & 0 & & 0 & \\
\hline Criconemella sp. ${ }_{\mathrm{a}}{ }^{1}$ & 0 & & 0 & & 15,4 & & 0 & \\
\hline Criconemella sp. ${ }_{b}$ & 0 & & 10,0 & & 7,7 & & 0 & \\
\hline D. mineira & 42,8 & & 0 & & 0 & & 0 & \\
\hline D. repleta & 57,1 & & 20,0 & & 0 & & 0 & \\
\hline Discocriconemella sp. & 0 & & 0 & & 0 & & 25,0 & \\
\hline Hemicycliophora lutosa & 0 & & 0 & & 7,7 & & 0 & \\
\hline$H$. poranga & 7,1 & & 0 & & 0 & & 0 & \\
\hline Criconematidae & 85,7 & 642 & 40,0 & 32 & 46,2 & 142 & 50,0 & 21 \\
\hline Tylenchulus semipenetrans & 0 & & 0 & & 7,7 & & 0 & \\
\hline Paratylenchus sp. & 7,1 & & 10,0 & & 0 & & 0 & \\
\hline Tylenchulidae & 7,1 & 19 & 10,0 & 7 & $\mathbf{0}$ & 190 & $\mathbf{0}$ & \\
\hline Aphelenchoides sp. & 7,1 & & 10,0 & & 0 & & 0 & \\
\hline Aphelenchoididae & 7,1 & 1 & 10,0 & 1 & $\mathbf{0}$ & $\mathbf{0}$ & $\mathbf{0}$ & 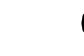 \\
\hline
\end{tabular}

'Novas espécies ainda inominadas em SPERANDIO (1992). 
anthurii é uma espécie rara (este é primeiro registro de ocorrência fora do sua localidade tipo), portanto seria praticamente impossível que os nematóides que vieram a infestar I. coccinea tenham vindo de outro local que não os remanescentes de floresta em estudo.

Uma espécie de Helicotylenchus provavelmente autóctone, $H$. caipora Mendonça \& Monteiro, 1972, que foi descrita a partir de exemplares coletados em remanescentes de floresta do "campus" Luiz de Queiroz e não foi registrada posteriormente em outros locais (COSTA MANSO et alii, 1994; MONTEIRO \& MENDONÇA, 1972), não foi identificada neste levantamento. Apesar de terem sido feitas coletas em todos os remanescentes do "campus" Luiz de Queiroz, não foi possível reencontrar a localidade tipo dessa espécie. Uma terceira ressalva refere-se a $M$. javanica. Como essa espécie ocorreu também nas áreas cultivadas, não foi possível determinar se era ou não autóctone. Vale lembrar, porém, que há fortes indícios de que, além de $M$. coffeicola Lordello \& Zamith, 1960 e M. exigua Goeldi, 1887, pelo menos 2 outras espécies de Meloidogyne, M. arenaria (Neal, 1889) Chitwood, 1949 raça 2 e $M$. javanica, também sejam nativas do Brasil, pois já foram detectadas, com uma freqüência de $6,5 \%$, em amostras de solo do cerrado virgem do Distrito Federal (SOUZA et alii, 1994). A última ressalva refere-se a $C$. xenoplax. Acredita-se que, na verdade, ela não seja autóctone, pois apenas um exemplar foi coletado e havia um pomar de Prunus persicae Batsch (pessegueiro), um ótimo hospedeiro de $C$. xenoplax, em área adjacente ao local de coleta. Infelizmente, não foi possível obter exemplares de $C$. xenoplax da amostra coletada no referido pomar (ver Figura 1 e Apêndice 3, amostras 9 e 41), o que confirmaria essa hipótese.

Notou-se uma grande concordância da lista de possíveis autóctones, citada acima, com resultados de trabalhos anteriores. Dentre os táxons coletados por LORDELLO (1955), ZAMITH \& LORDELLO (1957), LORDELLO \& ZAMITH (1958), MENDONÇA \& MONTEIRO (1972) e MENDONÇA (1976) na vegetação nati- 
va do "campus" Luiz de Queiroz, somente Paratrichodorus porosus e H. caipora não foram identificados no presente trabalho.

\subsection{Influência da cobertura vegetal na fauna nematológica}

Os 3 tipos de cobertura vegetal apresentaram faunas nematológicas bastante distintas, fato comprovado pelos índices de similaridade de Jaccard extremamente baixos: 0,25 entre os remanescentes e o parque, 0,06 entre os remanescentes e as áreas cultivadas e 0,21 entre o parque e as áreas cultivadas.

Os nematóides mais freqüentes no levantamento pertenceram a Hoplolaimidae e Criconematidae (Tabela 1). No entanto, verificaram-se grandes diferenças na composição específica nessas famílias. A espécie de nematóide espiralado (Hoplolaimidae) mais freqüente e abundante nos remanescentes de floresta foi Rotylenchus caudaphasmidius, que, por outro lado, não ocorreu em nenhuma das amostras das áreas cultivadas. Nessas, predominaram as espécies Rotylenchulus reniformis, Helicotylenchus dihystera e $H$. pseudorobustus. No parque da ESALQ, encontraram-se 6 espécies de nematóides espiralados, destacando-se $H$. dihystera. Esses resultados demonstraram que $R$. caudaphasmidius, possível espécie autóctone dos remanescentes, conseguiu sobreviver sob um bosque implantado (parque da ESALQ), mas desapareceu nas áreas utilizadas para cultivo, tanto anual como perene, sendo substituída por espécies provavelmente não autóctones, como $R$. reniformis e $H$. pseudorobustus.

Os nematóides anelados (Criconematidae) constituíram o grupo mais importante nos solos dos remanescentes de floresta, com pelo menos 9 espécies diferentes abrigadas sob essa cobertura vegetal. Os anelados foram o segundo grupo mais freqüente e abundante nos solos do parque da ESALQ e das áreas cultivadas, mas apresentando uma composição específica totalmente diferente da dos solos dos remanescentes de floresta. As únicas espécies que ocorreram tanto nos remanescentes como no parque 
da ESALQ foram Ogma cataracticum e Discocriconemella repleta, e não houve nenhuma coincidência entre as populaçōes de anelados dos remanescentes e das áreas cultivadas. Houve, portanto, com a substituição da vagetação nativa por plantas cultivadas, o total desaparecimento dos anelados autóctones. Notou-se, ainda, que, enquanto nos remanescentes predominaram Criconema e Discocriconemella, nas áreas cultivadas destacou-se Criconemella. Esses resultados coincidiram parcialmente com os de CARES \& HUANG (1991), que verificaram que os nematóides anelados são os mais freqüentes na vegetação natural do cerrado do Brasil, sendo que Criconema sp., Hemicriconemoides sp. e Discocriconemella sp. predominaram nos campos sujos, Criconemella spp. nos campos limpos e Hemicycliophora sp. nas florestas de galeria. Esta última seria o tipo de vegetação mais semelhante aos remanescentes de floresta mesófila semi-decídua que ocorrem no "campus" Luiz de Queiroz. CARES \& HUANG (1991) verificaram ainda que os nematóides anelados desapareciam ou tinham sua população muito reduzida quando a vegetação natural do cerrado era substituída por culturas, sejam anuais ou perenes [Oryza sativa L. (arroz), Glycine max L. (soja), Eucalyptus grandis W. Hill ex Maiden e Pinus caribaea Morelet]. No presente caso, além da redução populacional, houve a substituição dos gêneros autóctones por Criconemella.

Das 11 famílias de nematóides fitoparasitos constantes no levantamento, 2 não ocorreram nos remanescentes de floresta: Anguinidae e Pratylenchidae. Contudo, Pratylenchus brachyurus, $P$. zeae e $R$. similis, espécies de Pratylenchidae, ocorreram nas áreas cultivadas, tendo provavelmente nelas chegado através de material de plantio infestado. Em áreas de cerrado, CARES \& HUANG (1991) verificaram freqüência comum de nematóides da família Anguinidae, destacando-se Ditylenchus sp., tanto nos campos sujos como nos campos limpos e nas florestas de galeria. Já Pratylenchus sp., embora muito comum nos campos limpos, estava ausente nos campos sujos e florestas de galeria.

Nem sempre, porém, a substituição da vegetação nativa por plantas 
cultivadas representa o desaparecimento das espécies autóctones. Dentre as espécies autóctones do "campus" Luiz de Queiroz, as seguintes estão adaptadas a plantas cultivadas: Xiphinema krugi (a vários hospedeiros) (FERRAZ, L.C., 1980 $0_{\mathrm{a}, \mathrm{b}}$ ), Xiphidorus minor [a Theobroma cacao L. (cacaueiro), seu hospedeiro típico] (RASHID et alii, 1986), Helicotylenchus erythrinae (a vários hospedeiros) (COSTA MANSO et alii, 1994), H. exallus (a T. cacao) (SHARMA \& SHER, 1973), Criconema braziliense (a T. cacao e Citrus sp.) (FERRAZ, S., 1980; RASHID et alii, 1986 ), Ogma cataracticum (a vários hospedeiros) (CAMPOS \& STURHAN, 1987; FERRAZ, S., 1980; VOVLAS et alii, 1987) e Hemicycliophora poranga [a Brassica oleracea L. var. capitata L. (repolho), seu hospedeiro típico] (MONTEIRO \& LORDELLO, 1978).

\subsection{Estudo morfológico de algumas espécies}

Dezoito táxons coletados no presente trabalho são pouco comuns na fauna brasileira: Xiphidorus minor, Paratrichodorus anthurii, Rotylenchus caudaphasmidius, Helicotylenchus digonicus, $H$. exallus, Criconema braziliense, Criconema sp. (nova espécie ainda inominada em SPERANDIO, 1992), Ogma cataracticum, Ogma sp. (espécie não identificada, provavelmente ainda não registrada no Brasil), Criconemella denoudeni, $C$. palustris, Criconemella sp.a (nova espécie ainda inominada em SPERANDIO, 1992), Discocriconemella mineira, D. repleta, Hemicycliophora poranga, Paratylenchus sp. (espécie não identificada, provavelmente ainda não registrada no Brasil) e as 2 novas espécies. Dessas, 9 foram objeto deste estudo morfológico: $X$. minor, $P$. anthurii, $R$. caudaphasmidius, C. braziliense, O. cataracticum, C. palustris, Criconemella sp.a (espécie ainda inominada em SPERANDIO, 1992), D. mineira e D. repleta (as 2 novas espécies são descritas no item 4.5). Cinco outros táxons (Xiphinema krugi, $X$. vulgare, Hemicriconemoides mangiferae, Criconemella xenoplax e Hemicycliophora lutosa) também foram incluídos neste estudo, por serem de difícil identificação sem um 
estudo morfológico minucioso.

\section{Xiphinema krugi Lordello, 1955}

Sinônimos: X. denoudeni Loof \& Maas, 1972 e X. loosi Southey \& Luc, 1973.

Medidas: Fêmeas $(\mathrm{n}=12): \mathrm{L}=2.230 \pm 121 \mu \mathrm{m}(2.082-2.522)$; Oes $=411 \pm 18,6$ $\mu \mathrm{m}(384-441) ;$ Odt $=119 \pm 4 \mu \mathrm{m}(111-125) ;$ Odf $=69 \pm 1,6 \mu \mathrm{m}(67-73) ; \mathrm{St}=$ $188 \pm 3,7 \mu \mathrm{m}(180-196) ;$ anel-guia $=109 \pm 4,5 \mu \mathrm{m}(100-117) ;$ r.g.a. $=111 \pm$ $27,4 \mu \mathrm{m}(56-131)^{2} ; \mathrm{t}=32 \pm 2 \mu \mathrm{m}(27-35) ; \mathrm{V}=33,9 \pm 0,9(32,0-35,1) ; \mathrm{a}=$ $52 \pm 2(48-54) ; b=5,4 \pm 0,2(5,0-5,7) ; c=71 \pm 0,6(64-82) ; c^{\prime}=1,0 \pm 0,1$ $(0,9-1,1) ;$ r.g.a/ VB $=2,6 \pm 0,7(1,3-3,3)^{2}$.

Machos: não encontrados.

Observações: Xiphinema krugi pode ser diferenciado das outras espécies de Xiphinema pelas seguintes características: a) vulva anterior $(\mathrm{V}=28,6-36)$; b) ramo genital anterior reduzido (r.g.a. $=38-113 \mu \mathrm{m}$ ), consistindo de 3 partes: útero curto, esfíncter e oviduto vestigial; c) cauda curta $\left(\mathrm{t}=24-45 \mu \mathrm{m}, \mathrm{c}^{\prime}=0,57-1,74\right)$ (LORDELLO, 1955; LUC \& HUNT, 1978). As medidas e características morfológicas observadas nos exemplares aqui estudados estão de acordo com a descrição da espécie (LORDELLO, 1955) e com os trabalhos de LUC \& HUNT (1978) e FERRAZ, L.C. $\left(1980_{b}\right)$, com exceção das observações sobre o r.g.a. (Figura 2). De um total de 7 fêmeas observadas, 3 apresentavam um r.g.a. maior e com o oviduto mais desenvolvido que o dos exemplares estudados por LUC \& HUNT (1978).

Ocorrências: os exemplares estudados foram encontrados na rizosfera de Machaerium

$$
{ }^{2} n=7
$$


aculeatum Raddi (bico-de-pato), no parque da ESALQ (amostra 7: $0-20 \mathrm{~cm}$ de profundidade). A descrição original da espécie foi feita a partir de exemplares coletados no Brasil, na rizosfera de várias árvores nativas não identificadas, em um bosque de Piracicaba, SP (LORDELLO, 1955). Posteriormente, sua ocorrência foi relatada em várias outras localidades do Brasil, tratando-se, portanto, de uma espécie muito disseminada no país (FERRAZ, L.C. 1980 ${ }_{\mathrm{a}, \mathrm{b}}$; LOOF \& SHARMA, 1979).

\section{Xiphinema vulgare Tarjan, 1964}

Medidas: Fêmeas $(\mathrm{n}=2): \mathrm{L}=2.658 \mathrm{~mm}(2.647$ e 2.670$)$; Oes $=382 \mu \mathrm{m}(369$ e 395); Odt $=118 \mu \mathrm{m}(\mathrm{n}=1)$; Odf $=72,5 \mu \mathrm{m}(72$ e 73); St $=191 \mu \mathrm{m}(\mathrm{n}=1)$; anelguia $=100 \mu \mathrm{m}(98$ e 102$) ; \mathrm{t}=48,5 \mu \mathrm{m}(48$ e 49$) ; \mathrm{h}=18,7 \mu \mathrm{m}(18,7$ e 18,7$) ; \mathrm{V}=$ $38,9(38,5$ e 39,4$) ; \mathrm{a}=58$ (58 e 58$) ; \mathrm{b}=7,0(6,8$ e 7,2$) ; \mathrm{c}=55$ (54 e 56$) ; c^{\prime}=1,6$ $(1,6$ e 1,6$)$.

Machos: não encontrados.

Observações: essa é uma espécie muito semelhante a Xiphinema setariae Luc, 1958, havendo pequenas diferenças morfométricas entre as 2 nos comprimentos do corpo, odontostílio, cauda e porção hialina da cauda, e no valor a (TARJAN, 1964). X. setariae caracteriza-se pela região anterior separada do resto do corpo por uma constrição evidente, presença de 2 ramos genitais desenvolvidos, vulva anterior ( $V=35,4-38,5)$, ausência de cárdia, cauda curta ( $\left.c^{\prime}=2,0,-2,3\right)$ e de formato cônico-digitado (LUC, 1958). A grande semelhança entre as 2 espécies levantou dúvidas quanto à validade de $X$. vulgare mas, segundo LUC \& DALMASSO (1975), pelo menos os comprimentos da cauda (55- $63 \mu \mathrm{m}$ em X. setariae e $45-53 \mathrm{em} \mathrm{X}$. vulgare) e da sua porção hialina (23 - $29 \mu \mathrm{m}$ em X. setariae e 13 - 20 em X. vulgare) eram, àquela época, características suficientemente confiáveis para diferenciá-las. Admitiam, porém, que essa opinião seria 
revista se se verificasse a existência de populações de $X$. setariae/vulgare com valores de $t$ e $h$ intermediários entre os conhecidos até então.

Portanto, considerando a opinião de LUC \& DALMASSO (1975), a mais aceita atualmente, o presente material deve ser classificado como $X$. vulgare, pois apresentou $\mathrm{t}=48,5 \mu \mathrm{m} \mathrm{e} \mathrm{h}=18,7 \mu \mathrm{m}$.

Ocorrências: Xiphinema vulgare foi descrita a partir de exemplares coletados na rizosfera de Citrus reticulata Blanco (tangerina) cv. Cleópatra, em Lake Alfred, Flórida, E.U.A. (TARJAN, 1964).

Os exemplares estudados no presente trabalho foram coletados em rizosfera de Mangifera indica L. (mangueira/ amostra 13: $0-20 \mathrm{~cm}$ de profundidade). No Brasil, $X$. vulgare é muito comum. Sua ocorrência já foi relatada, por exemplo, nos estados do Acre, Bahia, Minas Gerais e São Paulo, nas rizosferas de Solanum melongena L. (berinjela), Saccharum officinarum L. (cana-de-açúcar), Crotalaria lanceolata E. Mey. e várias plantas invasoras (FERRAZ, L.C., 1980 a, ).

\section{Xiphidorus minor Rashid, Coomans \& Sharma, 1986}

Medidas: Fêmeas $(\mathrm{n}=10): \mathrm{L}=2.209 \pm 219 \mu \mathrm{m}(1.838-2.552)$; Oes $=269 \pm 16,8$ $\mu \mathrm{m}(237$ - 298); Odt $=83 \pm 4,4 \mu \mathrm{m}(78-92) ;$ Odf $=38 \pm 2,1 \mu \mathrm{m}(34-42) ; \mathrm{St}=$ $121 \pm 5,8 \mu \mathrm{m}(115$ - 131); anel-guia $=70 \pm 7,1 \mu \mathrm{m}(55-78) ; \mathrm{t}=25 \pm 1,7 \mu \mathrm{m}(23$ - 28); $\mathrm{V}=50 \pm 1,2$ (48 - 52); $\mathrm{a}=72 \pm 4,6$ (65 - 79); $\mathrm{b}=8,2 \pm 0,9(7,2-9,6)$; $c=87 \pm 5,7(79-98) ; c^{\prime}=1,3 \pm 0,1(1,1-1,5)$.

Machos: não encontrados.

$\underline{\mathrm{J} 4}(\mathrm{n}=4): \mathrm{L}=1.478 \pm 52 \mu \mathrm{m}(1.413-1.542) ;$ Oes $=239 \pm 23,7 \mu \mathrm{m}$ (212 - 259); Odt $=70 \pm 3,1 \mu \mathrm{m}(66-74) ;$ Odf $=33 \pm 0 \mu \mathrm{m} ; \mathrm{St}=103 \pm 3,1 \mu \mathrm{m}$ (99 - 107); Odt reserva $=80 \pm 2,4 \mu \mathrm{m}$ (76 - 82); anel-guia $=61 \pm 2,8 \mu \mathrm{m}(58$ - 64); 
$\mathrm{t}=25 \pm 2,3 \mu \mathrm{m}(22-28) ; \mathrm{a}=65 \pm 2,9(62-69) ; \mathrm{b}=6,2 \pm 0,7(5,5-7,0) ; \mathrm{c}=$ $59 \pm 3,4(55-63) ; c^{\prime}=1,6 \pm 0,1(1,5-1,8)$.

$\underline{\mathrm{J} 3}(\mathrm{n}=1): \mathrm{L}=1.191 \mu \mathrm{m} ;$ Oes $=237 \mu \mathrm{m} ;$ Odt $=56 \mu \mathrm{m} ;$ Odf $=31 \mu \mathrm{m}$; $\mathrm{St}=87 \mu \mathrm{m} ;$ Odt reserva $=68 \mu \mathrm{m}$; anel-guia $=48 \mu \mathrm{m} ; \mathrm{t}=31 \mu \mathrm{m} ; \mathrm{a}=52 ; \mathrm{b}=5,0 ;$ $\mathrm{c}=39 ; \mathrm{c}^{\prime}=2,0$.

$\underline{\mathrm{J} 2}(\mathrm{n}=2): \mathrm{L}=793 \mu \mathrm{m}(782$ e 803$) ;$ Oes $=196,5 \mu \mathrm{m}(181$ e 212$) ;$ Odt $=$ $47,5 \mu \mathrm{m}$ (47 e 48); Odf $=28 \mu \mathrm{m}(27$ e 29$) ; \mathrm{St}=75,5 \mu \mathrm{m}$ (75 e 76); Odt reserva $=$ $56,5 \mu \mathrm{m}(56$ e 57$) ;$ anel-guia $=38 \mu \mathrm{m}(36$ e 40$) ; \mathrm{t}=27,5 \mu \mathrm{m}(27$ e 28$) ; \mathrm{a}=48$ (47 e 49); b = 4,0 (3,8 e 4,3); c = 29 (29 e 29); c' = 2,5 (2,5 e 2,6).

Observações: essa espécie foi descrita originalmente a partir de material obtido da rizosfera de Theobroma cacao, em Itamaraju, BA (localidade tipo) e Ilhéus, BA (RASHID et alii, 1986 ). Nos exemplares aqui estudados, observaram-se claramente as características apontadas por Rashid e colaboradores como diferenciadoras da espécie, ou seja, região labial delimitada apenas por uma delicada constrição, comprimento do corpo pequeno $(\mathrm{L}<2.500 \mu \mathrm{m})$, ramos genitais curtos e cauda dorsalmente convexo-conóide, com término arredondado e sem processo digitiforme. As medidas diferem daquelas da descrição da espécie nos maiores comprimentos do corpo, odontostílio e estilete, e maiores valores de a, b e c. Essas diferenças são mais acentuadas nas fêmeas e juvenis de $4^{\circ}$ estádio e menos nos juvenis de $3^{\circ}$ e $2^{\circ}$ estádio [em fêmeas: $2.209(1.838-2.552)$ vs. $1.740 \mu \mathrm{m}(1.600-1.900) ; \mathrm{Odt}=83(78-92)$ vs. $76 \mu \mathrm{m}(73-77) ; \mathrm{St}=121(115$ - 131) vs. $111 \mu \mathrm{m}(108-116) ; \mathrm{a}=72(65-79)$ vs. $64(57-72) ; \mathrm{b}=8,2(7,2-9,6)$ vs. $6,8(6,4-7,4) ; c=87(79-98)$ vs. $73(66-83)]$. Os maiores comprimentos do corpo, odontostílio e estilete podem ser devidos ao clima mais frio em Piracicaba em relação a Itamaraju e Ilhéus, de acordo com a regra de variação de Bergmann. Segundo essa regra, os animais de sangue quente de regiões frias têm a tendência de ser maiores que os de regiões quentes. Essa regra normalmente inverte-se para vertebrados terrestres de sangue frio, como cobras e lagartos (ORR, 1986), mas aparentemente é válida para 
nematóides terrestres, pelo menos neste caso.

Ocorrências: os exemplares estudados foram extraídos da rizosfera de Bauhinia forficata Link. (pata-de-boi-de-espinho/ amostra 2: $0-5 \mathrm{~cm}$ de profundidade), Lantana camara $\mathrm{L}$. (amostra 10: $0-15 \mathrm{~cm}$ de profundidade). Além disso, foram encontrados exemplares na rizosfera de 2 mudas de Lxora coccinea (amostras 1 e 5) cedidas pelo Depto. de Horticultura da ESALQ/USP. É interessante notar que o Depto. de Horticultura utilizava solo de um remanescente de floresta de onde vieram as amostras 2 e 10 como substrato para produção de mudas, daí a ocorrência de $X$. minor naquelas mudas. Este é o primeiro registro da ocorrência de $X$. minor fora do estado da Bahia.

\section{Paratrichodorus anthurii Baujard \& Germani, 1985}

Medidas: Fêmeas $(\mathrm{n}=21): \mathrm{L}=451 \pm 50 \mu \mathrm{m}(349$ - 544); Oes $=88 \pm 12 \mu \mathrm{m}(71$ 111); $\mathrm{EP}=77,3 \pm 0,9 \mu \mathrm{m}(76,2-77,8)^{3} ; \mathrm{St}=28,3 \pm 1,2 \mu \mathrm{m}(26,1-30,8)^{4} ; \mathrm{Ga}$ $=22,3 \pm 2,5(17,5-26,5) ; \mathrm{Gp}=21,7 \pm 1,9(18,2-25,6) ; \mathrm{V}=55,1 \pm 1,5(52,2-$ 58,5); St\% L = 6,03 $\pm 0,49(5,26-6,88)^{4}$; St\% Oes $=31,1 \pm 4,3(25,3-36,8)^{4}$; $\mathrm{EP} \%$ Oes $=97,4 \pm 6,6(89,8-101,6)^{3} ; \mathrm{a}=17,5 \pm 2,1(15,0-21,6) ; \mathrm{b}=5,14 \pm$ $0,37(4,44-5,98) ; d=2,22 \pm 0,07(2,09-2,41) ; e=5,78 \pm 0,16(5,59-5,88)^{3}$; $z=16,7 \pm 1,4(14,5-19,0)^{4}$.

Machos: não encontrados.

Observações: segundo BAUJARD \& GERMANI (1985), Paratrichodorus anthurii diferencia-se das outras espécies do gênero pela ausência de poros caudais e pelo perfil tri-

$$
\begin{aligned}
& { }^{3} \mathrm{n}=3 \\
& { }^{4} \mathrm{n}=12
\end{aligned}
$$


angular das esclerotizações vulvares, quando em vista lateral (Figura 3). Nos exemplares examinados no presente trabalho, o perfil das esclerotizações vulvares poucas vezes correspondeu exatamente a esse formato triangular, mesmo nos exemplares em posição lateral. Por essa razão, sugere-se que um somatório de características de mais fácil visualização seja utilizado para a diagnose da espécie: a) limite esôfago-intestino praticamente reto, sem recobrimento de um pelo outro, podendo haver, no máximo, leve inclinação ventral do esôfago; b) vulva em forma de fenda transversal curta; $c$ ) espermateca de forma circular ou ovóide e cheia de espermatozóides; d) ausência de poros caudais; e) cauda de forma hemisférica.

Ocorrências: essa espécie foi descrita a partir de material coletado na rizosfera de $A n$ thurium sp., em Champsflore, ilha de Martinica (departamento ultramarino da França nas Antilhas) (BAUJARD \& GERMANI, 1985).

No presente trabalho, $P$. anthurii foi coletado em amostras de solo da rizosfera de uma muda de Lxora coccinea (amostra 5). Este é o primeiro registro de ocorrência dessa espécie no Brasil.

\section{Rotylenchus caudaphasmidius Sher, 1965}

Medidas: Fêmeas: $(\mathrm{n}=8): \mathrm{L}=676 \pm 44 \mu \mathrm{m}(599$ - 734); Oes $=134 \pm 7 \mu \mathrm{m}(124$ $141)^{5} ; \mathrm{EP}=100 \pm 7 \mu \mathrm{m}(89-108)^{5} ; \mathrm{St}=25,6 \pm 1,1 \mu \mathrm{m}(24,3-28,0) ; \operatorname{dadg}=5,9$ $\pm 0,6 \mu \mathrm{m}(5,1-6,1) ; \mathrm{t}=13,3 \pm 1,8 \mu \mathrm{m}(10,7-15,4) ; \mathrm{V}=60,9 \pm 1,5(58,5-63,8)$; $M=46,6 \pm 2,8(43,6-51,7) ; a=26,1 \pm 1,4(23,3-27,4) ; b=6,25 \pm 0,45(5,93$ $-7,02)^{6} ; b^{\prime}=5,11 \pm 0,45(4,28-5,58)^{5} ; c=51,3 \pm 5,6(46,2-62,1) ; c^{\prime}=0,81$

$$
\begin{aligned}
& { }^{5} \mathrm{n}=7 \\
& { }^{6} \mathrm{n}=5
\end{aligned}
$$


$\pm 0,08(0,71-0,94)$.

Machos: $(\mathrm{n}=3): \mathrm{L}=525 \pm 67 \mu \mathrm{m}(469-599) ;$ Oes $=117 \pm 6 \mu \mathrm{m}(112$ - 124); $\mathrm{EP}=90 \pm 6 \mu \mathrm{m}$ (85 - 97); St $=23,0 \pm 1,2 \mu \mathrm{m}$ (21,9 - 24,3); dadg = ?; esp. $=25,3 \pm 1,8 \mu \mathrm{m}(23,3-26,6)$; gub. $=9,2 \pm 0,2 \mu \mathrm{m}(8,9-9,3) ; \mathrm{t}=15,6 \pm 1,5 \mu \mathrm{m}$ $(14,5-17,3) ; M=54,7 \pm 2,1(53,1-57,1) ; a=29,8 \pm 2,0(27,9-31,9) ; b=5,19$ $\pm 0,44(4,75-5,63) ; b^{\prime}=4,46 \pm 0,33(4,19-4,83) ; c=33,7 \pm 1,1(32,4-34,6)$; $c^{\prime}=1,37 \pm 0,16(1,23-1,54)$.

Observações: Rotylenchus caudaphasmidius pode ser diferenciado das demais espécies do gênero pelas seguintes características: a) região labial hemisférica, contínua com o resto do corpo, com 5 anéis e sem estrias longitudinais (Figura 4); b) St $<30 \mu \mathrm{m} \mathrm{e}$ cone menor que haste do estilete $(\mathrm{M}<45)$; c) campo lateral areolado apenas na parte anterior do corpo; d) machos freqüentes; e) espermatecas circulares e normalmente cheias de espermatozóides arredondados; f) fasmídios na cauda (SHER, 1965). Algumas populações apresentam pequenas variações em relação ao material tipo: a) região labial levemente achatada e com 6 anéis; b) cone maior que haste do estilete ( $\mathrm{M}>50)$; c) campo lateral areolado por toda a extensão do corpo; d) fasmídios em posição mais anterior, até um anel antes do ânus ou da cloaca (MENDONÇA, 1976; SPERANDIO, 1992; VAN DEN BERG, 1978 e 1986).

As características dos exemplares aqui estudados coincidem com os do material tipo, exceto pela região labial levemente achatada e pelo valor $\mathrm{M}>50 \mathrm{em}$ algumas das fêmeas e em todos os machos. Essa última observação concorda com as de MENDONÇA (1976) e SPERANDIO (1992).

Ocorrências: o hospedeiro tipo e a localidade tipo de $R$. caudaphasmidius são, respectivamente, Solanum sp. e Huaras, no Peru (SHER, 1965).

O material utilizado no presente estudo foi coletado em solo da rizosfera de espécies vegetais não identificadas, em remanescentes de floresta (amostras 8, 
9, 11 e 14: profundidades de $0-5$ até $0-40 \mathrm{~cm})$. Sua ocorrência em remanescentes de floresta do "campus" Luis de Queiroz já havia sido relatada anteriormente (MENDONÇA, 1976). Depois desse registro, provavelmente o primeiro no Brasil, alguns outros foram feitos (SPERANDIO, 1992).

\section{Criconema braziliense (Raski \& Pinochet, 1975) Raski \& Luc, 1986}

Sinônimos: Merocriconema braziliensis Raski \& Pinochet, 1975 e Neolobocriconema braziliense (Raski \& Pinochet, 1975) Hashim, 1984.

Medidas: Fêmeas $(\mathrm{n}=9): \mathrm{L}=374 \pm 42 \mu \mathrm{m}(307$ - 437); Oes $=100 \pm 4,6 \mu \mathrm{m}$ (93 106); $\mathrm{EP}=138 \pm 13 \mu \mathrm{m}(112-151) ; \mathrm{St}=65 \pm 2,1 \mu \mathrm{m}(62-69) ; \mathrm{t}=17,3 \mu \mathrm{m}(\mathrm{n}$ $=2 ; 13,1$ e $21,5 \mu \mathrm{m}) ; \mathrm{R}$ (lado ventral) $=41 \pm 1,0(40-43) ; \mathrm{R}_{\mathrm{st}}=9 \pm 0,9(8-11) ;$ $\mathrm{R}_{\text {Oes }}=12 \pm 1,1(11-15) ; \mathrm{R}_{\mathrm{ex}}=16 \pm 0,9(15-18) ; \mathrm{R}_{\mathrm{v}}=6 \pm 0,5(5-7) ; \mathrm{R}_{\mathrm{Van}}=$ $0,5(\mathrm{n}=2 ; 0$ e 1$) ; \mathrm{R}_{\mathrm{an}}=4,5(\mathrm{n}=2 ; 4$ e 5$) ; \mathrm{M}=75,0 \pm 1,0(73,6-76,5) ; \mathrm{V}=$ $93,4 \pm 0,7$ (92 - 94); St\% L = 17,7 $\pm 1,6(15,4-20,7) ; \mathrm{St} \%$ Oes $=65,5 \pm 2,5$ $(60,4-69,0) ; a=9,3 \pm 0,8(8,4-10,3) ; b=3,7 \pm 0,4(2,9-4,2) ; c=20,3(n=$ $2 ; 17,2$ e 23,4$) ; \mathrm{VL} / \mathrm{VB}=0,81 \pm 0,08(0,69-0,94) ; \mathrm{VL} / \mathrm{St}=0,36 \pm 0,04(0,31-$ $0,39)$.

Machos: não encontrados.

Observações: Criconema braziliense caracteriza-se pelo corpo curto e roliço ( $\mathrm{L}=220$ $390 \mu \mathrm{m} ; \mathrm{a}=6-10)$, pequeno número de anéis do corpo $(\mathrm{R}=38-43)$, sendo o segundo de menor diâmetro e largura que o primeiro e terceiro ( $1^{\circ}$ anel: $14 \mu \mathrm{m}$ de diâmetro; $2^{\circ}$ anel: $12 \mu \mathrm{m}$ de diâmetro e $2 \mu \mathrm{m}$ de largura; $3^{\circ}$ anel: $19 \mu \mathrm{m}$ de diâmetro e $4 \mu \mathrm{m}$ de largura), dando a impressão que há uma constrição entre os 2 , e, principalmente, pela presença de apêndices de formato grosseiramente triangular na margem posterior dos anéis. Esses apêndices normalmente são mais conspícuos na metade poste- 
rior do corpo, e, de cada lado do corpo, são visíveis 1, 2 ou mais deles (Figura 5). Existe certa variação no formato e na disposição desses apêndices nos anéis (RASHID et alii, 1986 ${ }_{\mathrm{b}}$; RASKI \& PINOCHET, 1975).

As características observadas no material estudado no presente trabalho coincidem com as dos exemplares da descrição da espécie (RASKI \& PINOCHET, $1975)$ e dos exemplares estudados por RASHID e colaboradores $\left(1986_{b}\right)$. Quanto à ornamentação dos anéis, ela é mais semelhante à da descrição da espécie, ou seja, os anéis anteriores têm a margem posterior praticamente lisa, notando-se a presença dos apêndices a partir da altura dos bulbos do estilete, sendo que esses apêndices tornam-se cada vez mais conspícuos quando se avança em direção ao final do corpo.

Ocorrências: os exemplares aqui estudados foram obtidos de solo de um remanescente de floresta (amostras 2 e 11:0 - $10 \mathrm{~cm}$ de profundidade), na rizosfera de Bauhinia forficata e de espécies vegetais não identificadas.

A espécie foi descrita a partir de espécimes obtidos da rizosfera de Piper sp. em Seara, SC (RASKI \& PINOCHET, 1975). Mais tarde, outras populações de $C$. braziliense foram encontradas na rizosfera de Theobroma cacao em Ilhéus (BA), e Citrus sp., em Muriaé (MG) (FERRAZ, S., 1980; RASHID et alii, 1986 ).

Ogma cataracticum (Andrássy, 1979) Raski \& Luc, 1987

Sinônimos: Neolobocriconema cataracticum Andrássy, 1979; Paralobocriconema cataracticum (Andrássy, 1979) Minagawa, 1986.

Medidas: Fêmeas $(\mathrm{n}=7): \mathrm{L}=470 \pm 39 \mu \mathrm{m}(415-515)$; Oes $=144 \mu \mathrm{m}(\mathrm{n}=2$; 136 e 152); $\mathrm{EP}=166 \mu \mathrm{m}(\mathrm{n}=1) ; \mathrm{St}=106 \pm 7 \mu \mathrm{m}(95-114) ; \mathrm{t}=$ ?; $\mathrm{R}$ (lado ventral $)=42 \pm 1,3(40-44) ; R_{\mathrm{St}}=11,5 \pm 0,5(11-12) ; \mathrm{R}_{\mathrm{Oes}}=14,5(\mathrm{n}=2 ; 13$ e 16$) ;$ 
$\mathrm{R}_{\mathrm{ex}}=17(\mathrm{n}=1) ; \mathrm{R}_{\mathrm{v}}=3,1 \pm 0,4(3-4) ; \mathrm{M}=81,8 \pm 1,0(81,1-83,5) ; \mathrm{V}=95,5$ $\pm 0,6(94,6-96,4) ; \mathrm{St} \% \mathrm{~L}=22,8 \pm 1,9(20,9-26,3) ; \mathrm{St} \%$ Oes $=76,0(\mathrm{n}=2$ 74,6 e 77,4); $\mathrm{a}=8,58 \pm 0,50(7,98-9,36) ; \mathrm{b}=3,27(\mathrm{n}=2 ; 2,84-3,70) ; \mathrm{VL} / \mathrm{VB}$ $=0,66 \pm 0,06(0,53-0,71) ; \mathrm{VL} / \mathrm{St}=0,19 \pm 0,03(0,15-0,24)$.

Machos: não encontrados.

Observações: essa espécie caracteriza-se pelo corpo curto $(\mathrm{L}=340-514 \mu \mathrm{m})$, roliço $(\mathrm{a}=5,5-8,6)$ e em forma de " $\mathrm{C}$ ", pelo pequeno número de anéis do corpo $(\mathrm{R}=39$ $45)$, pela vulva fechada e em posição bem posterior $\left(R_{V}=3, V=94-96\right)$ e pelo formato da região labial (ANDRÁSSY, 1979; VOVLAS et alii, 1987). A região labial de $O$. cataracticum lembra a do gênero Discocriconemella, consistindo de um anel em forma de trapézio invertido, separado do resto do corpo por uma constrição (Figura 6). A ornamentação dos anéis é formada de numerosos e pequenos lobos (120 a 150 nos anéis do meio do corpo), que são mais desenvolvidos no terço posterior do corpo, em especial no último anel. Como esses lobos retêm partículas do solo, a cutícula do nematóide acaba adquirindo uma coloração castanha e a visualização das aberturas naturais do corpo e da anatomia interna torna-se difícil (ANDRÁSSY, 1979). As características morfológicas observadas e as medidas tomadas dos exemplares aqui estudados coincidem com as da descrição da espécie (ANDRÁSSY, 1979), exceto pelo maior comprimento do corpo $(\mathrm{L}=415-515$ vs. $340-440 \mu \mathrm{m})$, corpo mais esbelto $(\mathrm{a}=7,98$ $9,36$ vs. $5,5-6,8)$ e maior número de anéis $(\mathrm{R}=40-44$ vs. $39-42)$.

Ocorrências: Ogma cataracticum foi descrito a partir de 3 fêmeas e 3 juvenis coletados em solo de mata no Parque Nacional do Iguaçu, Brasil, por ANDRÁSSY (1979). A espécie ocorre também nos estados de Minas Gerais e Rio de Janeiro: em Campos Gerais (rizosfera de várias hortaliças), Coronel Xavier Chaves (Lycopersicon esculentum Mill., tomateiro), Leopoldina (Pennisetum purpureum Schum., capim elefante), Pedro Leopoldo (solo de mata natural) e Rio de Janeiro (Mangifera indica) (CAMPOS \& STUR- 

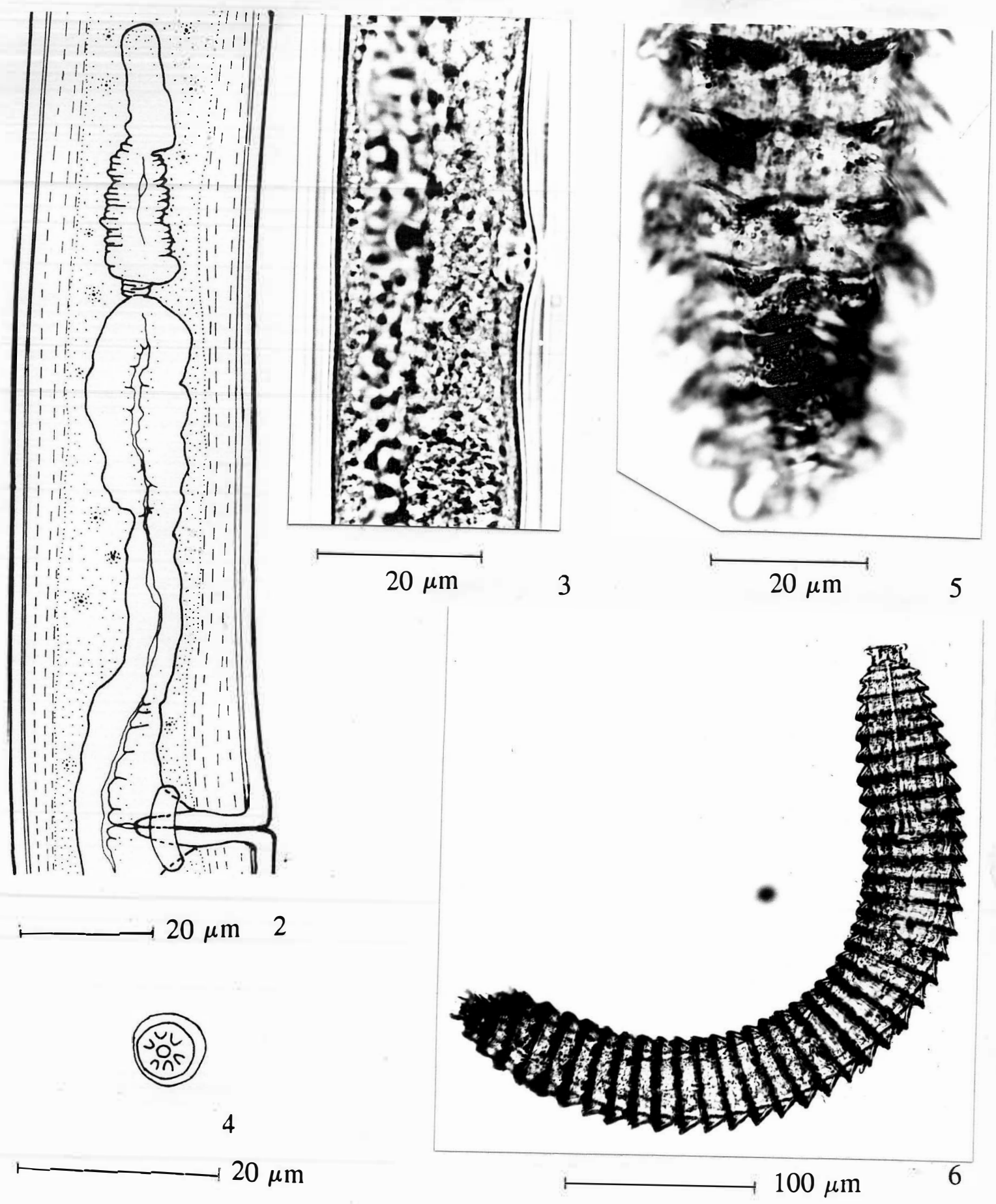

Figuras 2 - 6. 2: ramo genital anterior de Xiphinema krugi. 3: esclerotizações vulvares de Paratrichodorus anthurii. 4: região labial de Rotylenchus caudaphasmidius (seção óptica por um dos anéis labiais). 5: apêndices dos anéis de Criconema braziliense. 6: corpo de Ogma cataracticum. 
HAN, 1987; FERRAZ, 1980; VOVLAS et alii, 1987).

Os exemplares aqui estudados foram coletados na rizosfera de espécies vegetais não identificados, em remanescente de floresta (amostra 11: $0-10 \mathrm{~cm}$ de profundidade).

\section{Hemicriconemoides mangiferae Siddiqi, 1961}

Sinônimos: H. litchi Edward \& Misra, 1964; H. birchfieldi Edward, Misra \& Singh, 1964 e H. aberrans Phukan \& Sanwal, 1983.

Medidas: Fêmeas $(\mathrm{n}=10): \mathrm{L}=575 \pm 46 \mu \mathrm{m}(511-644)$; Oes $=123 \pm 4,7 \mu \mathrm{m}$ (117 - 131); $\mathrm{St}=78 \pm 1,2 \mu \mathrm{m}(76-80) ; \mathrm{t}=32 \pm 2,7 \mu \mathrm{m}(27-36) ; \mathrm{R}$ (lado ventral) $=147 \pm 5,9(135-153) ; R_{\mathrm{St}}=24 \pm 1,0(22-25) ; R_{\text {Oes }}=34 \pm 1,2(32-35) ; R_{e x}$ $=38 \pm 1,6(36-41) ; R_{v}=15 \pm 1,1(13-16) ; R_{\text {an }}=2,6 \pm 0,5(2-3) ; R_{\text {an }}=11$ $\pm 0,7(10-12) ; M=87,4 \pm 0,4(86,6-88,0) ; V=92,5 \pm 0,3(91,9-92,7) ; S t \%$ $\mathrm{L}=13,6 \pm 1,0(12,4-15,0) ; \mathrm{VA} \% \mathrm{t}=36,9 \pm 6,0(26,2-45,5) ; \mathrm{a}=18,6 \pm 1,6$ $(16,4-21,5) ; b=4,7 \pm 0,2(4,4-5,0) ; c=18,2 \pm 1,0(16,6-19,8) ; c^{\prime}=1,5 \pm$ $0,1(1,2-1,6) ; \mathrm{VL} / \mathrm{VB}=1,8 \pm 0,1(1,4-1,9)$.

Machos: não encontrados.

Observações: Hemicriconemoides mangiferae caracteriza-se pela região labial achatada formada por 2 anéis (tendo o primeiro formato angular e o segundo arredondado), anéis da bainha e do corpo arredondados, comprimento do corpo igual a $410-670 \mu \mathrm{m} \mathrm{(410} \mathrm{-}$ 600 na descrição da espécie), comprimento do estilete igual a $51-86 \mu \mathrm{m}$ (70 - 81 na descrição da espécie), número de anéis da bainha e do corpo igual a 111 - 152 (133 148 na descrição da espécie) e número de anéis entre o início do corpo e o poro excretor igual a 34 - 38. As medidas dos exemplares aqui examinados coincidem com as da descrição da espécie (SIDDIQI, 1961) e as de outras populações (PINOCHET \& 
RASKI, 1975; SIDDIQI, 1977), exceto pelo maior número de anéis entre o início do corpo e o poro excretor $\left(R_{e x}=38-41\right.$ vs. $\left.34-38\right)$. Além disso, o primeiro anel labial não apresentou um formato tão anguloso como mostra o desenho da descrição da espécie.

Ocorrências: o hospedeiro tipo de $H$. mangiferae é Mangifera indica e a localidade tipo é Aligarh, na Índia.

No presente trabalho, foi obtido da rizosfera de $M$. indica (amostra 13: $0-20 \mathrm{~cm}$ de profundidade). No Brasil, seu primeiro registro ocorreu no estado da Bahia, associado a Theobroma cacao, em Belmonte e em uma localidade não especificada (PINOCHET \& RASKI, 1975). Mais tarde, foi assinalado também no estado de Minas Gerais, na rizosfera de $M$. indica, em Viçosa, e de pastagens, em Sete Lagoas (FERRAZ, S., 1980).

\section{Criconemella palustris (Luc, 1970) Luc \& Raski, 1981}

Sinônimos: Criconemoides onoensis f. Kindia Luc, 1959; C. palustris Luc, 1970; Macroposthonia palustris (Luc, 1970) Loof \& De Grisse, 1973.

Medidas: Fêmeas $(\mathrm{n}=3): \mathrm{L}=507 \pm 39 \mu \mathrm{m}(463-537)$; Oes $=109 \pm 7,5 \mu \mathrm{m}(101$

- 114); $\mathrm{EP}=116 \pm 4,3 \mu \mathrm{m}(108-118) ; \mathrm{St}=47 \pm 0,6 \mu \mathrm{m}(47-48) ; \mathrm{t}=33 \mu \mathrm{m}(\mathrm{n}$ $=1) ; \mathrm{R}$ (lado ventral) $=124 \pm 3,5(120-127) ; \mathrm{R}_{\mathrm{St}}=17 \pm 0,6(16-17) ; \mathrm{R}_{\text {Oes }}=31$ $\pm 1,2(30-32) ; R_{e x}=33 \pm 0 ; R_{v}=10 \pm 0,6(10-11) ; R_{\text {Van }}=0(n=1) ; R_{a n}=$ $9(\mathrm{n}=1) ; \mathrm{M}=71,5 \pm 2,2(69,6-74,0) ; \mathrm{V}=93,0 \pm 0,6(92,5-93,7) ; \mathrm{St} \% \mathrm{~L}=$ $9,3 \pm 0,7(8,9-10,1) ; \mathrm{St} \%$ Oes $=43,0 \pm 2,8(41,0-46,2) ; \mathrm{a}=11,8 \pm 0,9(11,0-$ $12,7) ; \mathrm{b}=4,63 \pm 0,08(4,59-4,72) ; \mathrm{c}=16,4(\mathrm{n}=1) ; \mathrm{VL} / \mathrm{VB}=1,04 \pm 0,12$ $(0,91-1,11) ; \mathrm{VL} / \mathrm{St}=0,76 \pm 0,12(0,62-0,84)$. 
Machos: não encontrados.

Observações: essa espécie de Criconemella distingue-se pela combinação das seguintes características: a) lóbulos labiais submedianos muito pequenos, aproximadamente da mesma largura do disco e das placas labiais; b) número de anéis relativamente grande $(\mathrm{R}=117$ - 132); c) anéis com margens posteriores lisas e formando poucas anastomoses $(0$ - 4); c) vagina reta; d) cauda de formato trapezoidal; e) último anel da cauda pequeno e embutido telescopicamente no penúltimo anel, dando ao término do corpo uma forma aproximadamente côncava ("cup - like") (EBSARY, 1982; LUC, 1970). Todas essas características foram observadas nos exemplares ora estudados. Além disso, as medidas, exceto o comprimento do corpo ( $\mathrm{L}=463-537$ vs. $400-490 \mu \mathrm{m})$, coincidem com a descrição da espécie (LUC, 1970).

Ocorrências: Criconemella palustris foi originalmente descrita a partir de material obtido da rizosfera de Oryza sativa, em uma cultura irrigada, na rota KatiolaMarabadiassa, km 3, na Costa do Marfim.

No presente trabalho, $C$. palustris foi coletado da rizosfera de Indigofera hirsuta L. (anileira) e de plantas não identificadas, na várzea do ribeirão Piracicamirim (amostra 18:0 - $60 \mathrm{~cm}$ de profundidade). Há pelo menos 2 registros anteriores de ocorrência de $C$. palustris no Brasil: em hospedeiro não identificado, por MONTEIRO \& FERRAZ (1988), e na rizosfera de Prunus persica (pessegueiro), por SPERANDIO (1992).

\section{Criconemella xenoplax (Raski, 1952) Luc \& Raski, 1981}

Sinônimos: Criconemoides xenoplax Raski, 1952; Macroposthonia xenoplax (Raski, 1952) De Grisse \& Loof, 1965; Criconemoides nainitalense Edward \& Misra, 1963; M. 
nainitalensis (Edwards \& Misra, 1963) De Grisse \& Loof, 1965; Criconema pruni Siddiqi, 1961; M. pruni (Siddiqi, 1961) De Grisse \& Loof, 1965; Mesocriconema pruni (Siddiqi, 1961) Andrássy, 1965; Criconemoides pruni (Siddiqi, 1961) Raski \& Golden, 1966.

Medidas: Fêmea $(\mathrm{n}=1): \mathrm{L}=402 \mu \mathrm{m}$; Oes $=108 \mu \mathrm{m} ; \mathrm{St}=76 \mu \mathrm{m} ; \mathrm{t}=$ ?; $\mathrm{R}$ (lado ventral) $=84 ; \mathrm{R}_{\mathrm{St}}=18 ; \mathrm{R}_{\mathrm{Oes}}=25 ; \mathrm{R}_{\mathrm{ex}}=$ ?; $\mathrm{R}_{\mathrm{V}}=9 ; \mathrm{R}_{\mathrm{Van}}=$ ?; $\mathrm{Ran}=$ ?; $\mathrm{M}=79,0 ;$ $\mathrm{V}=90,6 ; \mathrm{St} \% \mathrm{~L}=18,8 ; \mathrm{St} \%$ Oes $=69,9 ; \mathrm{a}=10,8 ; \mathrm{b}=3,8 ; \mathrm{c}=? ; \mathrm{VL} / \mathrm{VB}=$ 1,$2 ; \mathrm{VL} / \mathrm{St}=0,51$.

Machos: não encontrados.

Observações: Criconemella xenoplax diferencia-se das outras espécies do gênero pela associação das seguintes características: presença de lobos submedianos bem desenvolvidos e, entre eles, placas labiais distintas; estilete reto e com comprimento igual a 55 $101 \mu \mathrm{m}$; vulva aberta e vagina sigmóide; cauda arredondada; anéis com poucas anastomoses e com a margem posterior lisa ou ligeiramente irregular; número de anéis do corpo igual a 74 - 118; número de anéis entre a vulva e o final do corpo igual a 6 - 11 (EBSARY, 1982; ORTON WILLIAMS, 1972; RASKI, 1952).

Ocorrências: o hospedeiro tipo de C. xenoplax é Vitis longii W.R. \& W. Prince vs. cv. 1613 e a localidade tipo é Fresno, Califórnia, E.U.A.

Essa espécie é muito disseminada, principalmente em associação com cravo e plantas arbustivas. No Brasil, já foi assinalada várias vezes: associada a Prunus salicina Lindl. (ameixeira) em Barbacena (MG), a Musa sp. (bananeira) em Viçosa (MG), a Coffea arabica L. (cafeeiro) em São Sebastião do Paraíso (SP), a Citrus sp. em Pelotas (RS), a Carya illinoensis Koch (nogueira-pecã) em Florestal (MG) e a $P$. persica em Machado (MG), Pelotas, Santo Antônio do Pinhal (SP) e Viçosa (CAMPOS 
et alii, 1987; FERRAZ, S., 1980; MONTEIRO et alii, 1990; SPERANDIO, 1992).

O único exemplar observado neste trabalho foi extraído da rizosfera de espécies vegetais não identificadas, em remanescente de floresta (amostra 9: 0 - 5 $\mathrm{cm}$ de profundidade).

\section{Criconemella sp.a (espécie ainda inomimada em SPERANDIO, 1992)}

Medidas: Fêmeas $(\mathrm{n}=4): \mathrm{L}=336 \pm 67 \mu \mathrm{m}(250$ - 413); Oes $=90 \pm 17,3 \mu \mathrm{m}(78$ 110); $\mathrm{EP}=87 \pm 17,8 \mu \mathrm{m}(70-111) ; \mathrm{Hem}=88,6 \mu \mathrm{m}(\mathrm{n}=2 ; 68,0$ e 109,2); $\mathrm{St}=$ $44 \pm 5,5 \mu \mathrm{m}(38-50) ; \mathrm{t}=9,3 \pm 0 \mu \mathrm{m}(\mathrm{n}=2) ; \mathrm{R}$ (lado ventral) $=131 \pm 12(114-$ $142) ; R_{\mathrm{St}}=20 \pm 1,4(18-21) ; \mathrm{R}_{\text {Oes }}=33 \pm 3,2(31-37) ; \mathrm{R}_{\mathrm{ex}}=33 \pm 0,5(32-33) ;$ $\mathrm{R}_{\mathrm{Hem}}=32 \pm 0 ; \mathrm{R}_{\mathrm{V}}=10 \pm 0,5(10-11) ; \mathrm{R}_{\mathrm{Van}}=2 \pm 0 ; \mathrm{R}_{\mathrm{an}}=8 \pm 0 ; \mathrm{M}=75,7 \pm$ $3,0(71,3-77,8) ; \mathrm{Ga}=44,7 \pm 3,3(40,9-46,9) ; \mathrm{V}=93,8 \pm 0,9(92,7-94,8) ; \mathrm{St} \%$ $\mathrm{L}=13,4 \pm 2,0(11,3-15,2) ; \mathrm{St} \%$ Oes $=47,6 \pm 5,6(42,6-53,9) ; \mathrm{a}=11,8 \pm 2,0$ $(9,6-13,4) ; b=3,76 \pm 0,69(3,08-4,46) ; c=32,2(n=2 ; 26,7$ e 37,6$) ; \mathrm{VL} / \mathrm{VB}$ $=0,88 \pm 0,08(0,78-0,97) ; \mathrm{VL} / \mathrm{St}=0,46 \pm 0,03(0,42-0,49)$.

Machos: não encontrados.

Observações: essa espécie caracteriza-se por: a) ausência de placas labiais entre os lóbulos submedianos; b) número relativamente grande de anéis do corpo $(R=138$ - 152); c) anéis com margens posteriores lisas e formando 1 a 10 anastomoses; d) vagina reta; e) cauda de formato trapezoidal, com o término voltado para o lado dorsal e os 2 últimos anéis embutidos telescopicamente no antepenúltimo. Há g rande coincidência entre o material aqui estudado e a descrição da espécie (SPERANDIO, 1992). O corpo mais curto $(\mathrm{L}=250-413$ vs. $360-460 \mu \mathrm{m})$, menos esbelto $(\mathrm{a}=9,6-13,4$ vs. $15,8-$ $20,2)$ e com menos anéis ( $R=114$ - 142 vs. 138 - 152) é, provavelmente, efeito do clima mais quente de Piracicaba em relação às localidades tipos (Camaquã e Pelotas, no RS), em concordância com a lei de variação de Bergmann (ORR, 1986). 
Ocorrências: Criconemella sp. $_{{ }_{\mathrm{a}}}$ foi encontrada em rizosfera de Indigofera hirsuta e outras plantas invasoras não identificadas, na várzea do ribeirão Piracicamirim (amostra 18: 0 - $60 \mathrm{~cm}$ de profundidade), e em área em pousio, em rizosfera de Parthenium hysterophorus (losna branca/amostra 22: $0-40 \mathrm{~cm}$ de profundidade). A espécie foi descrita a partir de material coletado no do Rio Grande do Sul, em rizosfera de gramíneas nativas e Triticum sp. (Pelotas) e de restolho de O. sativa (Camaquã) (SPERANDIO, 1992).

\section{Discocriconemella mineira Vovlas, Ferraz \& Dos Santos, 1989}

Medidas: Fêmeas $(\mathrm{n}=11): \mathrm{L}=324 \pm 22 \mu \mathrm{m}(292-357) ;$ Oes $=97 \pm 7,5 \mu \mathrm{m}(84-$ 109); $\mathrm{EP}=95 \pm 7,9 \mu \mathrm{m}(84-107) ; \mathrm{St}=68 \pm 5,7 \mu \mathrm{m}(59-75) ; \mathrm{t}=12,6 \pm 1,3 \mu \mathrm{m}$ $(10,3-14,0) ; \mathrm{R}$ (lado ventral) $=85 \pm 1,3(83-87) ; \mathrm{R}_{\mathrm{St}}=20 \pm 1,6(18-24) ; \mathrm{R}_{\text {Oes }}$ $=27 \pm 2,2(25-33) ; R_{e x}=27 \pm 0,7(26-28) ; R_{v}=7 \pm 1,2(6-9) ; R_{\text {Van }}=0,6$ $\pm 0,5(0-1) ; R_{\mathrm{an}}=5 \pm 0,7(4-6) ; \mathrm{M}=81,6 \pm 1,3(79,5-83,2) ; \mathrm{V}=93,5 \pm 1,1$ (91 - 95); St\% L = 21,1 $\pm 1,5(19-24) ; \mathrm{St} \%$ Oes = 70,5 $\pm 3,2(67-79) ; \mathrm{a}=8,6$ $\pm 0,5(7,5-9,1) ; b=3,4 \pm 0,2(2,9-3,6) ; c=26,0 \pm 3,6(21-31) ; \mathrm{VL} / \mathrm{VB}=$ $0,80 \pm 0,08(0,73-0,94) ; \mathrm{VL} / \mathrm{St}=0,30 \pm 0,05(0,26-0,40)$.

Machos: não encontrados.

Observações: o tipo de disco labial (redondo e com margem contínua) (Figura 7), a constrição evidente entre o disco labial e o anel seguinte, os anéis com margens posteriores lisas, as poucas anastomoses ( 0 a 3 ), a vulva aberta, a vagina praticamente reta, a espermateca contendo espermatozóides, o comprimento do corpo $(\mathrm{L}=292-357 \mu \mathrm{m})$, o comprimento do estilete $(\mathrm{St}=59-75 \mu \mathrm{m})$, o número de anéis do corpo $(\mathrm{R}=83$ 87) e o número de anéis entre a vulva e o final do corpo $\left(R_{\mathrm{V}}=6-9\right)$ são as características que definem D. mineira (VOVLAS, 1992; VOVLAS et alii, 1989). As medidas tomadas dos exemplares coletados no presente estudo estão de acordo com a descrição da espécie, com exceção da posição relativa do esôfago e poro excretor. Nos exem- 
plares aqui examinados, o final do esôfago está praticamente na mesma altura da abertura do poro excretor (Oes $=97 \pm 7,5 \mu \mathrm{m}, \mathrm{EP}=95 \pm 7,9 \mu \mathrm{m}, \mathrm{R}_{\text {oes }}=27 \pm 2,2$, $\left.R_{e x}=27 \pm 0,7\right)$, enquanto, no material tipo, o poro excretor é claramente anterior ao final do esôfago (Oes $=95 \pm 6,5 \mu \mathrm{m}, \mathrm{EP}=85 \pm 10,4 \mu \mathrm{m}, \mathrm{R}_{\text {Oes }}=27 \pm 1,9, \mathrm{R}_{\mathrm{ex}}=$ $25 \pm 1,1)$ (VOVLAS et alii, 1989).

Ocorrências: Discocriconemella mineira foi encontrada em amostras de solo (amostra 11: $0-10 \mathrm{~cm}$ de profundidade; amostra 16: $0-40 \mathrm{~cm}$ de profundidade), na rizosfera de espécies vegetais não identificadas, em remanescente de floresta.

A espécie foi originalmente descrita a partir de exemplares coletados no Brasil, em solo de cerrado do "campus" da Universidade Federal de Viçosa (VOVLAS et alii, 1989).

\section{Discocriconemella repleta Pinochet \& Raski, 1976}

Sinônimo: D. limitanea apud Sauer \& Winoto, 1975

Medidas: Fêmeas: $(\mathrm{n}=6): \mathrm{L}=255 \pm 7 \mu \mathrm{m}(246-262)$; Oes $=84 \pm 4,5 \mu \mathrm{m}(79$ 90); $\mathrm{EP}=97 \pm 3,4 \mu \mathrm{m}(93-103) ; \mathrm{St}=54 \pm 0,6 \mu \mathrm{m}(53-55) ; \mathrm{t}=10,0 \pm 2,2 \mu \mathrm{m}$ $(7,5-13,1) ; \mathrm{R}$ (lado ventral) $=102 \pm 4,6(96-107) ; \mathrm{R}_{\mathrm{St}}=21 \pm 1,3(19-22) ; \mathrm{R}_{\text {Oes }}$ $=31 \pm 2,1(29-34) ; \mathrm{R}_{\mathrm{ex}}=37 \pm 1,1(35-38) ; \mathrm{R}_{\mathrm{v}}=10 \pm 0,4(10-11) ; \mathrm{R}_{\mathrm{van}}=$ $2 \pm 1,4(1-4) ; R_{a n}=7 \pm 1,6(5-9) ; V=94,0 \pm 0,6(93-95) ; S t \% L=21,2 \pm$ 0,4 (21 - 22); St\% Oes = 64,8 $\pm 3,2(60-69) ; a=7,3 \pm 0,6(6,4-7,9) ; b=3,0$ $\pm 0,2(2,7-3,3) ; c=26,1 \pm 5,4(19,2-33,4) ; \mathrm{VL} / \mathrm{VB}=0,68 \pm 0,06(0,59-0,78)$; $\mathrm{VL} / \mathrm{St}=0,28 \pm 0,02(0,25-0,31)$.

Machos: não encontrados.

Observações: Discocriconemella repleta é uma espécie muito semelhante a $D$. limitanea 
(Luc, 1959) De Grisse \& Loof, 1965, compartilhando com esta as seguintes características: a) disco labial com 2 profundas incisuras, uma ventral e outra dorsal (Figura 8); b) anéis anteriores do corpo, normalmente do $4^{\circ}$ ao $23^{\circ}$, antrorsos; c) margem posterior dos anéis finamente crenada; d) várias anastomoses de anéis (normalmente 14 a 20 de cada lado do corpo) (LUC, 1959; PINOCHET \& RASKI, 1976).

PINOCHET \& RASKI (1976) diferenciaram as 2 espécies com base no tamanho do estilete da fêmea [62 $\mu \mathrm{m}(59-66)$ em $D$. repleta e $38-53 \mu \mathrm{m}$ em D. limitanea] e em características da cauda do macho (curta e com bursa rudimentar em D. repleta e mais longa e sem bursa em D. limitanea) (LUC, 1959; LUC, 1970). CHAWLA \& SAMATHANAM (1980) colocaram D. repleta como sinônimo de D. limitanea, baseados na existência de pelo menos um parátipo com comprimento do estilete igual a $52 \mu \mathrm{m}$ e no pouco valor taxonômico, para a família Criconematidae, da presença ou ausência de uma pequena bursa nos machos. Mais tarde, RASKI \& LUC (1987) revalidaram a espécie $D$. repleta, pela presença de uma característica única dentro do gênero: um estreitamento abrupto do corpo logo após a vulva. Seguindo essa linha de raciocínio, identificou-se o presente nematóide como $D$. repleta, embora tenha-se observado que esse estreitamento nem sempre é tão abrupto como nos desenhos da descrição da espécie (Figura 9). Acredita-se que a resolução dessa controvérsia só será possível após um reexame do material tipo de $D$. limitanea.

Ocorrências: essa espécie provavelmente é nativa do Brasil, tendo sido descrita a partir de exemplares coletados na rizosfera de Theobroma cacao, em Porto Seguro (BA), ocorrendo também no do Espírito Santo (PINOCHET \& RASKI, 1976). RASHID e colaboradores $\left(1986_{\mathfrak{b}}\right.$ ) estudaram exemplares de Discocriconemella coletados na rizosfera de T. cacao de vários municípios do da Bahia e de Coffea arabica L. de Belmonte, também na Bahia. Os exemplares poderiam tanto ser $D$. repleta como D. limitanea (ou uma mistura das 2 espécies), pois havia indivíduos com estreitamento pós-vulvar bem 
evidente e havia aqueles com estreitamento quase imperceptível (RASHID et alii, 1986 ). CAMPOS (1988) verificou a ocorrência de $D$. repleta em um município do estado do Espírito Santo (Apiacá) e 3 municípios do estado de Minas Gerais (Ijaci, Machado e Sarapieira), geralmente em associação a essências florestais [Cedrella fissilis Vell. (cedro), Eucalyptus sp., Ocotea sp. (canela), Piptadenia communis Benth. (jacaré) e Piptadenia sp. (angico)]. Relatos de ocorrência de D. limitanea no Brasil anteriores à descrição de $D$. repleta (SHARMA, 1976; SHARMA \& LOOF, 1973 e 1974) devem ser vistos com reservas, pois as coletas foram feitas próximo à localidade tipo de $D$. repleta (a região cacaueira dos estados da Bahia e Espírito Santo).

Os exemplares de $D$. repleta utilizados neste estudo morfológico foram coletados em solo da rizosfera de espécies vegetais não identificadas, em um remanescente de floresta (amostra 9: $0-5 \mathrm{~cm}$ de profundidade).

\section{Hemicycliophora lutosa Loof \& Heyns, 1969}

Medidas: Fêmeas $(\mathrm{n}=7): \mathrm{L}=896 \pm 46 \mu \mathrm{m}(826$ - 942); Oes $=143 \pm 7 \mu \mathrm{m}(135$ 151); $\mathrm{St}=78 \pm 3,8 \mu \mathrm{m}(75-84) ; \mathrm{t}=151 \pm 11,5 \mu \mathrm{m}(132-171) ; \mathrm{R}$ (lado ventral) $=287 \pm 11,4(269-302) ; R_{\mathrm{st}}=26 \pm 1,2(24-27) ; \mathrm{R}_{\text {Oes }}=48 \pm 2,4(44-51) ; \mathrm{R}_{\mathrm{ex}}$ $=51 \pm 1,3(50-53) ; \mathrm{R}_{\mathrm{Hem}}=49 \pm 2,6(45-53) ; \mathrm{R}_{\mathrm{V}}=65 \pm 2,6(61-67) ; \mathrm{R}_{\mathrm{Van}}=$ $17 \pm 3,1(14-23) ; R_{a n}=48 \pm 2,3(44-51) ; M=82,3 \pm 1,4(79,8-84,5) ; \mathrm{Ga}=$ $43,1 \pm 5,6(36,1-51,9) ; \mathrm{V}=78,5 \pm 0,6(77,4-79,2) ; \mathrm{St} \% \mathrm{~L}=8,7 \pm 0,3(8,2-$ $9,1) ; \mathrm{VA} \% \mathrm{t}=27,6 \pm 5,0(20,3-35,3) ; \mathrm{a}=25,6 \pm 1,5(23,6-27,5) ; \mathrm{b}=6,3 \pm$ $0,1(6,1-6,4) ; c=5,9 \pm 0,4(5,3-6,3) ; \mathrm{VL} / \mathrm{VB}=5,9 \pm 0,7(5,1-7,0)$.

Machos: não encontrados.

Observações: as principais características morfológicas dessa espécie (região labial truncada, com 2 anéis e não destacada do resto do corpo; campo lateral marcado por que- 
bras das linhas dos anéis, sem nenhum tipo de ornamentação; lábios da vulva discretamente alongados; cauda longa, uniformemente cônica e com anéis distais muito pequenos) foram claramente observados nos exemplares examinados. As medidas estão de acordo com a descrição da espécie (LOOF \& HEYNS, 1969), exceto pelo menor comprimento do corpo (896 vs. $1.070 \mu \mathrm{m})$ e vulva mais anterior ( $\mathrm{V}=77,4-79,2$ vs. 80 84). Há pequenas discordâncias também em relação aos exemplares examinados por BRZESKI (1974) e FERRAZ, L.C. (1980).

Ocorrência: Hemicycliophora lutosa foi coletada em rizosfera de Indigofera hirsuta e de outras plantas invasoras, não identificadas, na várzea do ribeirão Piracicamirim (amostra 18: 0 - $60 \mathrm{~cm}$ de profundidade).

No Brasil, essa espécie já foi assinalada várias vezes: em rizosfera de Phaseolus vulgaris L. (feijoeiro) em 4 municípios do estado de Minas Gerais (Astolfo Dutra, Coimbra, Paula Cândido e Raul Soares); em solo de cerrado desmatado no "campus" da UNESP em Ilha Solteira, SP, e na rizosfera de Eucalyptus citriodora em Cajamar e Jundiaí, SP (FERRAZ, L.C., 1980; FERRAZ et alii, 1984; FREIRE \& FERRAZ, 1977; MONTEIRO et alii, 1978).

\subsection{Descrições de novas espécies}

Foram identificadas 2 novas espécies no levantamento: Trophurus $\mathrm{n}$. sp. e Criconema n. sp.

\subsubsection{Descrição de Trophurus n. sp.}

(Figuras 10 a 12)

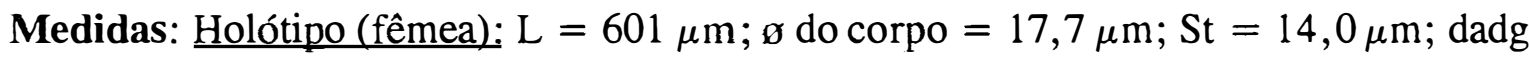


$=1,4 \mu \mathrm{m}$; Oes $=111,4 \mu \mathrm{m} ;$ comp. istmo $=25,2 \mu \mathrm{m} ;$ comp. bulbo basal $=18,7 \mu \mathrm{m}$; $\mathrm{EP}=78,8 \mu \mathrm{m}$; comp. cárdia $=2,8 \mu \mathrm{m}$; larg. campo lateral $=5,6 \mu \mathrm{m}$; comp. saco pós-uterino $=18,7 \mu \mathrm{m} ; \mathrm{h}=5,6 \mu \mathrm{m} ; \mathrm{t}=26,6 \mu \mathrm{m} ; \mathrm{V}=60,6 ; \mathrm{M}=40,0 ; \mathrm{St} \% \mathrm{~L}=$ 2,33; St\% Oes =12,6; EP\% L = 13,1; $a=34,0 ; b=5,40 ; c=22,6 ; c^{\prime}=2,20$. Material tipo: Fêmeas: Tabela 2; Machos: Tabela 3.

Descrição: Fêmeas; forma do corpo aproximadamente reta, freqüentemente dobrada em ângulo aberto para o lado ventral ou dorsal, quando mortas pelo calor. Cutícula delicadamente estriada; largura dos anéis variável entre 0,75 e 1,0 $\mu \mathrm{m}$. Campo lateral não areolado, com 4 incisuras e ocupando $1 / 4$ a $1 / 3$ do diâmetro do corpo. A banda formada pelas incisuras centrais é claramente mais estreita que as bandas marginais, equivalendo a 60 - $70 \%$ da largura de cada uma destas. O término do campo lateral não foi visualizado em nenhum exemplar, pois o corpo sempre apresentava torsões axiais, principalmente na região caudal. Fasmídio punctiforme, localizado exatamente no meio da banda central do campo lateral e aproximadamente no meio da cauda $(10,7$ a $14,0 \mu \mathrm{m}$ posterior ao ânus). Cauda cilindróide com término hemisférico a clavado; cutícula do término caudal lisa e com espessura variável entre 4,5 e 7,5 $\mu \mathrm{m}$ (Figura 10). Região labial lisa, elevada, de forma cônico-arredondada e contínua com o resto do corpo. Armadura cefálica não visualizada, provavelmente extremamente delicada. Cone do estilete muito delicado, de difícil visualização, e mais curto que a haste ( $\mathrm{M}=33,3$ a 41,9); bulbos pequenos, arredondados e inclinados para trás, com cerca de $2,5 \mu \mathrm{m}$ de largura. Abertura da glândula esofagiana dorsal muito próxima da base do bulbo do estilete (dagd = 0,9 a $1,9 \mu \mathrm{m}$ ). Bulbo mediano oval, istmo estreito e bulbo basal piriforme; istmo bem mais longo que o bulbo basal. Bulbo basal não cobre o início do intestino. Conduto excretor bem esclerotizado; poro excretor na primeira metade do istmo. Hemizonídio ocupa o espaço de 3 ou 4 anéis e está situado em posição 1,5 a 10 anéis posterior ao poro excretor. Anel nervoso situado no final do primeiro terço do comprimento do istmo. Vulva em forma de fenda transversal; vagina forma ângulo reto com o eixo do corpo. 


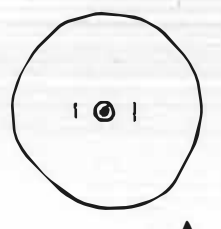

A

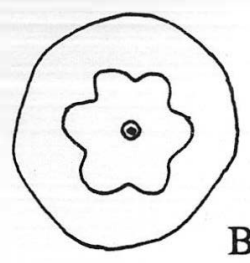

B

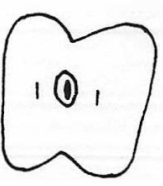

A

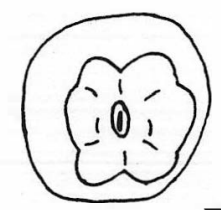

B

8

$20 \mu \mathrm{m} \quad 7$ e 8

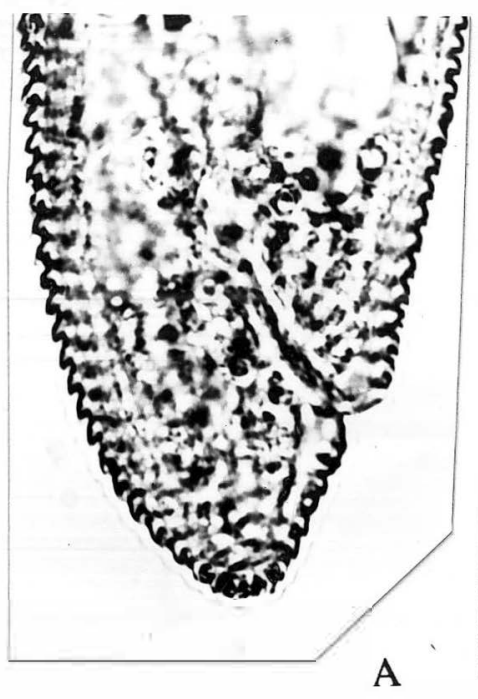

A

B

$20 \mu \mathrm{m}$
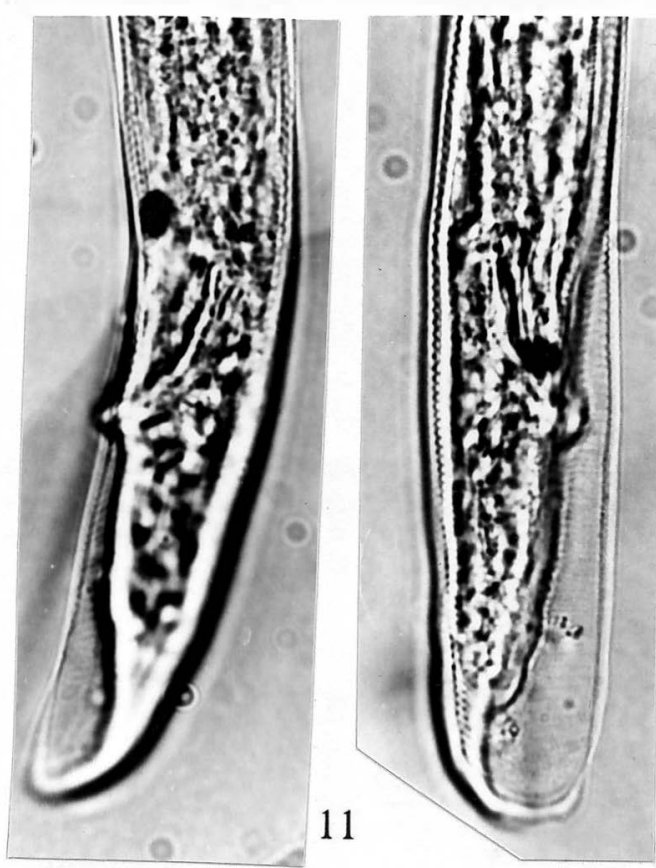

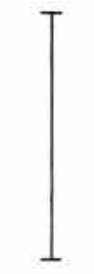

$20 \mu \mathrm{m}$

10 e 11

Figuras 7 - 11. 7: disco labial de Discocriconemella mineira (A: en face, B: seção óptica transversal). 8: disco labial de $D$. repleta (A: en face, B: seção óptica transversal). 9: região pós-vulvar de $D$. repleta (A: constrição muito evidente, B: constrição pouco evidente). 10: cauda de fêmea de Trophurus n. sp. (holótipo) 11: idem, de machos (parátipos). 

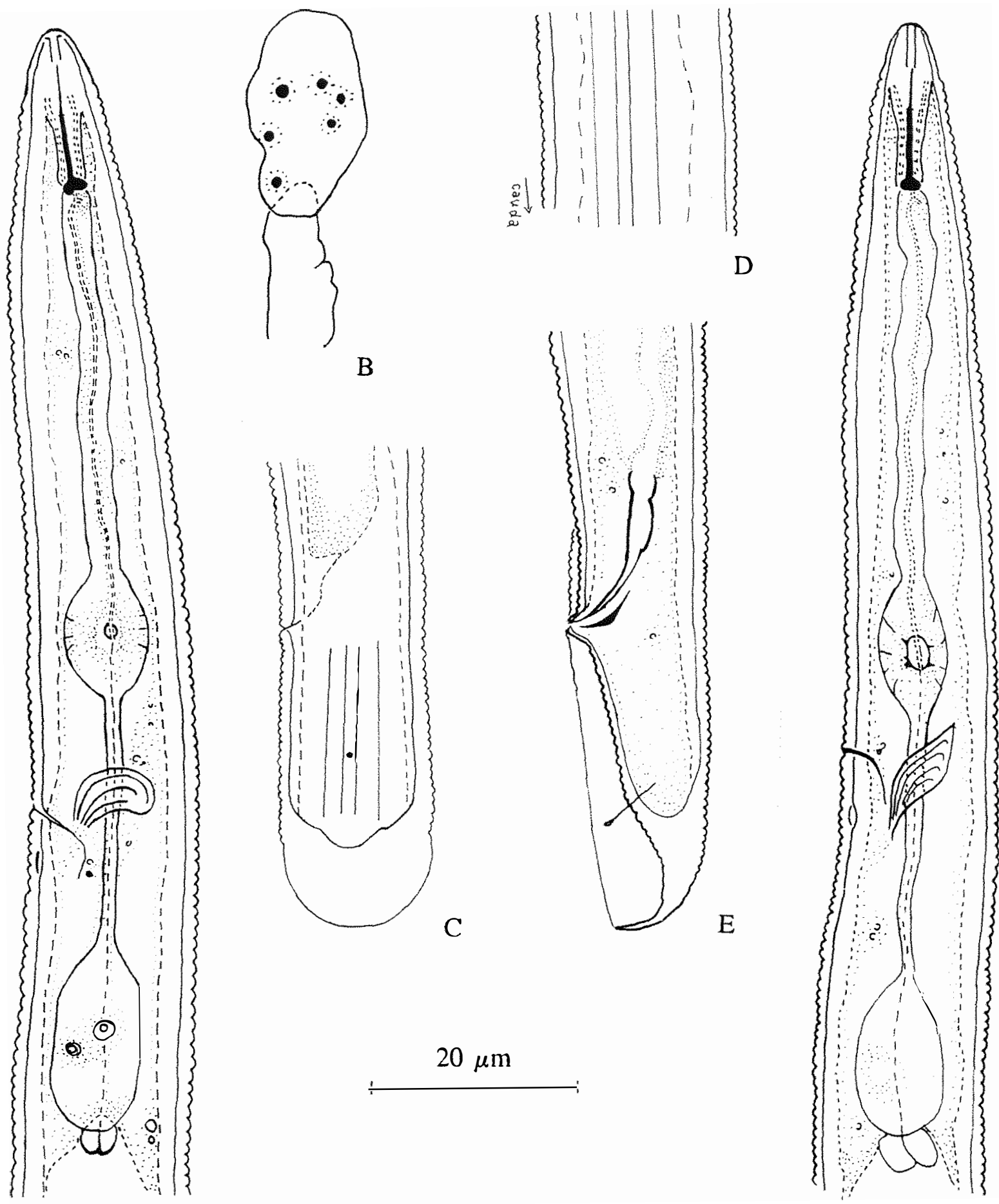

A

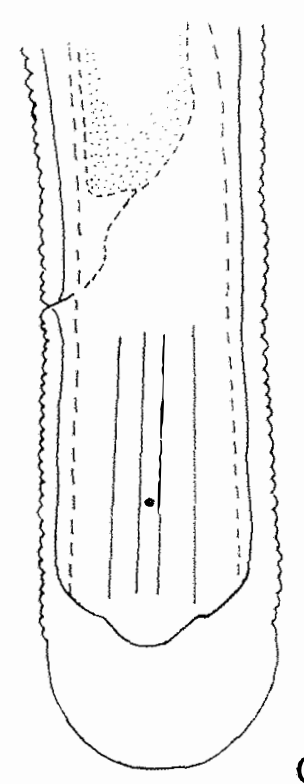

C
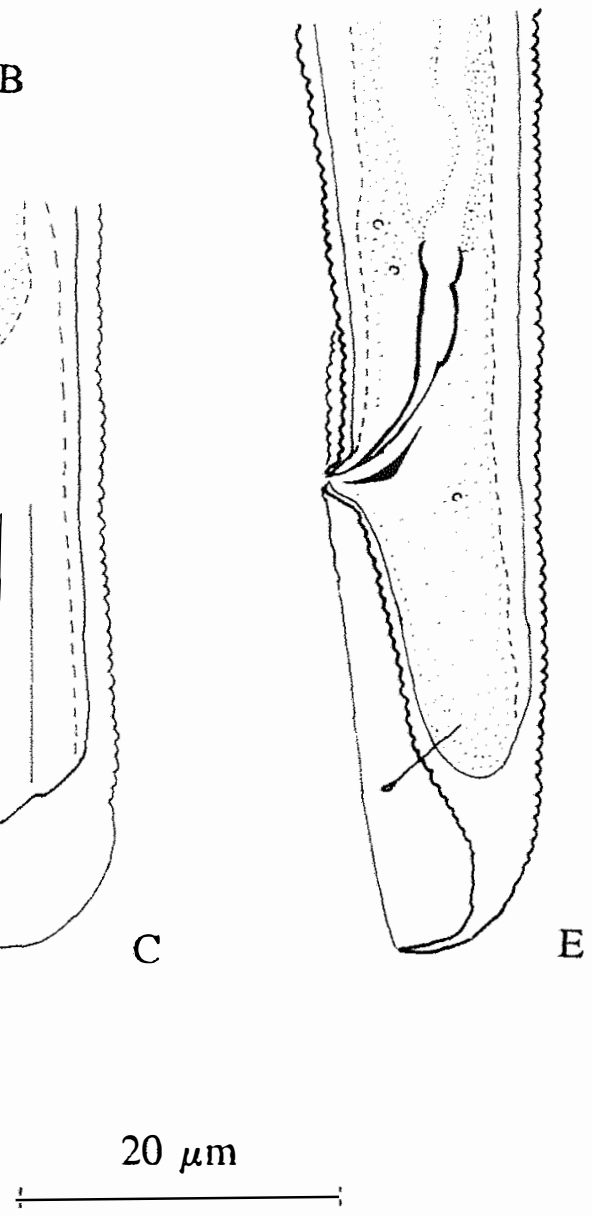

F

Figura 12. Trophurus n. sp. Fêmea (holótipo): A: região anterior, B: espermateca. Eêmea (parátipos): C: cauda, D: campo lateral. Macho (parátipos): E: cauda, F: região anterior. 
Tabela 2. Medidas de fêmeas do material tipo Trophorus n. sp.

\begin{tabular}{|c|c|c|c|c|}
\hline Características morfológicas & $\mathrm{n}$ & Variação & Média & $\begin{array}{l}\text { Desvio } \\
\text {-padrão }\end{array}$ \\
\hline \multicolumn{5}{|l|}{ Medidas em $\mu \mathrm{m}$} \\
\hline $\mathrm{L}$ & 22 & $586-744$ & 670 & 41 \\
\hline ø do corpo & 22 & $16,8-21,5$ & 19,3 & 1,2 \\
\hline St & 12 & $12,6-15,4$ & 14,0 & 0,7 \\
\hline dadg & 19 & $0,9-1,9$ & 1,4 & 0,3 \\
\hline Oes & 20 & $110,6-126,0$ & 116,9 & 4,4 \\
\hline comp. istmo & 20 & $25,2-32,0$ & 27,1 & 1,7 \\
\hline comp. bulbo basal & 20 & $16,3-22,4$ & 18,4 & 1,6 \\
\hline EP & 20 & $73,7-87,7$ & 81,8 & 3,0 \\
\hline comp. cárdia & 15 & $2,8-7,9$ & 5,5 & 1,2 \\
\hline larg. campo lateral & 17 & $4,5-6,1$ & 5,3 & 0,5 \\
\hline comp. saco pós-uterino & 13 & $9,8-19,0$ & 15,1 & 3,4 \\
\hline $\mathrm{h}$ & 19 & $4,5-7,5$ & 6,2 & 0,6 \\
\hline $\mathrm{t}$ & 17 & $23,8-31,7$ & 26,8 & 2,1 \\
\hline \multicolumn{5}{|l|}{ Porcentagens } \\
\hline $\mathrm{V}$ & 22 & $57,8-61,5$ & 59,5 & 1,0 \\
\hline M & 12 & $33,3-41,9$ & 37,6 & 3,4 \\
\hline St\% L & 12 & $1,91-2,34$ & 2,08 & 0,13 \\
\hline St\% Oes & 12 & $11,4-13,5$ & 12,0 & 0,6 \\
\hline EP\% L & 20 & $10,6-13,8$ & 12,3 & 0,8 \\
\hline \multicolumn{5}{|l|}{$\underline{\text { Relações }}$} \\
\hline $\mathrm{a}$ & 22 & $32,1-37,7$ & 34,7 & 1,7 \\
\hline $\mathrm{b}$ & 20 & $5,09-6,30$ & 5,74 & 0,31 \\
\hline $\mathrm{c}$ & 17 & $22,6-28,6$ & 25,1 & 1,8 \\
\hline$c^{\prime}$ & 17 & $1,65-2,19$ & 1,95 & 0,16 \\
\hline
\end{tabular}


Tabela 3. Medidas de machos do material tipo de Trophurus n. sp.

Características morfológicas

n Variação

Média Desvio

-padrão

\section{Medidas em $\mu \mathrm{m}$}

L

ø do corpo

St

dadg

Oes

comp. istmo

comp. bulbo basal

EP

comp. cárdia

larg. campo lateral

esp.

gub.

$\mathrm{t}$

\section{Porcentagens}

$\mathrm{M}$

St\% L

St\% Oes

EP\% L

Relaçōes
a
b
c
c'

\begin{tabular}{lcrl}
5 & $580-667$ & \multicolumn{1}{c}{637} & \multicolumn{1}{l}{38} \\
5 & $15,9-17,7$ & 16,7 & 0,8 \\
2 & $12,2-13,5$ & 12,8 & 0,9 \\
3 & $0,9-1,4$ & 1,0 & 0,2 \\
5 & $115,2-123,2$ & 120,1 & 3,4 \\
5 & $25,2-31,7$ & 29,3 & 2,7 \\
5 & $16,8-18,7$ & 17,7 & 1,0 \\
5 & $75,6-82,1$ & 78,3 & 2,6 \\
5 & $3,7-6,5$ & 4,9 & 1,1 \\
4 & $4,2-5,6$ & 4,9 & 0,6 \\
5 & $15,4-18,7$ & 17,5 & 1,3 \\
4 & $4,7-6,5$ & 5,5 & 0,9 \\
5 & $28,0-32,7$ & 31,0 & 1,8
\end{tabular}

$\begin{array}{cccl}2 & 34,2-41,4 & 37,8 & 5,1 \\ 2 & 2,02-2,10 & 2,06 & 0,06 \\ 2 & 10,6-11,4 & 11,0 & 0,6 \\ 5 & 11,6-13,0 & 12,3 & 0,6\end{array}$

$5 \quad 33,5-41,8$

$38,2 \quad 3,0$

$5 \quad 5,03-5,63$

$5,30 \quad 0,24$

$5 \quad 19,4-21,4$

$20,6 \quad 0,76$

$5 \quad 1,93-2,26$

2,15

0,14 
Ramo genital anterior curto (156 $\mu \mathrm{m})$, distendido, composto de ovário, oviduto, espermateca e útero. Espermateca quase sempre cheia de espermatozóides; sua forma é variável, às vezes é compacta e elíptica, mas normalmente forma uma alça curta. Ramo genital posterior típico do gênero: vestigial, formando saco pós-uterino curto $(9,8$ a $19,0 \mu \mathrm{m})$.

Machos: corpo aproximadamente reto, às vezes curvado ventralmente, quando mortos pelo calor. Estrutura da região labial e do esôfago semelhante à da fêmea. Cutícula delicadamente estriada, como das fêmeas; campo lateral como das fêmeas. Hemizonídio ocupa o espaço de 3 ou 4 anéis e está situado em posição 3 a 11 anéis posterior ao poro excretor. Ramo genital curto $(175 \mu \mathrm{m})$ e distendido. Espículos curvados ventralmente, tipicamente tilencóides. Gubernáculo em forma de canoa. Fasmídios situados um pouco depois do meio da cauda, 16,8 a 19,8 $\mu \mathrm{m}$ posterior ao ânus. Cauda cônica, aguda, freqüentemente curvada para o lado ventral na sua parte terminal. Início da bursa anelado, o restante com margens lisas. A bursa é relativamente pequena (Figura 11) e suas margens não formam lobo antes de atingir o término da cauda.

Juvenis: semelhantes às fêmeas.

Diagnose: a principal característica desta espécie é a banda interna do campo lateral, mais estreita que as marginais. Nem todas as descrições das espécies de Trophurus têm figuras representando o campo lateral; por essa razão, outras características devem ser também observadas para identificar esta espécie: a) armadura cefálica não conspícua; b) istmo bem mais comprido que o bulbo basal; c) bulbo basal não recobrindo o início do intestino; d) cárdia não bifurcada; e) fêmeas com ovário distendido; f) cauda da fêmea cilindróide com término hemisférico a clavado; g) fêmea com cutícula do término caudal lisa e com espessura de 4,5 a 7,5 $\mu \mathrm{m}$; h) macho com testículo distendido; i) macho com bursa de margens lisas, exceto no seu início, e não formando lobo antes de atingir o término da cauda.

A estrutura do estilete também chama a atenção, pelo cone muito curto 
$(M=33,3$ a 41,9). Essa estrutura é muito semelhante à do estilete representado no desenho contido na descrição de $T$. longimarginatus Román, 1962. Infelizmente, poucas descrições desse gênero pormenorizam a estrutura do estilete. Além disso, houve dificuldades em visualizar o ápice do cone do estilete de Trophurus n. sp., resultando em dúvidas quanto ao seu comprimento total. Por isso, além das medições em fêmeas infiltradas em glicerina (Tabela 2), foram tomadas medidas de fêmeas em lâminas temporárias (meio de formalina a $2 \%)$. As medidas obtidas foram $(\mathrm{n}=6)$ : $\mathrm{St}=15,2 \pm 0,6$ $\mu \mathrm{m}(14,5-15,8) ; M=39,9 \pm 2,5(37,5-41,9)$. Mesmo assim, preferiu-se não incluir essa característica na diagnose da espécie.

Isso também justifica a omissão da forma da espermateca. Em Trophurus n. sp., a espermateca assemelha-se a uma alça curta, como se fosse um "U", embora às vezes seja mais compacta, ovóide. Esse formato lembra a espermateca de T. imperialis Loof, 1956, segundo a redescrição feita por SIDDIQI (1973); em suas palavras, a espermateca é mencionada como tendo formato "pouch-like". No entanto, na descrição dessa espécie, a espermateca é descrita como retangular com ângulos arredondados (LOOF, 1955). Há, aparentemente, uma contradição, principalmente porque Siddiqi utilizou o holótipo e os parátipos de T. imperialis na sua redescrição. Note-se, entretanto, que uma estrutura em forma de alça curta pode ser observada de diversas maneiras, uma vez que ela pode aparecer de maneira mais alongada ou mais comprimida, variando de exemplar para exemplar ou conforme o método de fixação. Apesar do formato peculiar da espermateca de Trophurus n. sp., aparentemente compartilhado apenas pelas de $T$. imperialis e T. sculptus Loof, 1956, essa característica não foi incluída na diagnose da espécie, porque poucas das descrições das espécies de Trophurus dão destaque à estrutura da espermateca. Entretanto, na chave apresentada a seguir, elaborada com o fim de facilitar a identificação das espécies de Trophurus, o formato da espermateca foi utilizado uma vez como característica diferenciadora, devido à ausência de outras características relevantes nas descrições de algumas espécies. 
Relações: o tamanho do estilete e a estrutura da cauda da fêmea (lisa no término; forma cilindróide com término clavado) são características que aproximam Trophurus n. sp. de T. sculptus. As diferenças entre as 2 espécies são: a) abertura da glândula esofagiana dorsal mais próxima da base do estilete em Trophurus $\mathrm{n}$. sp. (dagd $=0,9$ a 1,9 vs. 3,0 $\mu \mathrm{m})$; b) banda interna do campo lateral mais estreita que as marginais em Trophurus $\mathrm{n}$. sp. e tão ou mais larga que as marginais em $T$. sculptus; c) machos com bursa pequena, anelada no seu início e com margens não formando lobo antes de atingir o término da cauda em Trophurus n. sp., e machos com bursa grande, com margens totalmente lisas e formando um lobo antes de atingir o término da cauda em $T$. sculptus.

Ocorrências: o material tipo de Trophurus n. sp. foi coletado na rizosfera de espécies vegetais não identificadas, em um remanescente degradado de floresta (amostra 9:0 $5 \mathrm{~cm}$ de profundidade), no "campus" Luiz de Queiroz, Piracicaba, São Paulo, Brasil, pelo autor do presente trabalho.

Depósito do material tipo: holótipo [fêmea/lâmina $Z_{9}\left(n^{0} 13\right)$ ] e 26 parátipos estão depositados na coleção nematológica da ESALQ, em Piracicaba, SP.

\subsubsection{Chaves para identificação de espécies de Trophurus Loof, 1956}

Para facilitar a identificação da espécie de Trophurus descrita no presente trabalho, foram elaboradas 2 chaves, uma para fêmea e outra para machos, com base nas descrições das 12 espécies conhecidas de Trophurus (CAVENESS, 1958; EROSHENKO, 1981; GANGULY \& KHAN, 1983; KHAN \& NANJAPPA, 1971; LOOF, 1955; RAZJIVIN et alii, 1973; ROMÁN, 1962; SAHA et alii, 1973; SIDDIQI \& LENNÉ, 1990; SURYAWANSHI, 1971; TALAMÉ, 1974). Consultaram-se também a redescrição de $T$. imperialis feita por SIDDIQI (1973) e a descrição de macho de $T$. 
sculptus (MORETTI et alii, 1978).

\section{Chave para espécies de Trophurus (fêmeas)}

1. Ovário reflexo . . . . . . . . . . . . . . T. scognamiglii Talamé, 1974

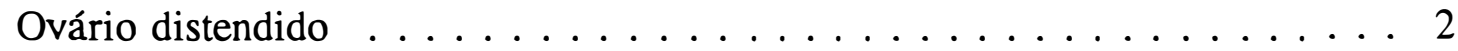

2. Término da cauda crenado $\ldots \ldots \ldots \ldots \ldots \ldots \ldots$

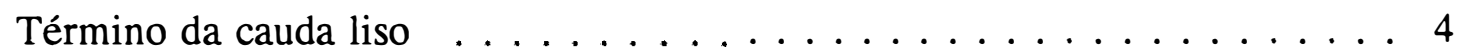

3. Cutícula terminal da cauda $=13-15 \mu \mathrm{m}$; corpo longo e esbelto $(\mathrm{L}=844-1052$ $\mu \mathrm{m}, \mathrm{a}=40,9-50,9) \ldots \ldots \ldots \ldots$. longimarginatus Román, 1962 Cutícula terminal da cauda $=4,0-5,2 \mu \mathrm{m}$; corpo curto e robusto $(\mathrm{L}=520-670$ $\mu \mathrm{m}, \mathrm{a}=27-36) \ldots \ldots \ldots \ldots$. . . . . vultus Siddiqi \& Lenné, 1990

4. Cárdia ausente; região labial destacada do resto do corpo

T. roigi Razjivin, O’Relley \& Pérez Milian, 1973

Cárdia presente; região labial contínua com o resto do corpo $\ldots \ldots \ldots 5$

5. Cárdia de base bifurcada . . . . . . . . . T. impar Ganguly \& Khan, 1983

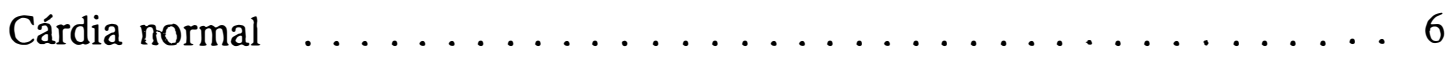

6. Banda interna do campo lateral mais estreita que as marginais Trophurus n. sp. Banda interna do campo lateral tão ou mais larga que as marginais . . . . 7

7. $\mathrm{St}=9-11 \mu \mathrm{m}$; corpo esbelto $(\mathrm{a}=40-58)$

. . . . . . . . . . . . . . T. similis Khan \& Nanjappa, 1971

$\mathrm{St}=14-21 \mu \mathrm{m} ;$ corpo mais robusto $(\mathrm{a}=25-42) \ldots \ldots \ldots \ldots \ldots 8$

8. Cauda cônica com término obtuso-arredondado; espermateca arredondada

T. marathwadensis Suryawanshi, 1971

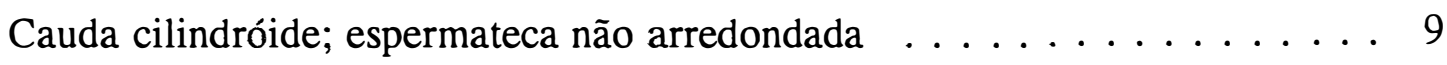

9. $\mathrm{St}=18-21 \mu \mathrm{m}$; término da cauda cônico-obtuso $\ldots \ldots \ldots \ldots \ldots \ldots$ 
$\mathrm{St}=14-18 \mu \mathrm{m}$; término da cauda hemisférico a clavado $\ldots \ldots \ldots 10$

10. Cauda não clavada; $\mathrm{St}=16-18 \mu \mathrm{m} \quad$. T. lomus Saha, Chawla \& Khan, 1973 Cauda clavada; $S t=13-16 \mu \mathrm{m} \ldots \ldots \ldots \ldots \ldots$

11. Saco pós-retal do intestino ausente; $\mathrm{St}=15-16 \mu \mathrm{m} \quad$. T. sculptus Loof, 1956 Saco pós-retal presente; $S t=13-14 \mu \mathrm{m} \ldots \ldots \ldots \ldots \ldots 12$

12. Saco pós retal longo, atinge quase o final da cauda $\ldots \ldots \ldots \ldots \ldots$ . . . . . . . . . T. minnesotensis (Caveness, 1958) Caveness, 1959 Saco pós-retal curto, menor que o diâmetro do corpo ao nível do ânus . . . . . T. ussuriensis Eroshenko, 1981

\section{Chave para espécies de Trophurus (machos) ${ }^{7}$}

1. Testículo reflexo _ . . . . . . . . . . . . T. scognamiglii Talamé, 1974 Testículo distendido $\ldots \ldots \ldots \ldots \ldots \ldots \ldots \ldots$

2. Cárdia presente . . . . . . T. roigi Razjivin, O’Relly \& Pérez Milian, 1973 Cárdia ausente . . . . . . . . . . . . . . . . . . . 3

3. Bulbo basal tão longo quanto o istmo . . . . . T. vultus Siddiqi \& Lenné, 1990 Bulbo basal bem mais curto que o istmo $\ldots \ldots \ldots \ldots \ldots \ldots$ 4. $\mathrm{St}=9-11 \mu \mathrm{m} \ldots \ldots \ldots \ldots$. . . . T. similis Khan \& Nanjappa, 1971

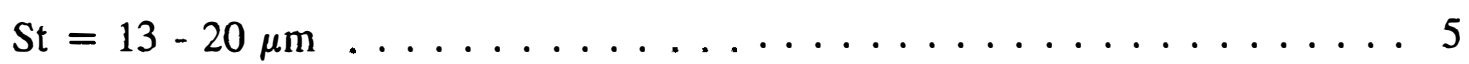

5. Parte distal da bursa forma lobo antes de se juntar à ponta da cauda . . . . . 6 Parte distal da bursa não forma lobo $\ldots \ldots \ldots \ldots \ldots \ldots$

6. Bursa anelada . . . . . . . . . . . . . T. ussuriensis Eroshenko, 1981

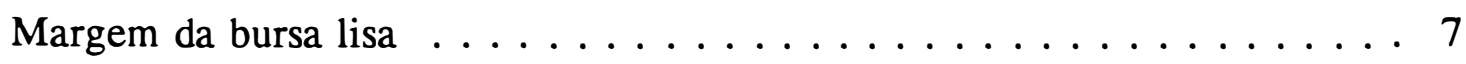

7. $\mathrm{St}=18-20 \mu \mathrm{m}$; espículos $=25 \mu \mathrm{m} \ldots \ldots \ldots$ T. imperialis Loof, 1956

${ }^{7}$ Exceto para T. impar Ganguly \& Khan, cujo macho não é conhecido. 
$\mathrm{St}=15-16 \mu \mathrm{m} ;$ espículos $=14-21,5 \mu \mathrm{m} \ldots \ldots \ldots \ldots \ldots$

8. Armadura cefálica relativamente bem esclerotizada; bursa pequena; espículo $=19$ $21,5 \mu \mathrm{m} \ldots \ldots \ldots \ldots$. . . . . marathwadensis Suryawanski, 1971 Armadura cefálica pouco esclerotizada; bursa grande; espículo $=14-17 \mu \mathrm{m} \ldots$ . . . . . . . . . . . . . . . . . . . . T. sculptus Loof, 1956

9. Banda interna do campo lateral mais estreita que as marginais Trophurus $\mathrm{n}$. $\mathrm{sp}$. Banda interna do campo lateral tão ou mais larga que as marginais . . . . 10 10. Margem da bursa lisa . . . . . . . . T. T. lomus Saha, Chawla \& Khan, 1973 Bursa anelada ou parcialmente anelada . . . . . . . . . . . 11

11. Armadura cefálica bem desenvolvida . . . . . . T. longimarginatus Román, 1962 Armadura cefálica ausente . T. minnesotensis (Caveness, 1958) Caveness, 1959

\subsubsection{Descrição de Criconema n. sp.}

(Figuras 13 a 15)

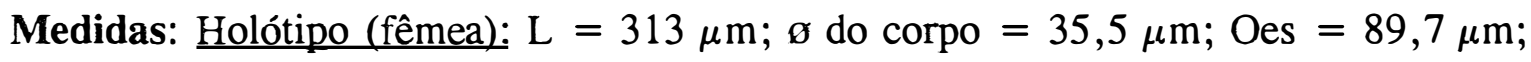
$\mathrm{EP}=98,6 \mu \mathrm{m} ; \mathrm{St}=60,6 \mu \mathrm{m} ; \mathrm{o}$ do anel labial $(\mathrm{vl})=13,1 \mu \mathrm{m} ;$ o dos bulbos St $(\mathrm{vl})$ $=9,3 \mu \mathrm{m} ; \mathrm{t}=23,3 \mu \mathrm{m} ; \mathrm{R}$ (lado ventral) $=77 ; \mathrm{R}_{\mathrm{St}}=16 ; \mathrm{R}_{\text {Oes }}=23 ; \mathrm{R}_{\mathrm{ex}}=25 ; \mathrm{R}_{\mathrm{v}}$ $=13 ; \mathrm{R}_{\mathrm{Van}}=3 ; \mathrm{R}_{\mathrm{an}}=9 ; \mathrm{V}=86,3 ; \mathrm{M}=84,6 ; \mathrm{St} \% \mathrm{~L}=19,4 ; \mathrm{St} \%$ Oes $=67,6 ; \mathrm{a}$ $=8,8 ; \mathrm{b}=3,49 ; \mathrm{c}=13,4 ; \mathrm{VL} / \mathrm{VB}=1,48 ; \mathrm{VL} / \mathrm{St}=0,71$.

Material tipo: Fêmeas: Tabela 4; Machos: não encontrados.

Descrição: Fêmeas: corpo em forma de " $\mathrm{C}$ " aberto quando relaxadas. Região labial com 4,2 a $4,7 \mu \mathrm{m}$ de largura e composta de 6 pseudolóbulos moderadamente proeminentes (6,5 a 7,5 $\mu \mathrm{m}$ de diâmetro e 1,4 a 2,3 $\mu \mathrm{m}$ de largura) e um único anel. Esse é formado por um disco não retrorso e um colar que o separa claramente dos anéis seguintes. Se 

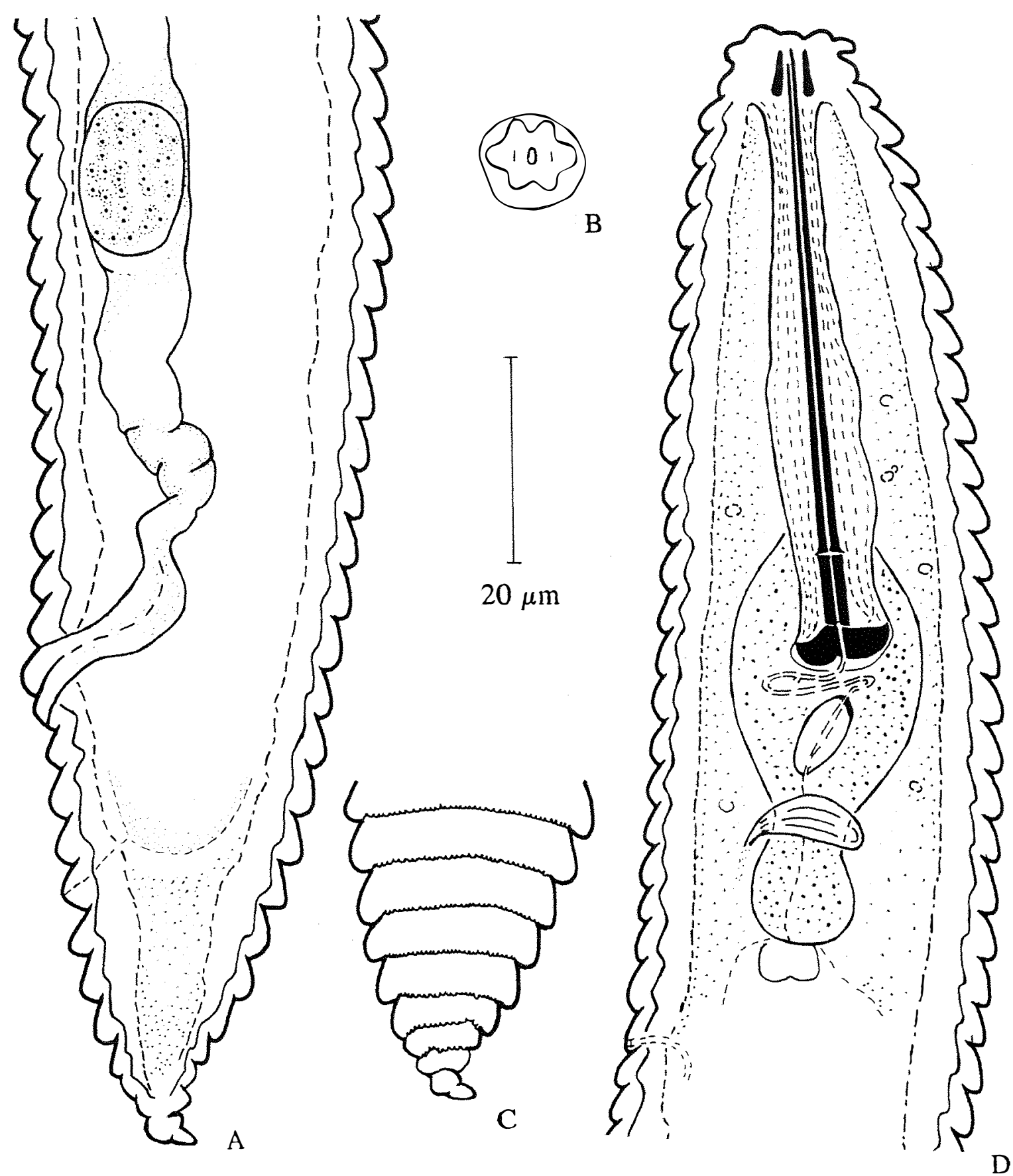

Figura 13. Criconema n. sp. Fêmea (holótipo) A: região posterior, C: cauda, D: região anterior. Fêmea (parátipo): B: região labial en face. 

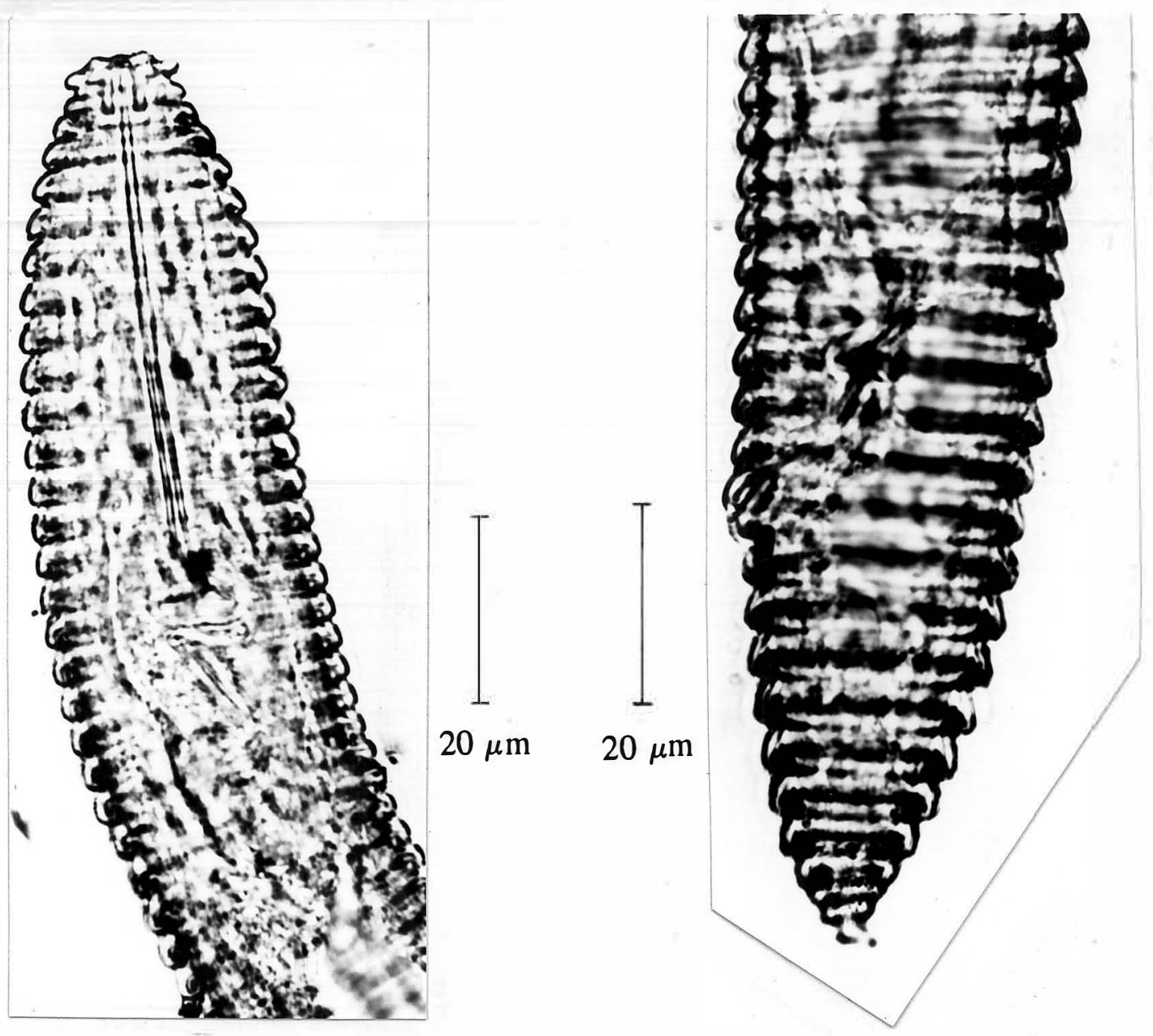

Figuras 14 e 15. Criconema n. sp. Fêmea (parátipo): 14: região anterior. Fêmea (holótipo): 15: região posterior.

gundo anel retrorso e ligeiramente maior que o anel labial (12,1 a 14,5 $\mu \mathrm{m}$ de diâmetro e 2,3 a 2,8 $\mu \mathrm{m}$ de largura vs. 11,7 a $13,1 \mu \mathrm{m}$ e 2,3 a 2,8 $\mu \mathrm{m}$ ). Anéis seguintes também retrorsos e cada vez maiores, atingindo maior tamanho depois do meio do corpo, normalmente à altura da espermateca (33,3 $\mu \mathrm{m}$ de diâmetro). No anel mediano do corpo, as medidas são 29,4 a 36,4 $\mu \mathrm{m}$ de diâmetro e 4,2 a 5,1 $\mu \mathrm{m}$ de largura. Margem posterior de todos os anéis, exceto o labial e os 2 a 4 últimos, de contorno finamente crena- 
Tabela 4. Medidas de fêmeas do material tipo de Criconema $\mathrm{n}$. sp.

\begin{tabular}{l}
$\begin{array}{l}\text { C a r a c terís t ica } \\
\text { morfológicas }\end{array}$ \\
\hline Medidas em $\mu \mathrm{m}$ \\
$\mathrm{L}$ \\
$\varnothing$ do corpo \\
Oes \\
EP \\
$\mathrm{St}$ \\
$\varnothing$ anel labial $(\mathrm{vl})$ \\
$\varnothing$ bulbos $\mathrm{St}(\mathrm{vl})$ \\
$\mathrm{t}$
\end{tabular}

Número de anéis

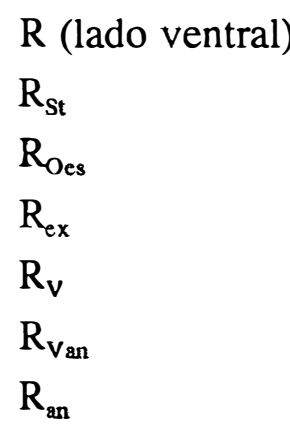

\section{Porcentagens}

$\mathrm{V}$

$\mathrm{M}$

St\% L

St\% Oes

\section{$\underline{\text { Relações }}$}

$\mathrm{a}$
$\mathrm{b}$
$\mathrm{c}$
$\mathrm{VL} / \mathrm{VB}$
$\mathrm{VL} / \mathrm{St}$

$$
\begin{aligned}
& \text { Variação } \\
& (\mathrm{n}=11)
\end{aligned}
$$

$\begin{array}{crl}307-371 & 333 & 19 \\ 29,4-36,4 & 33,3 & 2,2 \\ 87,9-98,2 & 93,9 & 3,5 \\ 95,5-107,6 & 101,4 & 4,4 \\ 56,9-64,8 & 61,4 & 2,5 \\ 11,7-13,1 & 12,3 & 0,5 \\ 7,5-9,3 & 8,9 & 0,7 \\ 23,3-28,9 & 26,3 & 2,0\end{array}$

73-83

15-17

22-23

24-26

$12-15$

3-5

$8-10$

84,4-86,9

$82,5-84,6$

$17,5-19,4$

$61,8-67,6$

79

3

16,3

23,3

25,0

13,7

3,5

9,2

0,6

0,8

0,8

1,0

0,7

0,6

85,5

0,8

83,9

1,1

18,5

0,6

65,4

1,7

$$
\text { 8,8-10,9 }
$$

$3,42-3,77$

$12,1-13,8$

10,0

0,6

3,54

0,11

1,48-1,93

12,6

0,7

1,69

0,13

0,70-0,86

0,05 
do. Campo lateral não evidente. Uma ou 2 anastomoses podem ocorrer em uma ou ambas as laterais do corpo. Espessura da cutícula, no meio do corpo, de 1,9 $\mu \mathrm{m}$. Esôfago criconemóide típico. Cone do estilete reto ou levemente curvado para o lado ventral e com 48 a $54 \mu \mathrm{m}$ de comprimento ( 82,5 a $84,6 \%$ do comprimento do estilete). Haste do estilete freqüentemente com colapso. Bulbos do estilete em forma de âncora e com 7,5 a 9,3 $\mu \mathrm{m}$ de diâmetro e 2,8 a 3,3 $\mu \mathrm{m}$ de altura. Abertura da glândula esofagiana dorsal a 3,7 a $5,6 \mu \mathrm{m}$ da base do estilete. Abertura do poro excretor a 96 a $108 \mu \mathrm{m}$ da extremidade anterior e a 3 a $13 \mu \mathrm{m}$ (1 a 3 anéis) da junção esôfago-intestino.

Vulva fechada e lábios vulvais pouco proeminentes; vagina sigmóide. Ovário bem desenvolvido, atingindo as proximidades da junção esôfago-intestino e normalmente formando uma alça. Espermateca elíptica, medindo 12 a $18 \mu \mathrm{m}$ de comprimento e 8 a $13 \mu \mathrm{m}$ de largura, e cheia de espermatozóides. Região pós-vulvar cônica. Últimos 3 a 5 anéis bem mais estreitos que os imediatamente anteriores (cerca de metade da largura) e 2 a 4 últimos freqüentemente fundidos (Figura 13).

Machos: não encontrados.

Juvenis: não encontrados.

Diagnose: esta espécie pode ser diferenciada das outras do gênero Criconema pelo seguinte conjunto de características: a) região labial composta por pseudolóbulos e um anel não retrorso (Figura 14); b) todos os anéis, exceto o labial e os últimos 2 a 4 , retrorsos e com margem posterior delicadamente crenada; c) corpo com 70 a 90 anéis; d) vagina sigmóide (Figura 15); e) região pós-vulvar cônica; f) últimos 3 a 5 anéis mais estreitos que os imediatamente anteriores e os 2 a 4 últimos normalmente fundidos.

Relações: a região labial composta de um único anel, o número de anéis do corpo e a forma cônica da região pós-vulvar são características comuns entre esta espécie e $C$. paraguayense (Andrássy, 1968) Raski \& Luc, 1985, que é a espécie mais semelhante a Criconema n. sp. (ANDRÁSSY, 1968). Criconema paraguayense, no entanto, possui 
anéis lisos e vagina reta.

Ocorrências: Criconema n. sp. foi coletada na rizosfera de Lantana camara L., em um remanescente degradado de floresta (amostra 10: 0 - $5 \mathrm{~cm}$ de profundidade), no "campus" Luiz de Queiroz, Piracicaba, São Paulo, Brasil, pelo autor do presente trabalho.

Depósito do material tipo: holótipo [fêmea/lâmina $Z_{9}\left(n^{0} 7\right)$ ] e 11 parátipos estão depositados na coleção nematológica da ESALQ, em Piracicaba, SP. 


\section{CONCLUSÕES}

A área onde se localiza o "campus" Luiz de Queiroz possuía uma fauna nematológica que foi extremamente alterada com a remoção da cobertura vegetal original. Algumas das espécies de nematóides autóctones conseguiram sobreviver sob a vegetação do parque da ESALQ, mas nenhuma, com 2 possíveis exceções, adaptou-se às plantas cultivadas estudadas. 


\section{REFERÊNCIAS BIBLIOGRÁFICAS}

ANDRÁSSY, I. Fauna paraguayensis. 2. Nematoden aus den Galeriewaldern des Acaray-flusses. Opusc. Zool. Budapest, $\underline{8}(2):$ 167-315, 1968.

ANDRÁSSY, I. Revision of the subfamily Criconematinae Taylor, 1936 (Nematoda). Opusc. Zool. Budapest, 16(1-2): 11-57, 1979.

BAUJARD, P. \& GERMANI, G. Description de Monotrichodorus sacchari n. sp., Paratrichodorus anthurii n. sp. et d'une population de Paratrichodorus westindicus Rodriguez-M., Sher \& Siddiqi, 1978 (Nematoda: Trichodoridae). Revue de Nematologie, Paris, $\underline{8}(1): 35-39,1985$.

BRZESKI, M.W. Taxonomy of Hemicycliophorinae (Nematoda, Tylenchida). Zeszyty Problemowe Postepow Nauk Rolniczych 154: 237-330, 1974.

CAMPOS, V.P. Morfologia, morfometria e hospedeiros de Discocriconemella repleta Pinochet \& Raski, 1976. Nematologia Brasileira, Piracicaba, 12: 62-68, 1988.

CAMPOS, V.P. \& STURHAN, D. Ocorrência e distribuição de nematóides em Minas Gerais. Nematologia Brasileira, Piracicaba, 11: 153-158, 1987.

CAMPOS, V.P.; D'ARC DE LIMA, R.; ALMEIDA, V.F. Nematóides parasitos de grandes culturas identificados em localidades de Minas Gerais e São Paulo. Nematologia Brasileira, Piracicaba, 11: 226-232, 1987.

CARES, J.E. Fauna fitonematológica de várzea e terra firme nas proximidades de Manaus - AM. Brasília, 1984. 251 p. (Mestrado - UnB).

CARES, J.H. \& HUANG, S.P. Nematode fauna in natural and cultivated cerrados of central Brazil. Fitopatologia Brasileira, Brasília, 16(3): 199-209, 1991.

CAVENESS, F.E. Clavaurotylenchus minnesotensis, n.gen., n.sp. (Tylenchida: Nema- 
toda) from Minnesota. Proceedings of the Helminthological Society of Washington, 25(2): 122-124, 1958.

CHAWLA, M.L. \& SAMATHANAM, G.J. Three new species of the superfamily Criconematoidea (Tylenchida: Nematoda) from Tamil Nadu (India). Indian Journal of Nematology, New Delhi, 10(1): 59-68, 1980.

COOLEN, W.A. \& D'HERDE, C.J. A method for the quantitative extraction of nematodes from plant tissue. Ghent, State Nematology and Entomology Research Station, 1972. $77 \mathrm{p}$.

COSTA MANSO, E.S.B.G.; TENENTE, R.C.V.; FERRAZ, L.C.C.B.; OLIVEIRA, R.S.; MESQUITA, R. Catálogo de nematóides fitoparasitos encontrados associados a diferentes tipos de plantas no Brasil. Brasília, EMBRAPA/SPI/CENARGEN, 1994. 488 p.

EBSARY, B.A. Bakernema yukonense n. sp. (Nematoda: Criconematidae) with keys to the species of Criconemella and Discocriconemella. Canadian Journal of Zoology Ottawa, 60: 3033-3047, 1982.

EROSHENKO, A.S. Phytopathogenic nematodes of forest undergrowth of the families Tylenchorhynchidae and Hoplolaimidae (Nematoda), 1981. In: FORTUNER, R., ed. English translations of selected taxonomic papers in Nematology. Sacramento, California Department of Food and Agriculture, 1987. v. 4, p. 21-35.

FERRAZ, L.C.C.B. Nematóides parasitos de Eucalyptus, Pinus e outras essências florestais cultivadas no Estado de São Paulo. Piracicaba, 1980a. 92 p. (Doutorado USP/ESALQ).

FERRAZ, L.C.C.B. Observations on some Xiphinema species found in Brazil (Nematoda, Dorylaimoidea). Nematologia Mediterranea, Bari, $\underline{8}(2)$ : 141-151, 1980 ${ }_{b}$.

FERRAZ, L.C.C.B.; LORDELLO, L.G.E.; MONTEIRO, A.R. Nematóides associados a espécies de Eucalyptus, Pinus e outras essências florestais cultivadas no Estado de São Paulo. Revista de Agricultura, Piracicaba, 59(1): 59-69, 1984.

FERRAZ, S. Reconhecimento das espécies de fitonematóides presentes nos solos do Estado de Minas Gerais. Experimentiae, Viçosa, 26(11): 255-328, 1980. 
FLEGG, J.J.M. \& HOOPER, D.J. Extraction of free-living stages from soil. In: SOUTHEY, J.F. ed. Laboratory methods for work with plant and soil nematodes. London, Ministry of Agriculture, Fisheries and Food (Technical Bulletin 2), 1970. p. 5-22.

FREIRE, F.C.O. \& FERRAZ, S. Nematóides associados ao feijoeiro, na Zona da Mata, Minas Gerais, e efeitos do parasitismo de Meloidogyne incognita e M. javanica sobre o cultivar 'Rico 23'. Revista Ceres, Viçosa, 24(132): 141-149, 1977.

GANGULY, S. \& KHAN, E. Trophurus impar sp. n. and Scutellonema eclipsi sp. n. (Nematoda: Tylenchida). Indian Journal of Nematology, New Delhi, 13(2): 230$234,1983$.

HARTMAN, K.M. \& SASSER, J.N. Identification of Meloidogyne species on the basis of differential host test and perineal-pattern morphology. In: BARKER, K.R.; CARTER, C.C.; SASSER, J.N., ed. An advanced treatise on Meloidogyne. II. Methodology. Raleigh, North Carolina State University (Department of Plant Pathology)/USAID, 1985. p. 69-77.

JENKINS, W.R. A rapid centrifugal-flotation technique for separating nematodes from soil. Plant Disease Reporter, Beltsville, 48(9): 692, 1964.

KHAN, E. \& NANJAPPA, C.K. Trophurus similis. sp. n. and Trichotylenchus astriatus sp. n. (Nematoda: Tylenchoidea) from Mysore, India. Indian Journal of Nematology, New Delhi, 1(1): 75-79, 1971.

LOOF, P.A.A. Trophurus, a new tylenchid genus (Nematoda). Overdruk uit Versl. en Medes. Plantenz. k. Dienst 129 (Jaarboek 1955): 191-195, 1955.

LOOF, P.A.A. \& HEYNS, J. Taxonomy of Hemicycliophora species from South Africa (Nematoda: Criconematoidea). Nematologica, Leiden, 15(4): 464-472, 1969.

LOOF, P.A.A. \& SHARMA, R.D. Plant parasitic nematodes from Bahia State, Brazil: the genus Xiphinema Cobb, 1913 (Dorylaimoidea). Nematologica, Leiden, 25(1): 111-127, 1979.

LORDELLO, L.G.E. Xiphinema krugi n. sp. (Nematoda, Dorylaimida) from Brazil with a key to species of Xiphinema. Proceedings of the Helminthological Society 
of Washington, 22(1): 16-21, 1955.

LORDELLO, L.G.E. \& ZAMITH, A.P.L. Nota sobre o gênero Trichodorus Cobb, 1913, com descrição de Trichodonus bucrius sp. n. (Nematoda, Dorylaimoidea). Anais da Academia Brasileira de Letras, Rio de Janeiro, 30(1): 103-105, 1958.

LUC, M. Xiphinema de l'ouest africain: description de cinq nouvelles espèces (Nematoda: Dorylaimidae). Nematologica, Leiden, $\underline{3}(1): 57-72,1958$.

LUC, M. Nouveaux Criconematidae de la zone intertropicale (Nematoda: Tylenchida). Nematologica, Leiden, 4(1): 16-22, 1959.

LUC, M. Contribution a l'étude du genre Criconemoides Taylor, 1936 (Nematoda: Criconematidae). Cahiers ORSTOM. (série Biologie, Nématologie), Paris, $\mathrm{n}^{\circ} \underline{11}$ : 69-150, 1970.

LUC, M. \& DALMASSO, A. Considerations on the genus Xiphinema Cobb, 1913 (Nematoda: Longidoridae) and a "lattice" for the identification of species. Cahiers ORSTOM (série Biologie, Nématologie), Paris, 10(3): 303-327, 1975.

LUC, M. \& HUNT, D.J. Redescription of Xiphinema longicaudatum Luc, 1961 and observations on Xiphinema krugi Lordello, 1955 (Nematoda, Longidoridae). Nematologica, Leiden, 24(1): 1-18, 1978.

MAGGENTI, A.R. Nemata: higher classification. In: NICKLE, W.R., ed. Manual of agricultural Nematology. New York, Marcel Dekker, inc., 1991. p. 147-187.

MAGGENTI, A.R.; LUC, M.; RASKI, D.J.; FORTUNER, R.; GERAERT, E. A reappraisal of Tylenchina (Nemata). 2. Classification of the suborder Tylenchina (Nemata: Diplogasteria). Revue de Nématologie, Paris, 10(2): 135-142, 1987.

MENDONÇA, M.M. Estudo sobre Hoplolaiminae encontrados no Brasil (Nemata: Tylenchoidea). Piracicaba, 1976. 91 p. (M.S. - USP/ESALQ).

MONTEIRO, A.R. Xiphidorus yepesara n. gen., n. sp. (Nemata: Longidoridae) from Brazil. Nematologia Mediterranea, Bari, 4(1): 1-6, 1976.

MONTEIRO, A.R. \& FERRAZ, L.C.C.F. Curso de identificação de nematóides parasitos de plantas. Piracicaba, ESALQ/Departamento de Zoologia, 1988. 214p. (postila). 
MONTEIRO, A.R. \& LORDELLO, L.G.E. A description of Hemicycliophora poranga n. sp. from Brazil (Nemata). Revista Brasileira de Biologia, Rio de Janeiro, $\underline{38(3):}$ 569-571, 1978.

MONTEIRO, A.R. \& MENDONÇA, M.M. Helicotylenchus caipora n. sp. (Nematoda, Hoplolaimidae). Revista de Agricultura, Piracicaba, 47(3-4): 199-204, 1972.

MONTEIRO, A.R.; FERRAZ, L.C.C.B.; INOMOTO, M.M.; MORAIS, S.R.A.C. Ocorrência de Criconemella xenoplax associada a pessegueiro com declínio no Brasil. Nematologia Brasileira, Piracicaba, .14: 4, 1990 (Resumo).

MONTEIRO, A.R.; LORDELLO, L.G.E.; NAKASONO, K. Xiphidorus parthenus $\mathrm{n}$. sp. (Nemata: Longidoridae) from Brazil. Revista de Agricultura, Piracicaba, $\underline{56}$ (1-2 93-97, 1981.

MONTEIRO, A.R.; MARTINELLI, N.M.; FERRAZ, L.C.C.B.; LORDELLO, R.R.A. Nematóides de plantas na região de Ilha Solteira., Estado de São Paulo. Sociedade Brasileira de Nematologia, Piracicaba, 3: 35-37, 1978.

MORETTI, F.; MANCINI, G.; COTRONEO, A. Redescription of male of Trophurus sculptus Loof, 1956 (Nematoda, Tylenchida). Nematologica, Leiden, 24(4): 474476, 1978.

ORR, R.T. Biologia dos vertebrados. São Paulo, Rocca, 1986. 508 p.

ORTON WILLIAMS, K.J. Macroposthonia xenoplax. In: WILLMOT, S.; GOOCH,

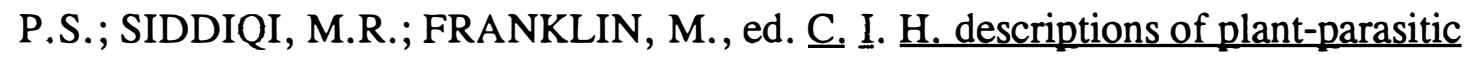
nematodes. St. Albans, Commonwealth Institute of Helminthology, 1972. Set 1, $\mathrm{n}^{\circ} 12$.

PINOCHET, J. \& RASKI, D.J. Discocriconemella repleta n. sp., and the male of Criconemoides inusitatus Hoffmann, 1974 (Criconematidae: Nematoda). Journal of Nematology, De Leon Springs, (4): 327-330, 1976.

PINOCHET, J. \& RASKI, D.J. Four new species of the genus Hemicriconemoides (Nematoda: Criconematidae). Journal of Nematology, St. Paul, Z(3): 263-270, 1975. RASHID, F.; DE WAELE, D.; COOMANS, A. Trichodoridae (Nematoda) from Brazil. Nematologica, Leiden, $\underline{31(3): 289-320,1985 .}$ 
RASHID, F.; COOMANS, A.; SHARMA, R.D. Longidoridae (Nematoda: Dorylaimida) from Bahia State, Brazil. Nematologia Mediterranea, Bari, 14(2): 235-250, 1986 .

RASHID, F.; GERAERT, E.; SHARMA, R.D. Criconematidae (Nemata) from Brazil. Nematologica, Leiden, 32(4): 374-397, 1986 ${ }_{b}$.

RASKI, D.J. On the morphology of Criconemoides Taylor, 1936, with descriptions of six new species (Nematoda: Criconematidae). Proceedings of the Helminthological Society of Washington, 19(2): 85-99, 1952.

RASKI, D.J. \& LUC, M. A reappraisal of Tylenchina (Nemata) 10. The superfamily Criconematoidea Taylor, 1936. Revue de Nematologie, Paris, 10)4): 409-444, 1987.

RASKI, D.J. \& PINOCHET, J. Merocriconema braziliensis g. n., sp. n. (Criconematidae: Nematoda) from Piper sp. Indian Journal of Nematology New Delhi, 5(1): 22-25, 1975.

RAZJIVIN, A.A.; O'RELLY, J.P.; PÉREZ MILIAN, J.R. Nuevas especies de nemátodos (Nematoda: Dorylaimidae y Hoplolaimidae) parázitos de la cana de azúcar en Cuba. Poeyana, $n^{\circ} \underline{108}$ 1973. Apud Helminthological Abstracts, Ser. B, St. Albans, 43(4): 257, 1974.

RODRIGUES, R.R. Vegetação da folha de Piracicaba. In: OLIVEIRA, J.L. \& PRADO, H., ed. Levantamento pedológico semidetalhado do estado de São Paulo. Folha de Piracicaba. II. Memorial descritivo. Campinas, Instituto Agronômico, no prelo.

RODRIGUEZ-M., R.; SHER, S.A.; SIDDIQI, M.R. Systematics of the monodelphic species of Trichodoridae (Nematoda: Diphtherophorina) with descriptions of a new genus and four new species. Journal of Nematology, DeLeon Springs, 10(2): 141$152,1978$.

ROMÁN, J. Trophurus longimarginatus n. sp. (Tylenchida: Nematoda) from Puerto Rico. Journal of Agriculture of the University of Puerto Rico, Rio Piedras, 46(4): 269-271, 1962. 
SAHA, M.; CHAWLA, M.L.; KHAN, E. Trophurus lomus sp. n. (Tylenchida: Nematoda) from soil around roots of Prunus armeniaca from India. Indian Journal of Nematology, New Delhi, $\underline{3}(1): 61-63,1973$.

SHARMA, R.D. Nematodes of the cocoa region of the State of Espírito Santo, Brazil. II. Nematodes associated with field crops and forest trees. Revista Theobroma, Ilhéus, $\underline{6}$ (4): 109-117, 1976.

SHARMA, R.D. \& LOOF, P.A.A. Nematodes of the cocoa region of Bahia, Brazil. I. Plant-parasitic and free-living nematodes associated with rubber (Hevea brasiliensis Mull. Arg.). Revista Theobroma, Itabuna, 3(1): 36-41, 1973.

SHARMA, R.D. \& LOOF, P.A.A. Nematodes of the cocoa region of Bahia, Brazil. IV. Nematodes in the rizospheres of pepper (Piper nigrum L.) and clove (Eugenia caryophyllata Thunb.). Revista Theobroma, Ilhéus, 4(3): 26-32, 1974.

SHARMA, R.D. \& SHER, S.A. Nematodes of the cocoa region of Bahia, Brazil. II. Occurrence and distribution of plant parasitic nematodes associated with cocoa (Theobroma cacao L.). Revista Theobroma, Itabuna, $\underline{3}$ (3): 17-24, 1973.

SHER, S.A. Revision of the Hoplolaiminae (Nematoda): V. Rotylenchus Filipjev, 1936. Nematologica, Leiden, 11(2): 173-198, 1965.

SIDDIQI, M.R. Studies on species of Criconematinae (Nematoda: Tylenchida) from India. Proceedings of the Helminthological Society of Washington, Beltsville, 28(1): 19-34, 1961.

SIDDIQI, M.R. Trophurus imperialis. In: WILLMOT, S.; GOOCH, P.S.; SIDDIQI,

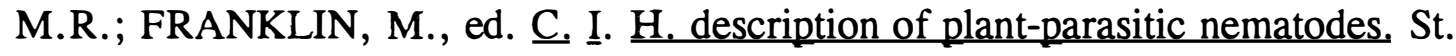
Albans, Commonwealth Institute of Helminthology, 1973. Set 2, $\mathrm{n}^{\circ} 22$.

SIDDIQI, M.R. Hemicriconemoides mangiferae. In: WILLMOT, S.; GOOCH, P.S.; SIDDIQI, M.R.; FRANKLIN, M., ed. C. $\underline{\text { I. }} \underline{\text { H. descriptions of plant-parasitic }}$ nematodes. St. Albans, Commonwealth Institute of Helminthology, 1977. Set 7, $\mathrm{n}^{\circ}$ 99.

SIDDIQI,M.R. \& LENNÉ, J.M. Xiphinema llanosum and Trophurus vultus, two new plant nematodes from pasture soils in Colombia. Journal of Nematology Lake 
Alfred, 22(3): 262-267, 1990.

SOUZA, R.M.; DOLINSKY, C.M.; HUANG, S.P. Survey of Meloidogyne spp. in native cerrado of Distrito Federal, B razil. Fitopatologia Brasileira, Brasília, 19(3): 463-465, 1994.

SPERANDIO, C.A. Identificação de nematóides fitoparasitos do Rio Grande do Sul Brasil. Piracicaba, 1992. 126 p. (Doutorado - USP/ESALQ).

SURYAWANSHI, M.V. Studies of Tylenchida (Nematoda) from Marathwada, India, with descriptions of four new species. Nematologica, Leiden, 17(3): 393-406, 1971.

TALAMÉ, M. Trophurus scognamiglii n. sp. (Nematoda: Tylenchida). Bolletino del Laboratorio di Entomologia Agraria "Filippo Silvestri", 31:9-15, 1974. Apud Helminthological Abstracts, Ser. B, St. Albans, 쑈(2): 66, 1979.

TARJAN, A.C. Two new american dagger nematodes (Xiphinema: Dorylaimida) associated with citrus, with comments on the variability of $X$. bakeri Williams, 1961. Proceedings of the Helminthological Society of Washington 31(1): 65-76, 1964.

UESUGI, C.H.; HUANG, C.S.; CARES, J.E. Xiphidorus amazonensis n.sp. (Nemata: Longidoridae) from the Brazilian Amazon Basin. Journao of Nematology, Lawrence, $17(3): 310-313,1985$.

VAN DEN BERG, E. Two new Rotylenchus species from the Cape Province with notes on some known Rotylenchus species (Rotylenchinae: Nematoda). Phytophylactica, Pretoria, 18(4): 169-176, 1986.

VAN DEN BERG, E. On some Helicotylenchus and Rotylenchus species from South Africa (Nematoda). Phytophylactica, Pretoria, 10(1): 7-12, 1978.

VIDAL-TORRADO, P.; SPAROVEK, G.; DEMATTÊ, J.L.I.; COOPER, M.; OLIVEIRA, M.C.; PRADO, G.V.B.; ALCARDE, G.V.B. Mapa pedológico detalhado do campus "Luiz de Queiroz". Piracicaba, ESALQ/Departamento de Ciência do Solo, 1993.

VOVLAS, N. Taxonomy of Discocriconemella (Nematoda: Criconematoidea) with redescription of D. mauritiensis. Journal of Nematology, Hanover (EUA), 24(3): 
391-398, 1992.

VOVLAS, N.; FERRAZ, S.; DOS SANTOS, J.M. Description of Discocriconemella mineira sp. n. and $D$. degrissei males from Brazil. Journal of Nematology, Lawrence, 21 (3): 335-341, 1989.

VOVLAS, N.; LAMBERTI, F.; PIMENTEL, J.P.; SHARMA, R.D.; CAMPOS, V.P. Morphological characteristics of Neolobocriconema cataracticum Andrássy. Nematologia Mediterranea, Bari, 15(2): 253-258, 1987.

ZAMITH, A.P.L. \& LORDELLO, L.G.E. Algumas observações sobre nematódeos em solo de mata e em solo cultivado. Revista de Agricultura, Piracicaba, 32(3): 183$188,1957$. 


\section{BIBLIOGRAFIA RECOMENDADA}

DASGUPTA, D.R.; RASKI, D.J.; SHER, S.A. A revision of the genus Rotylenchulus Lindford and Oliveira, 1940 (Nematoda: Tylenchida). Proceedings of the Helminthological Society of Washington, Beltsville, 35(2): 169-192, 1968.

DECRAEMER, W. Systematics of the Trichodoridae with keys to their species. Revue de Nématologie, Paris, $\underline{3}(1): 81-89,1980$.

DE GRISSE, A.T. Contribution to the morphology and the systematic of the Criconematidae (Taylor, 1936) Thorne, 1949. Ghent, 1969. 188 p. (Doutorado - Faculty of Agricultural Sciences, Coupure, 235, Ghent).

EISENBACK, J.D.; HIRSCHMANN, H.; SASSER, J.N.; TRIANTAPHYLLOU, A.C. Guía para la identificación de las cuatro especies más comunes del nemátodo agallador (Meloidogyne especies) con una clave pictórica. Raleigh, North Carolina State University, Colegio de Postgraduados (Chapingo) \& USAID, 1983. 48 p.

JEPSON, S.B. Identification of root-knot nematodes (Meloidogyne species). Wallingford, C.A.B. International, 1987. 265 p.

RASKI, D.J. \& LUC, M. A reappraisal of the genus Criconema Hofmanner \& Menzel, 1914 (Nematoda: Criconematidae). Revue de Nematologie, Paris, 7(4): 323-334, 1984.

SHER, S.A. Revision of the Hoplolaiminae (Nematoda): II. Hoplolaimus Daday, 1905 and Aorolaimus n. gen. Nematologica, Leiden, 9(2): 267-295, 1963.

SHER, S.A. Revised key to the Scutellonema Andrássy, 1958. (Hoplolaiminae: Nematoda). Nematologica, Leiden, 10(4): 648, 1964.

SHER, S.A. Revision of the Hoplolaiminae (Nematoda): VI. Helicotylenchus Steiner, 
1945. Nematologica, Leiden, 12(1): 1-56, 1966.

SIDDIQI, M.R. Tylenchida parasites of plants and insects. St. Albans, Commonwealth Institute of Parasitology, 1986. 645 p.

TARJAN, A.C. A synopsis of the genera and species in the Tylenchorhynchus (Tylenchoidea, Nematoda). Proceedings of the Helminthological Society of Washington. 40(1): 123-144, 1973.

TAYLOR, A.L.; DROPKIN, V.H.; MARTIN, G.C. Perineal patterns of root-knot nematodes. Phytopathology, Baltimore, 45(1): 26-34, 1955. 
A P ÊN D I C E 1 
Primeiro registro de ocorrência de nematóides fitoparasitos no Brasil

O catálogo de COSTA MANSO et alii (1994) foi utilizado na tarefa de verificar a ocorrência anterior das espécies identificadas neste levantamento. Com base nesse trabalho, elaborou-se a Tabela 5 , onde estão contidos os primeiros registros de ocorrência dos nematóides fitoparasitos no Brasil.

Tabela 5. Nematóides fitoparasitos registrados no Brasil e referências sobre o primeiro registro.

\subsection{Família Longidoridae}

Espécie

$1^{\mathrm{o}}$ registro de ocorrência ${ }^{3}$

Xiphinema americanum Cobb, $1913^{1}$

Carvalho, 1955

$X$. attorodorum Luc, $1961^{2}$

Ferraz, L.C, 1977

X. basiri Siddiqi, 1959

Sharma \& Sher, 1973

$X$. brasiliense Lordello, $1951^{1,2}$

Lordello, 1951

X. brevicolle Lordello \& Costa, 1961,

Lordello \& Costa, 1961

X. californicum Lamberti \& Bleve-Zacheo, 1979

Lamberti et alii, 1987

X. clavicaudatum Huang, Uesugi \& Raski, $1987^{1}$

Huang et alii, 1987

X. costaricense Lamberti \& Tarjan, 1974

Germani, 1989

X. dimidiatum Loof \& Sharma, $1979^{1}$

Loof \& Sharma, 1979

X. elongatum S. Stekhoven \& Teunissen, $1938^{2}$

Lordello, 1951 
5.1. Família Longidoridae (continuação)

Espécie

$1^{\circ}$ registro de ocorrência ${ }^{3}$

X. ensiculiferum (Cobb, 1893)Thorne, $1937^{2}$

Carvalho, $1955_{\mathrm{a}}$

$X$. fluminense Huang, Uesugi \& Raski, 1987

Huang et alii, 1987

X. georgianum Lamberti \& Bleve-Zacheo, $1979^{2}$

Ferraz, L.C, 1980

X. guillaumeti Germani, 1989

Germani, 1989

X. ifacolum Luc, 1961

Sharma \& Loof, 1972

$X$. index Thorne \& Allen, 1950

Ponte, 1986

X. krugi Lordello, $1955^{1,2}$

Lordello, 1955

X. machoni Hunt, 1980

Monteiro, 1985

X. pachtaicum (Tulaganov, 1988) Kirjanova, $1951^{2}$

Ferraz, L.C., 1980

X. paritaliae Loof \& Sharma, 1979,2

Loof \& Sharma, 1979

X. paulistanum Carvalho, $1965^{1,2}$

Carvalho, $1965_{\mathrm{b}}$

X. setariae Luc, $1958^{2}$

Sharma \& Sher, 1973

X. surinamense Loof \& Maas, $1972^{2}$

Zem, 1977

X. vulgare Tarjan, $1964^{2}$

Sharma \& Loof, 1972

Longidorus $\mathrm{sp.}^{2}$

Sharma \& Sher, 1974

Longidoroides $\mathrm{sp}$.

Rashid et alii, 1986

Xiphidorus amazonensis Uesugi, Huang \& Cares, 1985

Uesugi et alii, 1985

X. minor Rashid, Coomans \& Sharma, $1986^{1}$

Rashid et alii, 1986

X. parthenus Monteiro, Lordello \& Nakasono, 1981 $11^{1,2}$

Monteiro et alii, 1981

X. yepesara Monteiro, 1976,

Monteiro, 1976 


\subsection{Família Trichodoridae}

Espécie

$1^{\mathrm{o}}$ registro de ocorrência ${ }^{3}$

Trichodorus sp.

CARES \& HUANG, 1991

Paratrichodorus minor (Colbran, 1956) Siddiqi, $1974^{2}$

MONTEIRO, 1968

P. porosus (Allen, 1957) Siddiqi, $1974^{2}$

Lordello \& Zamith, 1958

Monotrichodorus monohystera (Allen, 1957) Andrássy, Sharma \& Sher, 1975 1976

Allotrichodorus brasiliensis Rashid, de Waele \& Rashid et alii, 1986 Coomans, 1986

A. campanulata Rodriguez-M., Sher \& Siddiqi, 1978 Rashid et alii, 1986

A. loofi Rashid,de Waele \& Coomans, $1986^{1}$

Rashid et alii, 1986

A. longispiculus Rashid, de Waele \& Coomans, $1986^{1}$ Rashid et alii, 1986

A. sharmae Rashid, de Waele \& Coomans, $1986^{1} \quad$ Rashid et alii, 1986

A. westindicus (Rodriguez-M., Sher \& Siddiqi, 1978) Rashid et alii, 1986

Rashid, de Waele \& Coomans, 1986

\subsection{Família Tylenchidae}

Espécie

$1^{\circ}$ registro de ocorrência ${ }^{3}$

Tylenchus davanei Bastian, $1965^{2}$

Rahm, 1928

Filenchus exiguus (de Man, 1876) Raski \& Geraert, Uesugi \& Huang, 1984 1986

F. facultativus (Szczygiel, 1970) Geraert \& Raski, Monteiro, 1974 1987

F. minutus (Cobb, 1893) Raski \& Geraert, 1986 Sharma \& Loof, 1977 Malenchus bryophilus (Steiner, 1914) Andrássy, 1980 Sharma \& Loof, 1977 a 
5.3. Família Tylenchidae (continuação)

Espécie

$1^{0}$ registro de ocorrência ${ }^{3}$

Cucullitylenchus amazonensis Huang \& Raski, $1986^{1}$

Huang \& Raski, 1986

Echphyadophora sp.

Ferraz, S., 1980

Lelenchus leptosoma (de Man, 1880) Andrássy, 1954

Sharma \& Loof, 1977a

Cephalenchus leptus (Siddiqi, 1963) Knobloch, 1972

SPERANDIO, 1992

Coslenchus alacinatus Siddiqi, 1980

SPERANDIO, 1992

C. areolatus (Egunjobi, 1967) Siddiqi, 1978

Rashid et alii, 1987

C. bisexualis Siddiqi, 1981

Uesugi \& Huang, 1984

C. costatus (de Man, 1921) Siddiqi, 1978

Sharma, 1976

Psilenchus hilarulus de Man, 1921

Sharma \& Loof, 1973

Boleodorus thylactus Thorne, 1941

Rashid et alii, 1987a

Basiria graminophila Siddiqi, 1959

Sharma \& Loof, 1977

B. tumida (Colbran, 1960) Geraert, 1968

Ferraz, S., 1980

Neopsilenchus sp.

Sharma, $1977_{b}$

Sakia sp.

Sharma \& Loof, 1977

\subsection{Família Anguinidae}

Espécie

$1^{0}$ registro de ocorrência ${ }^{3}$

Anguina sp. $^{2}$

Novaretti et alii, 1974

Ditylenchus anchilisposomus (Tarjan, 1958) Fortuner, Ferraz, S., 1980 1982

D. angustus (Butler, 1913) Filipjev, 1936

Lemos et alii, 1982

D. destructor Thorne, $1945^{2}$

Carvalho, 1953

D. dipsaci (Kühn, 1857) Filipjev, $1936^{2}$

Rahm, 1928 
5.4. Família Anguinidae (continuação)

Espécie

$1^{o}$ registro de ocorrência ${ }^{3}$

Pseudohalenchus minutus Tarjan, 1958

Huang \& Raski, 1986

Chitinotylenchus sp.

Cares \& Huang, 1984

\subsection{Família Dolichodoridae}

Espécie

$1^{\text {o }}$ registro de ocorrência ${ }^{3}$

Dolichodorus minor Loof \& Sharma, 1975

Loof \& Sharma, 1975

Dolichodorus sp. ${ }^{1,4}$

SPERANDIO, 1992

Neodolichodorus sp.

Rashid et alii, 1987.

\subsection{Família Belonolaimidae}

Espécie

$1^{0}$ registro de ocorrência ${ }^{3}$

Belonolaimus anama (Monteiro \& Lordello, 1977) Monteiro \& Lordello, 1977 Fortuner \& Luc, $1987^{1,2}$

B. jara (Monteiro \& Lordello, 1977) Fortuner \& Luc, Monteiro \& Lordello, 1977 $1987^{1,2}$

Tylenchorhynchus acutus Allen, 1955

Sharma \& Loof, 1972

T. annulatus (Cassidy, 1930) Golden, $1971^{2}$

Sharma \& Sher, 1974

T. contractus Loof, 1964

Sharma \& Loof, 1977

T. dubius (Butschli, 1973) Filipjev, 1936

Uesugi \& Huang, 1984

T. latus Allen, $1955^{2}$

Lordello \& Mendonça, 1970

T. leviterminalis Siddiqi, Mukherjee \& Dasgupta,

Campos \& Sturhan, 1987 
5.6. Família Belonolaimidae (continuação)

Espécie

$1^{0}$ registro de ocorrência ${ }^{3}$

$1982^{2}$

T. mashhoodi Siddiqi \& Basir, 1959

Sharma \& Loof, 1977

T. phaseoli Sethi \& Swarup, 1968

Sharma, 1973 a

T. queirozi Monteiro \& Lordello, $1976^{1}$

Monteiro \& Lordello, 1976

T. striatus Allen, 1955

Luz, 1982

Tylenchorhynchus sp. "A"4

SPERANDIO, 1992

Tylenchorhynchus sp. "B"4

SPERANDIO, 1992

Trophurus sp.

Sharma \& Sher, $1973_{\mathrm{c}}$

Paratrophurus sp.

Sharma, 1976

Triversus hollisi (Siddiqi, 1976) Fortuner \& Luc, 1987 SPERANDIO, 1992

5.7. Família Pratylenchidae

Espécie

$1^{\circ}$ registro de ocorrência ${ }^{3}$

Pratylenchus brachyurus (Godfrey, 1929) Filipjev \& S. Lordello et alii, 1954

Stekhoven, $1941^{2}$

P. coffeae (Zimmermann, 1898) Filipjev \& S. Stek- Rahm, 1928 hoven, $1941^{2}$

P. jordaniensis Hashim, 1983

Café $\mathrm{F}^{\circ}$ \& Huang, 1988

P. neglectus (Rensch, 1924) Filipjev \& S. Stekhoven, Luz, 1982 1941

P. penetrans (Cobb, 1917) Filipjev \& S. Stekhoven, Charchar et alii, 1980; Mon$1941^{2}$ teiro, 1980

P. pseudofallax Café $\mathrm{F}^{\circ} \&$ Huang, $1988^{1}$

Café $F^{\circ} \&$ Huang, 1988 
5.7. Família Pratylenchidae (continuação)

Espécie

$1^{0}$ registro de ocorrência ${ }^{3}$

P. pseudopratensis Seinhorst, 1968

Café $\mathrm{F}^{\circ}$ \& Huang, 1988

P. scribneri Steiner in Sherbakoff \& Stanley, 1943

MONTEIRO et alii, 1987

P. vulnus Allen \& Jensen, $1951^{2}$

Monteiro \& Lordello, 1976

P. zeae Graham, $1951^{2}$

Monteiro, 1963

Radopholus similis (Cobb, 1893) Thorne, 1949²

Carvalho, 1959

Hirschmanniella oryzae (van Breda de Haan, 1902) Sharma \& Loof, 1978 Luc \& Goodey, $1964^{2}$

\subsection{Família Hoplolaimidae}

Espécie

$1^{0}$ registro de ocorrência ${ }^{3}$

Hoplolaimus galeatus (Cobb, 1913) Filipjev \& S. Novaretti et alii, 1974 Stekhoven, $1941^{2}$

H. tylenchiformis von Daday, 1905

Rotylenchus caudaphasmidius Sher, $1965^{2}$

R. nexus Ferraz, $1980^{1}$

R. robustus (de Man, 1876) Filipjev, 1936

Helicotylenchus africanus (Micoletzky, 1916) Andrássy, 1958

H. caipora Monteiro \& Mendonça, 19721,2

H. californicus Sher, 1966

H. cavenessi Sher, $1966^{2}$

H. crenacauda Sher, 1966

H. digonicus Perry, Darling \& Thorne, 1959
Luz, 1982

Sharma, 1976

Ferraz, S., 1980

Huang et alii, 1976

Moreira \& Huang, 1980

Monteiro \& Mendonça, 1972

Sharma, 1976

Ferraz et alii, 1978

Sharma \& Loof, 1984

Sharma \& Swarup, 1982 
5.8. Família Hoplolaimidae (continuação)

Espécie

$1^{0}$ registro de ocorrência ${ }^{3}$

H. dihystera (Cobb, 1893) Sher, $1961^{2}$

Lordello \& Zamith, 1956

H. egyptiensis Tarjan, $1964^{2}$

Zem \& Lordello, 1976

H. erythrinae (Zimmermann, 1904) Golden, $1956^{2}$

Sharma \& Sher, 1973

H. exallus Sher, 1966

SHARMA \& SHER, 1973

H. flatus Román, 1965

Sharma \& Loof, 1984

H. lobus Sher, 1966

Lordello \& Mendonça, 1970

H. longicaudatus Sher, 1966

Huang et alii, 1976

H. microcephalus Sher, $1966^{2}$

Zem \& Lordello, 1976

H. multicinctus (Cobb, 1893) Golden, $1956^{2}$

Carvalho, 1956

H. pseudorobustus (Steiner, 1914) Golden, $1956^{2}$

Novaretti et alii, 1974

H. pteracercus Singh, 1971

Ferraz, S., 1980

H. retusus Siddiqi \& Brown, 1964

Sharma \& Loof, 1984

H. serenus Siddiqi, 1963

Sharma \& Loof, 1984

H. stylocercus Siddiqi \& Pinochet, 1979

Ferraz, S., 1980

H. talonus Siddiqi, 1972

Moreira \& Huang, 1980

H. truncatus Román, 1965

MENDONÇA, 1976

Helicotylenchus sp. ${ }^{4}$

Scutellonema bizanae Van den Berg \& Heyns, 1973

SPERANDIO, 1992

S. brachyurus (Steiner, 1938) Andrássy, $1958^{2}$

SPERANDIO, 1992

S. bradys (Steiner \& LeHew, 1933) Andrássy, $1958^{2}$

Lordello, 1957

Lordello, 1959

Aorolaimus amazonensis (Bittencourt \& Huang, 1986)

Bittencourt \& Huang, 1986 Fortuner, $1987^{1}$

A. areolatus (Bittencourt \& Huang, 1986) Fortuner, Bittencourt \& Huang, 1986 $1987^{1}$

A. banoae (Rashid, Geraert \& Sharma, 1987) Fortuner, Rashid et alii, 1987 
5.8. Família Hoplolaimidae (continuação)

Espécie

$1^{0}$ registro de ocorrência ${ }^{3}$

$1987^{1}$

A. cerradoensis (Bittencourt \& Huang, 1986) Fortuner, Bittencourt \& Huang, 1986 $1987^{1}$

A. christiei (Golden \& Taylor, 1956) Fortuner, 1987 Freire \& Monteiro, 1978

A. holdemani (Sher, 1964) Fortuner, $1987 \quad$ Sharma \& Loof, 1972

A. ibiboca (Monteiro \& Choudhury, 1978) Fortuner, Monteiro \& Choudhury, 1978 $1987^{1}$

A. levicaudatus (Bittencourt \& Huang, 1986) Fortuner, Bittencourt \& Huang, 1986 $1987^{1}$

A. nigeriensis (Sher, 1964) Fortuner, 1987 $\quad$ Rashid et alii, 1987

A. paraensis (Bittencourt \& Huang, 1986) Fortuner, Bittencourt \& Huang, 1986 $1987^{1}$

A. perscitus Doucet, 1980

SPERANDIO, 1992

A. raskii (Bittencourt \& Huang, 1986) Fortuner, 1987 $\quad$ Bittencourt \& Huang, 1986

A. vigiae (Bittencourt \& Huang, 1986) Fortuner, 1987 ${ }^{1}$ Bittencourt \& Huang, 1986

Rotylenchulus reniformis Linford \& Oliveira, $1940 \quad$ Carvalho, 1957

5.9. Família Heteroderidae

Espécie

$1^{\circ}$ registro de ocorrência ${ }^{3}$

Heterodera fici Kirjanova, 1954

Monteiro et alii, 1977

H. glycines Ichinohe, $1951^{2}$

Monteiro \& Morais, 1992

Atalodera gibbosa Souza \& Huang, 1994

Souza \& Huang, 1994 apud

SOUZA et alii, 1994 
5.9. Família Heteroderidae (continuação)

Espécie

$1^{\mathrm{o}}$ registro de ocorrência ${ }^{3}$

Thecavermiculatus sp.

Meloidogyne acrita Chitwood, $1949^{2}$

M. arenaria (Neal, 1889) Chitwood, $1949^{2}$

M. coffeicola Lordello \& Zamith, 19601,2

M. exigua Goeldi, $1887^{1,2}$

M. graminicola Golden \& Birchfield, $1968^{2}$

M. hapla Chitwood, $1949^{2}$

M. incognita (Kofoid \& White, 1919) Chitwood, $1949^{2}$

M. javanica (Treub, 1885) Chitwood, $1949^{2}$

M. thamesi Chitwood in Chitwood, Specht \& Havis, $1952^{2}$
Santos \& Ferraz, S., 1984

Lordello, 1960

Carvalho, 1954

Lordello \& Zamith, 1960

Goeldi, 1887

Monteiro \& Ferraz, L.C., 1988

Ponte, 1964

Boock, 1951

Lordello \& Arruda, 1956

Moura, 1967

\subsection{Família Criconematidae}

Espécie

$1^{\circ}$ registro de ocorrência ${ }^{3}$

Criconema braziliense (Raski \& Pinochet, 1975) Raski Ferraz, S., 1980 \& Luc, 1985

C. demani Micoletzki, 1925

SPERANDIO, 1992

C. mutabile (Taylor, 1936) Raski \& Luc, 1985

Sharma \& Loof, $1977_{\mathrm{b}}$

Criconema sp. "A"4

SPERANDIO, 1992

Criconema sp. "B"

SPERANDIO, 1992

Ogma cataracticum (Andrássy, 1979) Raski \& Luc, Andrássy, 1979 $1987^{1}$ 
5.10. Família Criconematidae (continuação)

Espécie

$1^{0}$ registro de ocorrência ${ }^{3}$

O. civellae (Steiner, 1949) Luc \& Raski, 1987

SPERANDIO, 1992

O. decalineatum (Chitwood, 1957) Andrássy, 1979

Sharma \& Sher, 1973

O. octangulare (Cobb, 1914) S. Stekhoven \& Teunis-

Rashid et alii, 1987 sen, 1938

Hemicriconemoides cerradensis sp.

Lozano, 1994 apud SOUZA et alii, 1994

H. cocophilus (Loos, 1949) Chitwood \& Birchfield, Sharma \& Loof, 1977 a 1957

H. mangiferae Siddiqi, 1961

Sharma, 1976

H. minutus Esser, 1960

SPERANDIO, 1992

Criconemella azania (Van den Berg, 1979) Luc \& Sharma \& Loof, 1984 Raski, 1981

C. curvata (Raski, 1952) Luc \& Raski, 1981

Sharma \& Loof, 1977

C. ferniae (Luc, 1959) Luc \& Raski, 1981

Rashid et alii, 1987

C. onoensis (Luc, 1959) Luc \& Raski, $1981^{2}$

Sharma \& Loof, 1973;

Sharma \& Sher, $1973_{\mathrm{d}}$

C. ornata (Raski, 1958) Luc \& Raski, $1981^{2}$

Monteiro, 1973

C. palustris (Luc, 1970) Luc \& Raski, 1981

MONTEIRO \& FERRAZ,

L.C., 1988

C. paradenoudeni Rashid, Geraert \& Sharma, $1987^{1}$

Rashid et alii, 1987

C. paralineolata Rashid, Geraert \& Sharma, 1987 $\quad$ Rashid et alii, 1987

C. peruensiformis (De Grisse, 1967) Luc \& Raski, Ferraz, S., 1980 1981

C. reedi (Diab \& Jenkins, 1966) Luc \& Raski, 1981 SPERANDIO, 1992

C. sphaerocephala (Taylor, 1936) Luc \& Raski, 1981² Freire \& Ferraz, S., 1977 
5.10. Família Criconematidae (continuação)

Espécie

C. xenoplax (Raski, 1952) Luc \& Raski, $1981^{2}$

Criconemella sp. ${ }^{4}$

Discocriconemella conicaudata Vovlas \& Sharma, $1989^{1}$

D. degrissei Loof \& Sharma, $1980^{1}$

D. glabrannulata De Grisse, 1967

D. limitanea (Luc, 1959) De Grisse \& Loof, 1965

D. mineira Vovlas, Ferraz \& dos Santos, $1989^{1}$

D. paraglabrannulata Vovlas \& Sharma, $1989^{1}$

D. repleta Pinochet \& Raski, 1976

Discocrinemella sp. ${ }^{4}$

Discocriconemella "A"4

Hemicycliophora arenaria Raski, 1958

H. belemnis Germani \& Luc, 1973

H. catarinensis Costa Manso \& Luc, 1991

H. chilensis Brzeski, 1974

H. diolaensis Germani \& Luc, 1973

H. loofi Maas, 1970

H. lutosa Loof \& Heyns, $1969^{2}$

H. oostenbrinki Luc, 1958

H. poranga Monteiro \& Lordello, $1978^{1,2}$

H. ripa Van den Berg, 1981

H. similis Thorne, $1955^{2}$ $1^{\mathrm{o}}$ registro de ocorrência ${ }^{3}$

Ferraz, S., 1980

SPERANDIO, 1992

Vovlas \& Sharma, 1989

Loof \& Sharma, 1980

Loof \& Sharma, 1980

SHARMA \& LOOF, 1973

Vovlas et alii, 1989

Vovlas et alii, 1989

Loof \& Sharma, 1980

SPERANDIO, 1992

DOLINSKI \& HUANG, 1994

Moura \& Almeida, 1982

COSTA MANSO \& LUC, 1991

COSTA MANSO \& LUC, 1991

Rashid et alii, 1987

COSTA MANSO \& LUC, 1991

Sharma \& Loof, 1972

Freire \& Ferraz, S., 1977

Ferraz, S., 1980

Monteiro \& Lordello, 1978

SPERANDIO, 1992

Carvalho \& Bona, 1962 
5.10. Família Criconematidae (continuação)

Espécie

$1^{0}$ registro de ocorrência ${ }^{3}$

H. tenuistriata Doucet, 1982

SPERANDIO, 1992

H. thienemanni (Schneider, 1925) Loos, 1948

Rashid et alii, 1987

Caloosia luci Dhanachand \& Jairajpuri, 1979

COSTA MANSO \& LUC, 1991

C. paradoxa (Luc, 1958) Brzeski, 1974

SPERANDIO, 1992

\subsection{Família Tylenchulidae}

Espécie

$1^{\mathrm{o}}$ registro de ocorrência ${ }^{3}$

Tylenchulus semipenetrans Cobb, 1913

Trophotylenchulus arthemidis Dolinski, Souza \& Huang
Carvalho, 1942

Dolinski et alii (no prelo) apud MONTEIRO et alii, 1994

Paratylenchus aquaticus Merny, 1966

SPERANDIO, 1992

P. bukowinensis Micoletzky, $1922^{2}$

Monteiro, 1978

P. colbrani Raski, 1975

Huang \& Raski, 1987

P. dauriis Dolinsky, Souza \& Huang, 19931

P. flectospiculus Huang \& Raski, $1987^{1}$

P. italiensis Raski, 1975

P. leptos Raski, $1975^{1}$

P. minutus Linford in Lindford, Oliveira \& Ishii, 1949

P. perlaptus Raski, 1975

P. rostrocaudatus Huang \& Raski, $1987^{1}$

P. salubris Raski, 1975
DOLINSKI et alii, 1993

Huang \& Raski, 1987

Huang et alii, 1976

RASKI, 1975

Sharma \& Loof, 1982

Huang \& Raski, 1987

Huang \& Raski, 1987

Huang \& Raski, 1987 
5.11. Família Tylenchulidae (continuação)

Espécie

$1^{0}$ registro de ocorrência ${ }^{3}$

Cacopaurus sp.

Gracilacus aculenta (Brown, 1959) Raski, 1962

G. brasiliensis Huang \& Raski, $1986^{1}$

G. colina Huang \& Raski, $1986^{1}$

G. latescens Raski, 1976

G. longilabiata Huang \& Raski, $1986^{1}$

G. punctata Huang \& Raski, $1986^{1}$

G. teres Raski, $1976^{1}$
Cares \& Huang, 1984

Sharma \& Sher, 1974

Huang \& Raski, 1986

Huang \& Raski, 1986

Freire \& Campos, 1986

Huang \& Raski, 1986

Huang \& Raski, 1986

Raski, 1976

\subsection{Família Aphelenchoididae}

Espécie

Aphelenchoides besseyi Christie, $1942^{2}$

A. bicaudatus (Imamura, 1931) Filipjev \& S. Stek- Sharma \& Loof, $1977_{\mathrm{a}}$ hoven, 1941

A. coffeae (Zimmermann, 1898) Filipjev, 1934

A. composticola Franklin, 1957

A. dactylocercus Hooper, 1958

A. fragariae (Ritzema-Bos, 1890) Christie, 1932

A. helicus Heyns, 1964

A. parabicaudatus Shavrov, 1967

A. ritzemabosi (Schwartz, 1911) Steiner \& Buhrer, 1932

A. spicomucronatus Truskova, 1973
$1^{0}$ registro de ocorrência ${ }^{3}$

Carvalho, 1953

Silveira et alii, 1992

Rashid et alii, 1986

Huang, 1982

Rashid et alii, 1986

Rashid et alii, 1986

Curi \& Pitta, 1971

Rashid et alii, 1986 
5.12. Família Aphelenchoididae (continuação)

Espécie

$1^{0}$ registro de ocorrência ${ }^{3}$

Rhadinaphelenchus cocophilus (Cobb, 1919) Goodey, Ferreira Lima \& Cruz, 1945 1960

${ }^{1}$ Espécie descrita a partir de material coletado no Brasil;

2 espécie que ocorre no Estado de São Paulo;

${ }^{3}$ as referências foram obtidas de COSTA MANSO et alii (1994), exceto as escritas em letras maiúsculas. Estas são citadas abaixo.

${ }^{4}$ espécies ainda inominadas.

CARES, J.E. Fauna fitonematológica de várzea e terra firme nas proximidades de Manaus - AM. Brasília, 1984. 251 p. (Mestrado - UnB).

CARES, J.H. \& HUANG, S.P. Nematode fauna in natural and cultivated cerrados of central Brazil. Fitopatologia Brasileira, Brasília, 16(3): 199-209, 1991.

CAVENESS, F.E. Clavaurotylenchus minnesotensis, n.gen., n.sp. (Tylenchida: Nematoda) from Minnesota. Proceedings of the Helminthological Society of Washington, 25(2): 122-124, 1958.

COSTA MANSO, E.S.B.G. \& LUC, M. Contribuição ao estudo de representantes da subfamília Hemicycliophorinae Skarbilovich, 1959 no Brasil, com a descrição de Hemicycliophora catarinensis $\mathrm{n}$. sp. (Nematoda: Tylenchida). In: CONGRESSO BRASILEIRO DE NEMATOLOGIA, 15., Botucatu, 1991. Resumos. Piracicaba, Sociedade Brasileira de Nematologia, 1991. p. 13.

COSTA MANSO, E.S.B.G.; TENENTE, R.C.V.; FERRAZ, L.C.C.B.; OLIVEIRA, R.S.; MESQUITA, R. Catálogo de nematóides fitoparasitos encontrados associados a diferentes tipos de plantas no Brasil. Brasília, EMBRAPA/SPI/CENARGEM, 1994. 488 p. 
DOLINSKI, C.M. \& HUANG, S.P. Discocriconemella "A" n. sp. (Nematoda: Criconematoidea) encontrada no cerrado virgem do Distrito Federal. In: CONGRESSO BRASILEIRO DE FITOPATOLOGIA 27., Itajaí, 1994. Fitopatologia Brasileira, 19 (suplemento). Brasília, Sociedade Brasileira de Fitopatologia, 1994. p. 323.

DOLINSKI, C.M.; SOUZA, R.M.; HUANG, S.P. Morfologia de uma população de Trophotylenchulus (Tylenchulinae: Tylenchulidae) encontrada no cerrado virgem do Brasil Central. In: CONGRESSO BRASILEIRO DE NEMATOLOGIA, 16., Lavras, 1992. Resumos. Piracicaba, Sociedade Brasileira de Nematologia, 1992. p. 37.

DOLINSKI, C.M.; SOUZA, R.M.; HUANG, S.P. Paratylenchus dauriis n. sp., espécie encontrada no cerrado virgem do Brasil central. In: CONGRESSO BRASILEIRO DE NEMATOLOGIA, 17., Jaboticabal, 1993. Resumos. Piracicaba, Sociedade Brasileira de Nematologia, 1993. p. 88.

FERRAZ, L.C.C.B. Nematóides parasitos de Eucalyptus, Pinus e outras essências florestais cultivadas no Estado de São Paulo. Piracicaba, 1980. 92 p. (Doutorado USP/ESALQ).

FERRAZ, L.C.C.B. Observations on some Xiphinema species found in Brazil (Nematoda, Dorylaimoidea). Nematologia Mediterranea, Bari, 8 (2): 141-151, 1980.

FERRAZ, S. Reconhecimento das espécies de fitonematóides presentes nos solos do Estado de Minas Gerais. Experimentiae Viçosa, 26(11): 255-328, 1980.

MENDONÇA, M.M. Estudo sobre Hoplolaiminae encontrados no Brasil (Nemata: Tylenchoidea). Piracicaba, 1976. 91 p. (M.S. - USP/ESALQ).

MONTEIRO, A.R. Ocorrência no Brasil de importante nematóide fitoparasito. $\underline{\text { O Solo, }}$ Piracicaba, 60(2): 81, 1968.

MONTEIRO, A.R. \& FERRAZ, L.C.C.B. Curso de identificação de nematóides parasitos de plantas. Piracicaba, ESALQ/Departamento de Zoologia, 1988. 214 p.

MONTEIRO, A.R.; FERRAZ, L.C.C.B.; PIVETTA, F.A.; SANHUEZA, R.M.V. Ocorrência de Pratylenchus scribneri em pomares e viveiros de macieira na região de Vacaria, RS. In: CONGRESSO BRASILEIRO DE NEMATOLO- 
GIA, 11., Viçosa, 1987. Resumos. Piracicaba, Sociedade Brasileira de Nematologia, 1987. p. 41.

MONTEIRO, A.R.; FERRAZ, L.C.C.B.; INOMOTO, M.M. Nemata. Curso de nematóides parasitos de plantas. Piracicaba, ESALQ/Departamento de Zoologia, 1994. $150 \mathrm{p}$.

RASKI, D.J. On the morphology of Criconemoides Taylor, 1936, with descriptions of six new species (Nematoda: Criconematidae). Proceedings of the Helminthological Society of Washington, 19(2): 85-99, 1952.

SHARMA, R.D. \& SHER, S.A. Nematodes of the cocoa region of Bahia, Brazil. II. Occurrence and distribution of plant parasitic nematodes associated with cocoa (Theobroma cacao L.). Revista Theobroma, Itabuna, 3(3): 17-24, 1973.

SOUZA, R.M.; DOLINSKY, C.M.; HUANG, S.P. Survey of Meloidogyne spp. in native cerrado of Distrito Federal, Brazil. Fitopatologia Brasileira, Brasília, 19(3): 463-465, 1994.

SPERANDIO, C.A. Identificação de nematóides fitoparasitos do Rio Grande do Sul Brasil. Piracicaba, 1992. 126 p. (Doutorado - USP/ESALQ). 
A P Ê N D I C E 2 
Lista de abreviaturas do mapa do campus "Luiz de Queiroz" de VIDAL-TORRADO et alii, 1993 (tipos de solos)

LV: Latossolo vermelho-amarelo álico, A moderado, textura média (Typic Hopludox). PEL: Podzólico vermelho escuro latossólico álico, A moderado, textura argilosa/muito argilosa (Rhodic Kandiudox).

TRL: Terra roxa estruturada latossólica eutrófica, A moderado, textura argilosa/muito argilosa (Kandiudalfic Eutrudox).

TR1: Terra roxa estruturada eutrófica, A moderado, textura argilosa/muito argilosa (Kandiudalfic Eutrudox).

TR2: Terra roxa estruturada distrófica, A moderado, textura argilosa/muito argilosa (Rhodic Kandiudox).

TR3: Terra roxa estruturada eutrófica pouco profunda, A moderado, textura argilosa/muito argilosa (Kandiudalfic Eutrudox).

TR4: Associação de terra roxa estruturada eutrófica pouco profunda, A moderado ou chernozêmico, textura argilosa, fase pedregosa (Rhodic Kandiudalf) + terra roxa estruturada eutrófica, A moderado, textura argilosa (Rhodic Kandiudalf) + cambissolo eutrófico, A moderado ou chernozêmico, $\mathrm{Tb}^{1}$, textura argilosa, substrato diabásio, fase pedregosa (Typic Eutrachrept).

PE: Podzólico vermelho-escuro eutrófico, Tb, A moderado, textura argilosa/muito argilosa (Kandiudalfic Eutrudox).

PV1: Podzólico vermelho-amarelo distrófico, Tb, A moderado, textura média/média (Typic Paleudult).

PV2: Podzólico vermelho-amarelo álico, Tb, A moderado, textura argilosa/muito 
argilosa (Typic Kandiudox).

PV3: Associação de podzólico vermelho-amarelo, álico pouco profundo, Tb, A moderado, textura argilosa/muito argilosa (Ochreptic Hapludulf) + cambissolo distrófico ou álico, Tb, A moderado, textura média ou argilosa (Aquic Dystric Eutrochrept).

BV1: Brunizem avermelhado, textura argilosa, substrato sedimentos pelíticos carbonáticos ou não da formação Irati (Typic Argiudoll).

BV2: Associação brunizem avermelhado, textura argilosa, substrato diabásio (Typic Argiudoll) + terra roxa estruturada intermediária para brunizem avermelhado (Typic Hapludoll) + terra roxa estruturada eutrófica, textura argilosa/muito argilosa (Rhodic Kandiudalf).

B: Associação de brunizem textura argilosa, substrato diabásio (Typic Argiudoll) + brunizem vértico substrato diabásio (Vertic Argiudoll) + vertisolo (Typic Chromudert) com inclusões de plintossolo vértico (Plintaquept ?).

C: Cambissolo distrófico, Tb, A moderado, textura argilosa, substrato folhelho (Aquic Distric Eutrochrept).

A1: Solo aluvial eutrófico, Tb, textura média/arenosa (7ypic Udifluvent).

G1: Gleissolo eutrófico, A chernozêmico, textura média a argilosa (Humic Haplaquept?).

G2: Gleissolo eutrófico, A moderado, textura argilosa/argilosa ou média/média a argilosa (Typic Haplaquept) com inclusões de solos vérticos (Vertic Haplaquept). TT: Terreno para a extração de pedras e cascalho.

${ }^{1}$ Argila de atividade baixa. 
A P E N D I C E 3 


\section{Resultados do levantamento populacional (ver 4.1)}

A seguir são relacionados pormenorizadamente os nematóides identificados em cada local de amostragem. Os resultados da quantificação referem-se a $5 \mathrm{~g}$ de raízes e/ou $250 \mathrm{~cm}^{3}$ de solo, exceto quando houver alguma indicação.

Amostra $n^{0} 1$ : muda de Lxora coccinea produzida pelo Depto. de Horticultura da ESALQ; raízes $(1,0 \mathrm{~g})$ e solo; 03/06/92 (data da coleta).

- raízes: nenhum nematóide fitoparasito foi encontrado.

- solo: 9 Xiphidorus minor, 25 Paratrichodorus anthurii, 25 espiralados (Rotylenchus sp. + Helicotylenchus sp.), 20 Meloidogyne sp. $\left(\mathrm{J}_{2}\right)$ e 25 Discocriconemella sp.

Amostra $\mathbf{n}^{0}$ 2: remanescente degradado de floresta; solo de 0 a $10 \mathrm{~cm}$ de profundidade da rizosfera de Bauhinia forficata; 17/06/92.

- solo: não foi feita a quantificação; espécies identificadas: X. minor, Rotylenchus caudaphasmidius, Criconema braziliense, Criconema n. sp., Discocriconemella mineira e $D$. repleta.

Amostra $\mathbf{n}^{0}$ 3: remanescente degradado de floresta; solo de 40 a 60 $\mathrm{cm}$ de profundidade da rizosfera de espécies vegetais não identificadas; 18/10/94.

- solo: 10 Rotylenchus sp., 205 Paratylenchus sp. e 10 Aphelenchoides sp.

Amostra $\mathbf{n}^{0}$ 4: remanescente degradado de floresta; solo de 0 a $10 \mathrm{~cm}$ de profundidade da rizosfera de espécies vegetais não identificadas; 17/06/92.

- solo: 35 R. caudaphasmidius e 30 Helicotylenchus egyptiensis. 
Amostra $\mathbf{n}^{0}$ 5: muda de 1 . coccinea produzida pelo Depto. de Horticultura da ESALQ; solo; 19/08/92.

- solo: $1 X$. minor e $11 P$. anthurii.

Amostra n ${ }^{0}$ 6: parque da ESALQ; solo de 0 a $20 \mathrm{~cm}$ de profundidade da rizosfera de Machaerium aculeatum; 30/08/92.

- solo: não foi feita a quantificação; espécies identificadas: Xiphinema krugi.

Amostra ${ }^{0}$ 7: parque da ESALQ; solo de 0 a $20 \mathrm{~cm}$ de profundidade da rizosfera de espécies vegetais não identificadas; 30/08/92.

- solo: 480 espiralados (Helicotylenchus dihystera + Scutellonema brachyurus).

Amostra $\mathbf{n}^{0}$ 8: remanescente degradado de floresta; terriço (substrato utilizado pelo Depto. de Horticultura da ESALQ para produção de mudas); 16/04/92. - solo: 277 espiralados $(R$. caudaphasmidius + Rotylenchus sp. $+H$. dihystera + Helicotylenchus sp.), 230 Meloidogyne sp. $\left(\mathrm{J}_{2}\right)$ e 305 anelados (Criconema n. sp. + D. repleta).

Amostra $\mathbf{n}^{0}$ 9: remanescente degradado de floresta; solo de 0 a $5 \mathrm{~cm}$ de profundidade da rizosfera de espécies vegetais não identificadas; 14/09/92.

- solo: 128 Trophurus n. sp., 407 R. caudaphasmidius, 1 Criconemella xenoplax e 322 D. repleta.

Amostra $n^{0}$ 10: remanescente degradado de floresta; solo de 0 a $5 \mathrm{~cm}$ de profundidade da rizosfera de Lantana camara; 14/09/92.

- solo: 1 X. minor, 4 Paratrichodorus sp., 35 Boleodorus sp., 18 Trophurus n. sp., 93 Helicotylenchus exallus, 18 Meloidogyne sp. $\left(\mathrm{J}_{2}\right), 18$ C. braziliense, 35 Criconema n. sp. e 235 D. repleta.

Amostra $\mathbf{n}^{0}$ 11: remanescente degradado de floresta; solo de 0 a 10 cm de profundidade da rizosfera de espécies vegetais não identificadas; 23/04/93.

- solo: 1 X. minor; 2.600 espiralados ( $R$. caudaphasmidius $+H$. exallus), 600 Meloidogyne sp. $\left(\mathrm{J}_{2}\right)$ e 180 anelados $(C$. braziliense + Ogma cataracticum 
+ D. mineira).

Amostra $\mathbf{n}^{0}$ 12: remanescente degradado de floresta; solo de 0 a 20 cm de profundidade da rizosfera de espécies vegetais não identificadas; 23/07/93.

- solo: 350 Helicotylenchus exallus, 140 Meloidogyne sp. $\left(\mathrm{J}_{2}\right)$ e 495 D.

mineira.

Amostra n' 13: pomar de Mangifera indica; solo de 0 a $20 \mathrm{~cm}$ de profundidade da rizosfera de $M$. indica; 25/07/93.

- solo: 1 Xiphinema vulgare, 515 Helicotylenchus sp. e 1.247 Hemicriconemoides mangiferae.

Amostra $n^{0}$ 14: remanescente degradado de floresta; solo de 0 a 40 cm de profundidade de espécies vegetais não identificadas; 11/08/93.

- solo: 22 Xiphinema sp., 1.320 R. caudaphasmidius, 22 Criconema n. sp. e 3.036 D. mineira $+D$. repleta.

Amostra $n^{0}$ 15: remanescente degradado de floresta; solo de 0 a 40 cm de profundidade de espécies vegetais não identificadas; 11/08/93.

- solo: 10 Paratrichodorus sp., 170 R. caudaphasmidius e 1.270 D. repleta.

Amostra n' 16: remanescente degradado de floresta; solo de 0 a 40 cm de profundidade de espécies vegetais não identificadas; 05/01/94.

- solo: não foi feita a quantificação; espécies identificadas: Xiphinema sp. (talvez X. americanum/X. peruvianum), Trophurus n. sp., Criconema n. sp. e D. mineira.

Amostra $\mathbf{n}^{\circ}$ 17: bosque de Eucalyptus sp.; raízes e solo da rizosfera de Eucalyptus sp.; data: ?

- raízes: nenhum nematóide fitoparasito foi encontrado.

- solo: não foi possível fazer a identificação dos nematóides; eram anelados (família Criconematidae) que encontravam-se cobertos por partículas de solo.

Amostra $n^{0}$ 18: área em pousio na várzea do ribeirão Piracicamirim; solo de 0 a $60 \mathrm{~cm}$ de profundidade da rizosfera de Indigofera hirsuta e plantas invasoras 
não identificadas; 28/02/94.

- solo: 45 Paratrichodorus minor, 20 Tylenchorhynchus annulatus, 95 Pratylenchus zeae, 1.480 Helicotylenchus pseudorobustus, 35 Criconemella palustris + Criconemella sp. (SPERANDIO, 1992) e 195 Hemicycliophora lutosa.

Amostra $\mathbf{n}^{\circ}$ 19: solo nu em torno de Chorisia speciosa; raízes e solo da rizosfera de C. speciosa; 21/03/94.

- raízes: nenhum nematóide fitoparasito foi encontrado.

- solo: não foi feita a quantificação; espécie identificada: H. pseudorobustus.

Amostra $\mathbf{n}^{\circ}$ 20: remanescente degradado de floresta; solo de 0 a 30 cm de profundidade de espécies vegetais não identificadas; 04/11 /94.

- solo: 1 Xiphinema sp., 270 Helicotylenchus erythrinae, 1 C. braziliense, 1 O. cataracticum, 80 D. mineira e 355 D. repleta.

Amostra $\mathbf{n}^{\circ}$ 21: remanescente degradado de floresta; solo de 0 a 50 cm de profundidade de espécies vegetais não identificadas; 26/05/94.

- raízes: não foi feita a quantificação; espécie identificada: Meloidogyne javanica.

- solo: não foi feita a quantificação; espécies identificadas: $R$. caudaphasmidius, Helicotylenchus sp. e D. mineira.

Amostra n ${ }^{\circ}$ 22: área de cultivo em pousio; raízes e solo de 0 a $40 \mathrm{~cm}$ de profundidade da rizosfera de Parthenium hysterophorus; 15/06/94.

- raízes: $20 R$. reniformis.

- solo: 5 Ditylenchus sp., 250 Rotylenchulus reniformis e 3 Criconemel-

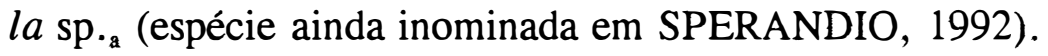

Amostra $\mathbf{n}^{\circ}$ 23: parque da ESALQ; solo de 0 a $20 \mathrm{~cm}$ de profundidade da rizosfera de espécies vegetais não identificadas; 19/06/94.

- solo: 5 Paratrichodorus sp., 690 H. dihystera + H. pseudorobustus, 25 S. brachyurus, $100 \mathrm{R}$. reniformis, 65 Meloidogyne sp. $\left(\mathrm{J}_{2}\right)$ e $10 \mathrm{H}$. mangiferae.

Amostra $n^{\circ}$ 24: parque da ESALQ; raízes e solo de 0 a $20 \mathrm{~cm}$ de 
profundidade da rizosfera de Taxodium distichum Rich.; 19/06/94.

- raízes: 5 Helicotylenchus sp.

- solo: 205 H. dihystera + H. pseudorobustus, 45 Meloidogyne sp. $\left(\mathrm{J}_{2}\right)$ e $50 \mathrm{D}$, repleta.

Amostra n 25: parque da ESALQ; solo de 0 a $20 \mathrm{~cm}$ de profundidade da rizosfera de espécies vegetais não identificadas; 19/06/94.

- solo: 25 X. brevicolle, 75 Boleodorus sp., $195 \mathrm{H}$. dihystera, 10 Criconemella sp. e 105 D. repleta.

Amostra $n^{0}$ 26: parque da ESALQ; raízes e solo da rizosfera de Paspalum notatum Flügge; 30/07/94.

- raízes: 20 Basiria sp., 3 P. brachyurus, 50 H. dihystera, 75 Paratylenchus sp. e 5 Aphelenchoides sp.

- solo: $565 H$. dihystera e $75 C$. ornata.

Amostra n' 27: parque da ESALQ; solo de 0 a $40 \mathrm{~cm}$ de profundidade da rizosfera de espécies vegetais não identificadas; 30/07/94.

- solo: $95 \mathrm{H}$. dihystera e $275 \mathrm{R}$. reniformis.

Amostra n 28: parque da ESALQ; solo de 0 a $40 \mathrm{~cm}$ de profundidade da rizosfera de espécies vegetais não identificadas; 30/07/94.

- raízes: $155 R$. caudaphasmidius e 87 Meloidogyne sp. $\left(\mathrm{J}_{2}\right)$.

- solo: $15 X$. krugi, $140 R$. caudaphasmidius, $8 \mathrm{H}$. dihystera, $35 R$. reniformis, 75 Meloidogyne sp. $\left(\mathrm{J}_{2}\right)$ e 80 O. cataracticum.

Amostra n 29: parque da ESALQ; solo de 0 a $40 \mathrm{~cm}$ de profundidade da rizosfera de espécies vegetais não identificadas; 30/07/94.

- raízes: $5 R$. caudaphasmidius e $10 H$. dihystera $+H$. pseudorobustus.

- solo: 1 Xiphinema sp., 10 R. caudaphasmidius e 405 H. dihystera + H. pseudorobustus.

Amostra $\mathbf{n}^{0}$ 30: bosque de Pinus sp.; solo de 0 a $40 \mathrm{~cm}$ de profundidade da rizosfera de Pinus sp. e Panicum maximum Jacq.; 20/09/94. 
- solo: 30 Xiphinema vulgare, 1 Paratrichodorus sp., 1.455 Helicotylenchus digonicus e 50 Criconemella denoudeni.

Amostra n $\mathbf{n}^{0}$ 31: campo arado (cultura anterior: Zea mays L.); solo de 0 a $40 \mathrm{~cm}$ de profundidade; 20/09/94.

- solo: 1.110 P. zeae, 2 Hoplolaimus galeatus e 1.180 H. dihystera + H. pseudorobustus.

Amostra $n^{0}$ 32: campo de $Z$. mays recém-colhido; solo de 0 a $40 \mathrm{~cm}$ de profundidade; $24 / 09 / 94$.

- solo: 350 P. zeae, $2.270 \mathrm{H}$. dihystera, $30 \mathrm{R}$. reniformis e 240 Meloidogyne sp. $\left(\mathrm{J}_{2}\right)$.

Amostra $\mathbf{n}^{0}$ 33: vegetação da margem de um lago; de 0 a $40 \mathrm{~cm}$ de profundidade da rizosfera de espécies vegetais não identificadas; 27/09/94.

- solo: 40 Basiria sp., 10 Tylenchorhynchus sp., $80 \mathrm{H}$. pseudorobustus e 610 C. denoudeni.

Amostra $n^{0}$ 34: bosque de Eucalyptus sp.; solo de 0 a $30 \mathrm{~cm}$ de profundidade da rizosfera de $P$. maximum e gramíneas não identificadas; 27/09/94.

- solo: 20 P. zeae, $1.020 H$. digonicus $+H$. dihystera $+H$. pseudorobustus e 10 Aphelenchoides sp.

Amostra $\mathbf{n}^{0}$ 35: plantação de Coffea arabica; solo de 0 a $40 \mathrm{~cm}$ de profundidade da rizosfera de $C$. arabica e plantas invasoras não identificadas; 26/10/94. - solo: 95 P. zeae, 285 H. dihystera, $1.632 R$. reniformis e 76 Criconemella sp. $_{\mathbf{a}}$ (espécie ainda inominada em SPERANDIO, 1992).

Amostra $\mathbf{n}^{0}$ 36: remanescente degradado de floresta; solo de 0 a 40 cm de profundidade da rizosfera de espécies vegetais não identificadas; 18/11/94.

- solo: 7 X. krugi, 145 H. dihystera, 116 Criconema sp. (espécie ainda inominada em SPERANDIO, 1992, designada como Criconema sp. "B"), 35 Ogma sp., 523 D. repleta e 29 Hemicycliophora poranga.

Amostra $n^{0}$ 37: plantação de Z. mays; solo de 0 a $25 \mathrm{~cm}$ de profundidade da rizosfera de $Z$. mays; 16/11/94. 
- solo: 200 P. zeae, $720 \mathrm{H}$. dihystera, $10 \mathrm{~S}$. brachyurus, $2.310 \mathrm{R}$. reniformis, 10 Meloidogyne sp. $\left(\mathrm{J}_{2}\right)$ e 90 Criconemella onoensis.

Amostra $n^{0}$ 38: horta do Depto. de Horticultura da ESALQ; raízes e solo de 0 a $10 \mathrm{~cm}$ de profundidade da rizosfera de Citrus sp; 12/01/95.

- raízes: 325 Tylenchulus semipenetrans.

- solo: $70 \mathrm{H}$. dihystera, $640 \mathrm{R}$. reniformis e $2.280 \mathrm{~T}$. semipenetrans.

Amostra no 39: parque da ESALQ; raízes e solo de 0 a $5 \mathrm{~cm}$ de profundidade da rizosfera de Impatiens sp., 12/01/95.

- raízes: não foi feita a quantificação; gênero identificado: Meloidogyne. Não foi possível a identificação de espécie(s) devido à grande variação morfológica entre os exemplares, mas a maioria deles é muito semelhante a $M$. thamesi Chitwood, 1952 (Goodey, 1963), segundo JEPSON (1987)1, ou M. arenaria thamesi Chitwood, 1952, segundo TAYLOR et alii (1955)2.

- solo: $75 \mathrm{H}$. dihystera $+H$. erythrinae e 100 Meloidogyne sp. $\left(\mathrm{J}_{2}\right)$.

Amostra no 40: pomar do Depto. de Entomologia da ESALQ; raízes $(10,0 \mathrm{~g})$ e solo de 0 a $10 \mathrm{~cm}$ de profundidade da rizosfera de Musa acuminata Colla AAA; 15/01/95. - raízes: $45 \mathrm{R}$. similis, $580 \mathrm{H}$. multicinctus e 5 Meloidogyne sp. $\left(\mathrm{J}_{2}\right)$. - solo: $30 R$. similis, 620 espiralados $(H$. dihystera $+H$. multicinctus + S. brachyurus $), 890$ R. reniformis e 30 Meloidogyne sp. $\left(\mathrm{J}_{2}\right)$.

Amostra $n^{0}$ 41: pomar do Depto. de Horticultura da ESALQ; raízes (5,0 g) e solo de 0 a $20 \mathrm{~cm}$ de profundidade da rizosfera de Prunus persica; 15/01/95.

- raízes: $10 P$. brachyurus e $2 M$. javanica.

- solo: 20 P. brachyurus + P. zeae, 5 H. dihystera, $185 R$. reniformis, 80 M. javanica $\left(\mathrm{J}_{2}\right)$ e 1 Criconemella sp.

\footnotetext{
${ }^{1}$ JEPSON, S.B. Identification of root-knot nematodes (Meloidogyne species). Walling ford, C.A.B. International, 1987. 265 p.

${ }^{2}$ TAYLOR, A.L.; DROPKIN, V.H.; MARTIN, G.C. Perineal patterns of root-knot nematodes. Phytopathology, Baltimore, 45(1): 26-34, 1955.
} 